\title{
A Phylogenetic Investigation of the New Zealand Pteridaceae Ferns
}

\author{
Whitney LM Bouma
}

A Thesis Presented for the Degree Master of Science in Ecology and Evolution at Victoria University of Wellington, New Zealand.

February, 2008 


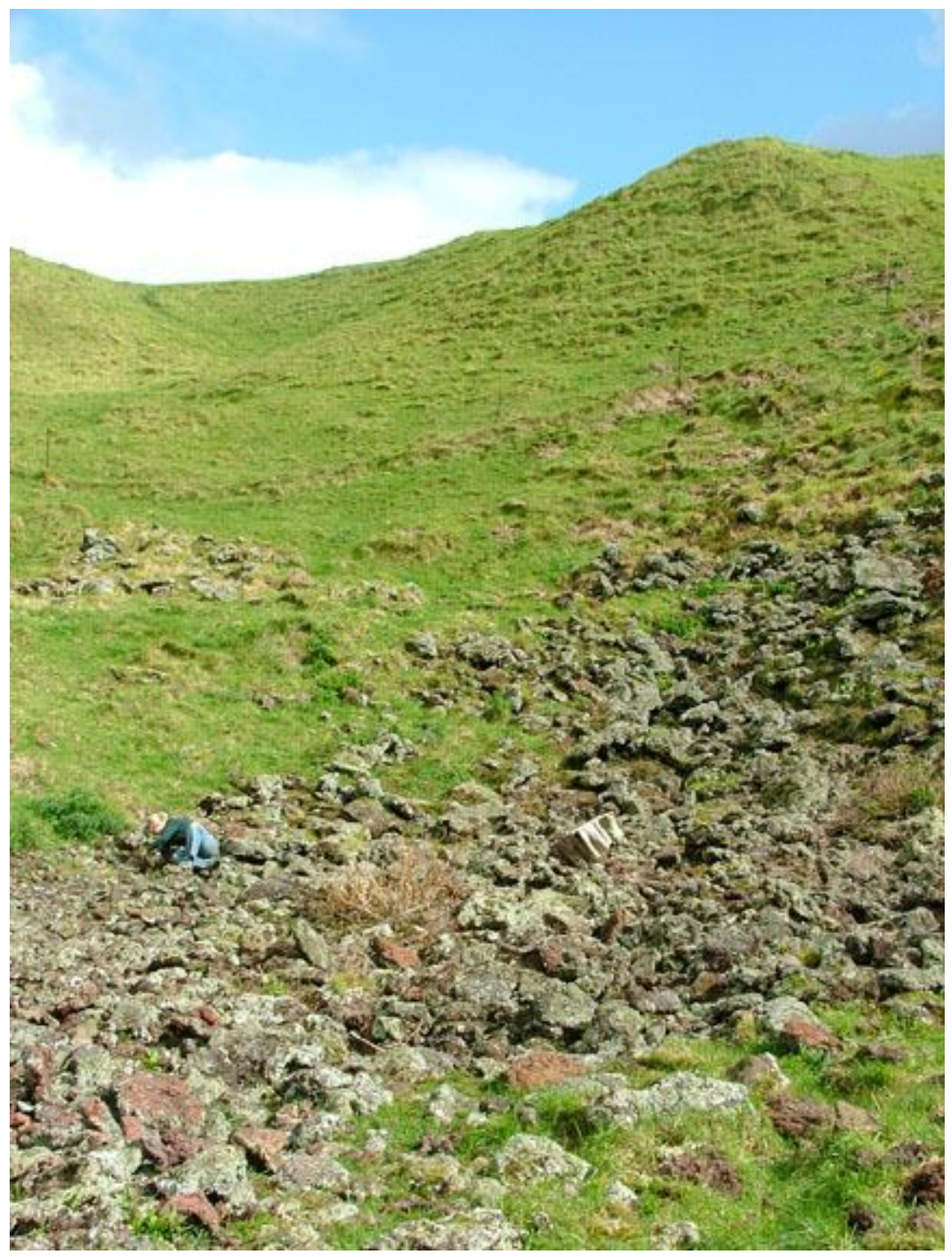

In search of Pellaea - Mt. Wellington, Auckland

September 2007 


\begin{abstract}
The fern family Pteridaceae is among the largest fern families in New Zealand. It comprises 17 native species among five genera. Traditionally the classification of Pteridaceae was based on morphological characters. The advent of molecular technology, now makes is possible to test these morphology-based classifications. The Pteridaceae has previously been subjected to phylogenetic analyses; however representatives from New Zealand and the South Pacific have never been well represented in these studies. This thesis research aimed to investigate the phylogenetic relationships of the New Zealand Pteridaceae, as well as, the phylogenetic relationships of the New Zealand species to their overseas relatives. The DNA sequences of several Chloroplast loci (e.g. $t r n L-t r n F$ locus, $r p s 4$ and $r p s 4$-trnS IGS, atpB, and $r b c L$ ) were determined and the phylogenetic relationships of the New Zealand Pteridaceae and several species-specific question within the genus Pellaea and Adiantum were investigated. Results presented in this thesis confirm previously published phylogenetics of the Pteridaceae, which show the resolution of five major clades, i.e., cryptogrammoids, ceratopteridoids, pteridoids, cheilanthoids, and the adiantoids. The addition of the New Zealand species revealed a possible South West Pacific groups formed by the respective genera, where New Zealand species were generally more related to one another than to overseas relatives. Within the New Zealand Pellaea, the

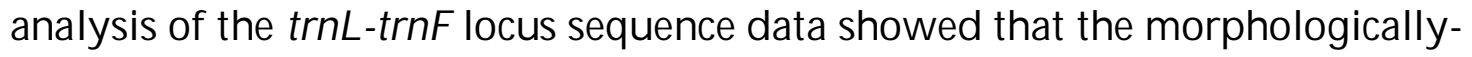
intermediate plants $P$. aff. falcata, responsible for taxonomic confusion, were more closely related to $P$. rotundifolia than to $P$. falcata. Furthermore, the species collected on the Kermadec Islands, previously thought to be $P$. falcata, are genetically distinct from the Australian P. falcata and they could constitute a new species. Adiantum hispidulum, which is polymorphic for two different hair types being used to distinguish them as different species, was also reinvestigated morphologically and molecularly. Morphological inspection of hairs revealed three hair types as opposed to the previous thought two, and furthermore, they correspond to three different $\operatorname{trnL}-\operatorname{trn} F$ sequences haplotypes.
\end{abstract}




\section{Acknowledgements}

I would first like to thank my supervisors, Dr. Leon Perrie and Dr. Peter Ritchie, for their help and support throughout my project.

This project was possible by a scholarship through New Zealand Museum Te Papa Tongarewa for work on plant molecular systematics.

The following people kindly provided fern specimens and offered insights for my study: Leon Perrie, Pat Brownsey, Phil Garnock-Jones, Ewen Cameron, Alex Buchanan, Peter de Lange, and David Glenny.

I would lastly like to thanks my family, friends, and most importantly my husband Skip. He has been the best support I could ask for and also an amazing field partner. I am sure he has a new found love for ferns! 


\section{Table of Contents}

Chapter 1

1.1 General Introduction

1.1.1 New Zealand flora

1.1.2 New Zealand fern flora

1.1.3 Phylogenetics of New Zealand flora

1.1.4 Research objectives and contributions

\subsection{References}

Chapter 2 - Relationships of the New Zealand Pteridaceae

\subsection{Introduction}

2.2 Material \& Methods

2.3 Results

2.4 Discussion

2.5 References

Chapter 3 - Morphological intermediates cause taxonomic confusion in New Zealand Pellaea

3.1 Introduction

3.2 Material \& Methods

3.3 Results

3.4 Discussion

3.5 References

Chapter 4 - A molecular phylogeny for New Zealand's Adiantum ferns from analyses of chloroplast DNA sequences and another look at the Adiantum hispidulum Swartz complex.

4.1 Introduction

4.2 Material \& Methods

4.3 Results

4.4 Discussion

4.5 References

Chapter 5

5.1 General Discussion

5.1.1 New Zealand Pteridaceae

5.1.2 Pellaea 


\subsubsection{Adiantum}

5.1.4 Taxonomic sampling

5.1.5 New Zealand biodiversity

\subsection{References}

Appendix A - Distribution maps of New Zealand Pteridaceae

Appendix B - Transition vs. transversion graphs for $r b c L$ and $a t p B$ data sets

CD Appendix - Sequence files and Nexus files for Pteridaceae samples 
2.1 Summary trees of Schuettpelz et al. (2007) and Prado et al. (2007) 14

$\begin{array}{ll}2.2 & \text { Pteridaceae distribution map } \\ 2.37\end{array}$

2.3 Core topologies 25

2.4 Expanded $r b c L$ tree $\quad 30$

3.1 Pellaea distribution map with haplotypes 59

$\begin{array}{ll}3.2 & \text { Pellaea frond morphology } \\ 3.3 & 61\end{array}$

$\begin{array}{lll}3.3 & P \text {. aff. falcata frond variation } & 62\end{array}$

3.4 Graph of morphology variation $\quad 66$

$\begin{array}{ll}3.5 & \text { Graph of spore measurements }\end{array}$

$\begin{array}{lll}3.6 & \text { trnL-trnF IGS network } & 68\end{array}$

3.7 rps4 and rps4-trnS IGS network $\quad 69$

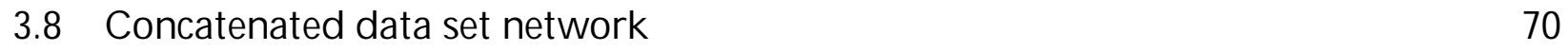

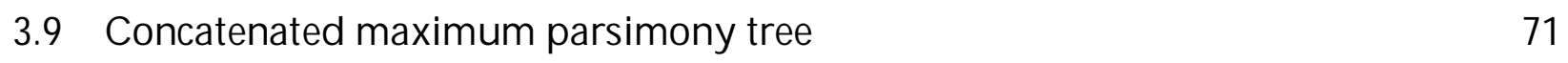

4.1 Adiantum distribution map 86

4.2 Hair type photographs 94

4.3 Maximum parsimony tree 96

4.4 Adiantum hispidulum haplotype 97

$\begin{array}{ll}4.5 \text { network Adiantum hispidulum complex distribution map } & 102\end{array}$

\section{List of Tables}

2.1 Collection list (found at the end of Chapter 2) 47

$\begin{array}{lll}2.2 & \text { Alignment statistics } & 22\end{array}$

$\begin{array}{lll}2.3 & \text { Pairwise comparisons } & 23\end{array}$

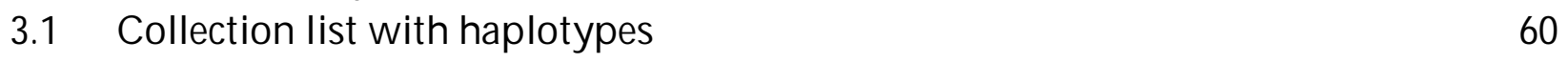

$\begin{array}{lll}3.2 & \text { Alignment statistics } & 68\end{array}$

$\begin{array}{lll}4.1 & \text { Collection list } & 90\end{array}$

$\begin{array}{lll}4.2 & \text { Alignment statistics } & 95\end{array}$ 


\section{Chapter 1}

\subsection{General Introduction}

\subsubsection{New Zealand flora}

New Zealand has been geographically isolated in the southern Pacific Ocean for nearly 80 million years. It is believed that through tectonic uprifting 115 mya, New Zealand began to separate from the supercontinent Gondwanaland and reached its current position in the Pacific around 55 mya (McLoughlin 2001). It was during this time, throughout the Cretaceous and early Tertiary era, that New Zealand was thought to have evolved its unique and diverse native flora (Mildenhall 1980). This New Zealand flora has attracted many botanists to focus studies on the biogeography, phylogenetics, and biodiversity of New Zealand plant species.

New Zealand shared a common origin with many other South Pacific landmasses (i.e., Australia, Tasmania, New Caledonia). With increased 
taxonomic sampling it has become apparent that there are many similarities with respect to species of ferns and genera in angiosperms in the flora between New Zealand and these surrounding landmasses (Winkworth et al. 2002). These floral similarities have been a subject of debate among scientists and many hypotheses for the origins of the native New Zealand flora have been suggested. One is that much of New Zealand's flora has been isolated since its separation from Gondwana over 80 million years ago. However, evidence from molecular dating and phylogenetic analyses support another hypothesis, being that much of the New Zealand flora is a result of recent arrival by long distance dispersal where New Zealand species are found to be closely related to other overseas taxa and most often Australian taxa (Brownsey 2001b, Winkworth et al. 2002, Perrie and Brownsey 2007).

Long distance dispersal as the mechanism for explaining the recent origins of New Zealand's extant biota is becoming increasingly supported (Brownsey 2001b, Perrie and Brownsey 2007). It is also becoming increasingly important to understand these origins in order to determine the relationships among the species in the New Zealand flora, as well as to their overseas relatives. Investigations of the flora are an important part of an ongoing effort to accurately document plant species diversity in New Zealand. Currently, close to 1,900 species of angiosperms, 200 species of pteridophytes, and 20 species of gymnosperms make up the native New Zealand vascular flora (Brownsey and Smith-Dodsworth 2000, Wilton and Breitwieser 2000).

Accurate records of native, endemic, and introduced plant species and their evolutionary relationships provide necessary information for defining, understanding, and ultimately protecting the indigenous flora. It is also important to document the biota as it changes in response to new introductions. Long distance dispersal most likely played an important role 
in the colonization of New Zealand's flora and it may continue to be an important process that shapes the composition of the flora in the future (de Lange and Crowcroft 1997, Heenan and de Lange 2004).

\subsubsection{New Zealand fern flora}

Pteridophytes occurring in the New Zealand Botanical Region, extending from the Kermadec Islands to Macquarie Island, have been useful plants for phylogenetic and biogeographical studies (Brownsey 2001b, Perrie and Brownsey 2005b, a, 2007, Shepherd et al. 2007a). They are part of an old lineage of vascular plants, having first evolved around 364 million years ago. Most of the leptosporangiate ferns, or true ferns, seen today are believed to have evolved around 200 million years ago and it is believed that many of the extant fern families in New Zealand evolved prior to the separation of New Zealand from Gondwanaland (Pryer et al. 2004). This ancient origin makes them ideal candidates for testing the competing hypotheses of the origins of New Zealand flora.

The first attempt to systematically catalogue the New Zealand ferns was by the Frenchman Achille Richard in 1832, although he had never visited New Zealand (Breitwieser et al. in press). In later years, as botanists began to visit New Zealand more frequently, more accurate records began to be developed. The initial volume of the Flora of New Zealand series was published in 1961, and described 164 pteridophyte species (Allan 1961). This work was followed by numerous descriptions and cataloging of new fern species. The number of fern species described in New Zealand grew from 164 to 196 by the mid 1980's (Breitwieser et al. in press). 
Today, New Zealand is home to nearly 200 recognized indigenous pteridophyte species, from approximately 60 genera. Among the ferns, 25 of the 37 fern families worldwide recognized worldwide by Smith et al. (2006) are represented (Brownsey and Smith-Dodsworth 2000, Smith et al. 2006). Less than half of the native New Zealand fern flora is endemic and many of the species are found elsewhere in the South Pacific. Approximately 90 percent of those species found elsewhere occur in temperate Australia (Brownsey 2001b). Although the diversity of ferns in New Zealand is low compared to most tropical regions, the sheer abundance of ferns and their dominance in the flora for a temperate region make them an important component of the New Zealand biota (Brownsey 2001a).

\subsubsection{Phylogenetics of New Zealand flora}

Molecular phylogenetic studies play an important role in revealing the relationships between and among fern species and these techniques are becoming increasingly vital to the classification of species in conjunction with traditional morphological characters. The Aspleniaceae, Gleicheniaceae, Polystichum, and Blechnum are among the few of the 60 genera and 25 fern families represented in New Zealand that have undergone investigations of a molecular nature (Perrie et al. 2003, Perrie and Brownsey 2005b, a, Perrie et al. 2007, Perrie and Brownsey 2007, Shepherd et al. 2007a, Shepherd et al. 2007b). Most of the studies to date have focused on the genus Asplenium. Among representatives of $A$. hookerianum, it was found that its morphological variation of pinnules was not concordant with its genetic variation (Perrie and Brownsey 2005a). Further investigations of Asplenium gave insights into its complex evolutionary history and found that New Zealand Asplenium are not monophyletic (Perrie and Brownsey 2005b). Molecular studies on the fern family Glecheniaceae suggest that the previous taxonomy was insufficient to 
explain the relationships that are present among the members and is in need of revision (Perrie et al. 2007). All these investigations, with the addition of DNA sequence data, have improved the understanding of both the origins of these ferns and their relationships to one another and their overseas relatives.

\subsubsection{Research objectives and contributions}

The fern family Pteridaceae is among the largest of the fern families present in New Zealand. It contains 17 native species among five genera in New Zealand, with five of the species being endemic (Brownsey and SmithDodsworth 2000). The majority of the species in this family are distributed throughout New Zealand, occurring on both the North and South Islands, while a few species are restricted only to the North Island. The distributions of the species of New Zealand Pteridaceae are mapped in Appendix A. Furthermore, previous classifications of the New Zealand Pteridaceae were based primarily on traditional morphological characters. Advances in molecular technology have allowed for the use of DNA sequence data to test morphology-based classifications.

The Pteridaceae ferns on a global level are a large and very diverse family and are found throughout the world (Tryon et al. 1990). Recently, several studies have focused on resolving the relationships of this family with DNA sequence data (Kirkpatrick 2007, Prado et al. 2007, Schuettpelz et al. 2007, Zhang et al. 2007). While the taxonomic sampling efforts for these previous studies has

greatly improved, the New Zealand and South Pacific species were not well represented in world-wide studies of the Pteridaceae.

The aim of this thesis research was to investigate the relationships of the Pteridaceae fern family by carrying out the first phylogenetic analysis for this 
group of ferns as it is represented in New Zealand. Chloroplast DNA sequence data was obtained to infer the relationships between the five genera within New Zealand and also their relationship to the other members of the Pteridaceae on a world-wide scale (Chapter 2).

Several other species-specific questions were investigated dealing with particular members within the genera Pellaea (Chapter 3) and Adiantum (Chapter 4). Within the genus Pellaea, three species are recognized in New Zealand (Brownsey and Smith-Dodsworth 2000). However, morphologicallyintermediate plants have caused confusion regarding the taxonomy of $P$. rotundifolia and P. falcata. Chloroplast DNA from the trnL-trnF locus was sequenced to determine the relationships of the morphologically-intermediate plants. Also, DNA sequence data from overseas Pellaea sect. Platyloma was obtained to determine the relationships of the New Zealand Pellaea species to their overseas relatives.

Within Adiantum, seven native species are recognized in New Zealand. However, the polymorphic $A$. hispidulum has been subject to debate as to whether those plants containing long lax hairs should be a distinct species from those plants with short rigid hairs. The trnL-trnF locus was selected to investigate molecular variation among the plants of $A$. hispidulum. In addition, several chloroplast loci were sequenced to determine the relationships between all of the native Adiantum species in New Zealand.

Collection efforts for this thesis project obtained 54 native plant samples from around New Zealand representing many wild populations, and will be deposited in the WELT herbarium. These samples were used along with previously collected Pteridaceae specimens for molecular and morphological analyses needed for this study. Newly generated DNA sequences were 
obtained from several chloroplast loci (57 trnL-trnF locus, 21 rbcL, 21 atpB, and 16 rps4 gene and rps4-trnS IGS) for the samples collected and will be deposited into GenBank for future use. The distributions of the species of New Zealand Pteridaceae have not been previously mapped. Comprehensive distribution maps were generated for each of the 17 native species by combining collection details from each of the three major herbaria; CHR, WELT, and AK. These maps are presented in Appendix A.

Molecular phylogenies were generated for the New Zealand genera, Pellaea and Adiantum. The largest to date data set of chloroplast $r b c L$ sequence data for the Pteridaceae was compiled to determine the relationships of the New Zealand species to the Pteridaceae world-wide. The results of this study will not only clarify the diversity and relationships among the New Zealand Pteridaceae, but also the relationships among the Pteridaceae on a global scale. 


\subsection{References}

Allan, H. H. 1961. Flora of New Zealand. Government Printer, Wellington, New Zealand.

Breitwieser, I., P. J. Garnock-Jones, A. D. Wilton, J. I. Raine, D. C. Mildenhall, M. S. Pole, P. J. Brownsey, and L. R. Perrie. in press. Phylum Tracheophyta, Lycophytes, Ferns, and seed plants.in D. Gordon, editor. The New Zealand Inventory of Biodiversity: A Species 2000 Symposium Review. The University of Canterbury Press, Christchurch, New Zealand.

Brownsey, P. J. 2001a. Ferns - The Glory of the Forest. New Zealand Geographic 49.

Brownsey, P. J. 2001b. New Zealand's pteridophyte flora--- plants of ancient lineage but recent arrival? Brittonia 53:284-303.

Brownsey, P. J., and J. C. Smith-Dodsworth. 2000. New Zealand Ferns and Allied Plants. 2nd edition. David Bateman Ltd., Auckland, New Zealand.

de Lange, P. J., and G. M. Crowcroft. 1997. Macrothelypteris torresiana (Thelypteridaceae) at North Cape, North Island, New Zealand - a new southern limit for a tropical fern. New Zealand Journal of Botany 35:555-558.

Heenan, P. B., and P. J. de Lange. 2004. Alternanthera denticulata (Amaranthaceae) in New Zealand: a new addition to the indigenous or naturalised flora? New Zealand Journal of Botany 42.

Kirkpatrick, R. E. B. 2007. Investigating the monophyly of Pellaea (Pteridaceae) in the context of a phylogenetic analysis of Cheilantoid Ferns. Systematic Botany 32:504-518.

McLoughlin, S. 2001. The breakup history of Gondwana and its impact on pre-Cenozoic floristic provincialism. Australian Journal of Botany 49:271-300.

Mildenhall, D. C. 1980. New Zealand late Cretaceous and Cenozoic plant biogeopgraphy: a contribution. Palaeogeography Palaeoclimatology \& Palaeoecology 31:197-233. 
Perrie, L. R., M. J. Bayly, C. A. Lehnebach, and P. J. Brownsey. 2007. Molecular phylogenetics and molecular dating of the New Zealand Gleicheniaceae. Brittonia 59:129-141.

Perrie, L. R., and P. J. Brownsey. 2005a. Genetic variation is not concordant with morphological variation in the fern Asplenium hookerianum sensu lato (Aspleniaceae). American Journal of Botany 92:1559-1564.

Perrie, L. R., and P. J. Brownsey. 2005b. Insights into the biogeography and polyploid evolution of New Zealand Asplenium from chloroplast DNA sequence data. American Journal of Botany 95:1-21.

Perrie, L. R., and P. J. Brownsey. 2007. Molecular evidence for long-distance dispersal in the New Zealand pteridophyte flora. Journal of Biogeography 34:2028-2038.

Perrie, L. R., P. J. Brownsey, P. J. Lockhart, E. A. Brown, and M. F. Large. 2003. Biogeography of temperate Australasian Polystichum ferns as inferred from chloroplast sequence and AFLP. Journal of Biogeography 30:17291736 .

Prado, J., C. Del Nero Rodrigues, A. Salatino, and M. L. F. Salatino. 2007. Phylogenetic relationships among Pteridaceae, including Brazilian species, inferred from $r b c L$ sequences. TAXON 56:355-368.

Pryer, K. M., E. Schuettpelz, P. G. Wolf, H. Schneider, A. R. Smith, and R. Cranfill. 2004. Phylogeny and evolution of ferns (monilophytes) with a focus on the early leptosporangiate divergences. American Journal of Botany 91:1582-1598.

Schuettpelz , E., H. Schneider, L. Huiet, M. D. Windham, and K. M. Pryer. 2007. A molecular phylogeny of the fern family Pteridaceae: Assessing overall relationships and the affinities of previously unsampled genera. Molecular Phylogenetics and Evolution 44:1172-1185.

Shepherd, L. D., L. R. Perrie, and P. J. Brownsey. 2007a. Fire and ice: volcanic and glacial impacts on the phylogeography of the New Zealand forest fern Asplenium hookerianum. Molecular Ecology 16:4536-4549.

Shepherd, L. D., L. R. Perrie, B. S. Parris, and P. J. Brownsey. 2007b. A molecular phylogeny for the New Zealand Blechnaceae ferns from analyses of chloroplast trnL-trnF DNA sequences. New Zealand Journal of Botany 45:67-80. 
Smith, A. R., Pryer, K.M.,, E. Schuettpelz, P. Korall, H. Schneider, and P. G. Wolf. 2006. A classification for extant ferns. TAXON 55:705-731.

Tryon, R. M., A. F. Tryon, and K. U. Kramer. 1990. Pteridaceae. Pages 230-256 The Families and Genera of Vascular Plants Vol. 1. Pteridophytes and Gymnosperms. Springer-Verlag, Berlin.

Wilton, A. D., and I. Breitwieser. 2000. Composition of the New Zealand seed plant flora. New Zealand Journal of Botany 38:537-549.

Winkworth, R. C., S. J. Wagstaff, D. Glenny, and P. J. Lockhart. 2002. Plant dispersal N.E.W.S from New Zealand. Trends in Ecology and Evolution 17:514-520.

Zhang, G., X. Zhang, Z. Chen, H. Liu, and W. Yang. 2007. First insights in the phylogeny of Asian cheilanthoid ferns based on sequences of two chloroplast markers. TAXON 56:369-378. 


\section{Chapter 2}

\section{Relationships of the New Zealand Pteridaceae}

\subsection{Introduction}

The Pteridaceae fern family has been the subject of extensive taxonomic and phylogenetic research on the basis of non-molecular (Ching 1940, Copeland 1947, Tryon and Tryon 1982, Tyron et al. 1990) and molecular data (SànchesBaracaldo 2004, Smith et al. 2006, Kirkpatrick 2007, Prado et al. 2007, Schuettpelz et al. 2007, Zhang et al. 2007). This family is morphologically characterized by creeping rhizomes, marginal sori or sori borne along the veins, and a chromosome number that is typically $n=29$ or 30 (Tyron et al. 1990, Smith et al. 2006). It is distributed worldwide, though the majority of these ferns are centered in the tropics. The classification of this family is complicated by its sheer size, extensive distribution, morphological variability, and diverse ecological habitats; and despite the array of studies 
focusing on this family, many relationships between the members of this family remain unclear.

Past classifications for the Pteridaceae have fluctuated greatly with respect to the number of genera recognized in this family. Numbers have been reported ranging from only a few (Ching 1940, Pichi Sermolli 1977) to 63 (Copeland 1947) and most recently 50 (Smith et al. 2006). A clearer picture of the relationships among the genera is being developed as more sophisticated phylogenetic methods are being employed. There has been agreement over the subfamily classifications of the Pteridaceae across recent studies (Hasebe et al. 1995, Pryer et al. 2004, Smith et al. 2006, Schuettpelz et al. 2007).

However, the generic classifications within those subfamilies are still widely debated.

Using morphological characters alone as a basis for classifying generic relationships in the Pteridaceae has been shown by analysis of DNA sequences to be misleading, most notably in circumscription of the cheilanthoid ferns (Gastony and Rollo 1995, Kirkpatrick 2007). Because of convergence as a result of ecological habitats (Gastony and Rollo 1995), certain morphological characters fail to reflect the evolutionary lines determined by DNA sequence data. A study by Smith et al. (2006) revised the classifications of extant ferns to ordinal and familial rank, and also provided a synopsis of included genera. They combined both morphological and molecular data to derive a consensus phylogeny of fern relationships. In the Pteridaceae, Smith et al. (2006) recognized 50 genera, with over 950 species. Five putatively major monophyletic groupings were recognized within this family (see below). They pointed out that several of the genera they accepted in the Pteridaceae are likely to be paraphyletic or polyphyletic and in need of redefinition. 
Utilizing molecular data, several recent studies on Pteridaceae ferns have addressed the generic relationships within this family. Prado et al. (2007) used $r b c L$ sequence data to investigate relationships within the Pteridaceae, with an expanded taxon sampling of native Brazilian species. A study by Schuettpelz et al. (2007) provided a much more extensive investigation of the family by incorporating seven genera previously unsampled and expanding the data set to a multi-gene analysis with chloroplast loci atp $B$ and $\operatorname{atp} A$ along with the commonly used $r b c L$ gene.

The phylogenetic relationships within the Pteridaceae reported by both Prado et al. (2007) and Schuettpelz et al. (2007) were in general agreement (Figure 2.1) The Pteridaceae formed five major clades corresponding to those reported by Smith et al. (2006). However, the relationship of these clades to one another was further resolved. The major clades were as follows as named by Schuettpelz et al. (2007): 1) cryptogrammoids, 2) ceratopteridoids (Parkeraceae), 3) pteridoids, 4), adiantoids, and 5) cheilanthoids. The cryptogrammoids, containing approximately 23 species among the genera Coniogramme, Cryptogramma, and Llavea, were sister to rest of the Pteridaceae. The ceratopteridoids (6 species among Acrostichum and Ceratopteris) are sister to pteridoids (app. 400 species among Pteris and ferns belonging to the monotypic Platyzomatotoideae; and Taenitidoideae, 14 genera, as described by Tryon et al, 1990). The genus Adiantum (app. 150 species) and the vittaroid ferns (12 genera, 300 species) are collectively called the adiantoids and are sister to cheilanthoids (20 genera, 400 species). Both studies showed support with $r b c L$ sequence data for including the vittaroids as nested within Adiantum, and also paraphyly of the genus Pteris. Despite the increased resolution found from these studies, questions still remain regarding the 
monophyletic status of several genera including those found in New Zealand, i.e., Adiantum, Cheilanthes, Pellaea, Pteris, and Anogramma.

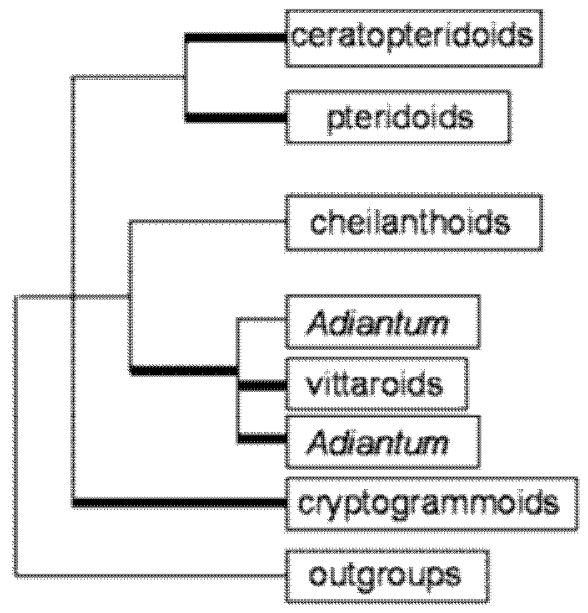

Prado et al. (2007) rbcL parsimony analysis

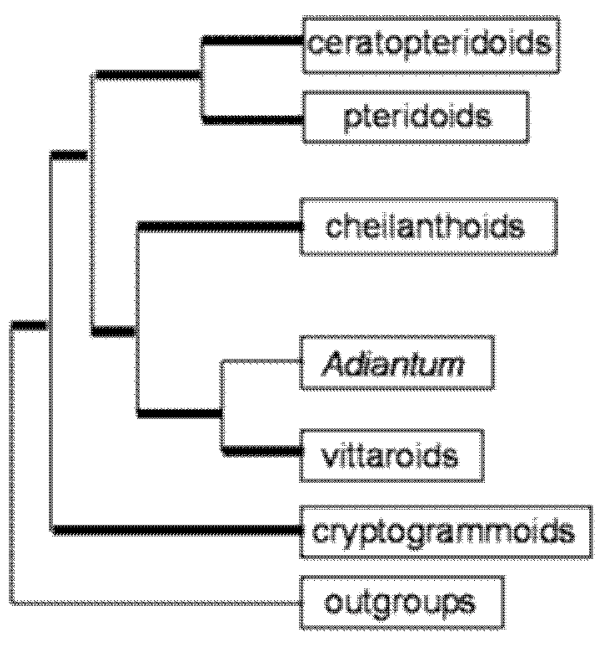

Schuettpelz et al. (2007) $r b c L$, atp $B$, and atp $A$ combined gene Bayesian analysis
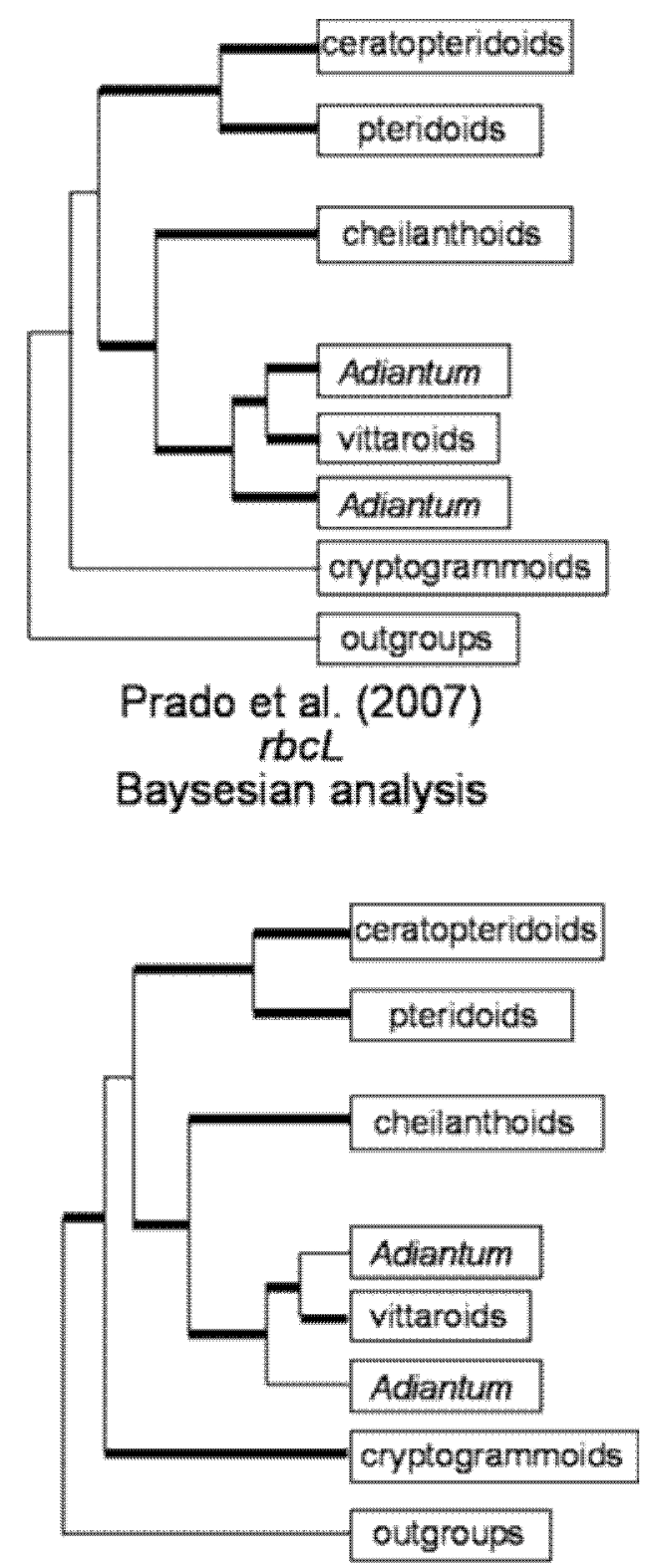

Schuettpelz et al. (2007) expanded $r b c L$ Bayesian analysis

Figure 2.1. Summary topologies of most recent Pteridaceae studies from Prado et al, 2007 and Schuettpelz et al, 2007. Thickened branches indicate those clades that received good posterior probabilities and bootstrap values according their respective studies (Prado et al. 2007, Schuettpelz et al. 2007). 
The $r b c L$ gene has been a popular choice for inferring plant phylogenies and is still a common chloroplast marker used for constructing single gene phylogenies (Gastony and Rollo 1995, Hasebe et al. 1995, Prado et al. 2007). Despite the popularity of $r b c L$, multiple gene phylogenies are becoming increasingly favored for providing better resolution of evolutionary relationships. This present study utilizes two chloroplast genes, $r b c L$ and $a t p B$, both of which have been used in previous phylogenetic investigations of the Pteridaceae. These genes have proven to provide sufficiently variable DNA sequence data necessary for reconstructing relationships among the members of the Pteridaceae. This, along with large numbers of $r b c L$ sequences available on GenBank, makes them ideal markers for phylogenetic investigations.

This study adds to the examination of the overall relationships of the fern family Pteridaceae by including all of the 17 native species in the five genera recognized in the New Zealand. In addition, estimated divergence dates for the genera within the New Zealand Pteridaceae are inferred from results obtained by previous studies to hypothesize whether the species of Pteridaceae arrived in New Zealand by long-distance dispersal or are of a vicariant origin (Pryer et al. 2004, Perrie and Brownsey 2007). Because this study constructs the most comprehensive $r b c L$ data set to date by combining all of the Pteridaceae DNA sequences available from the different data sets of previous studies of Pteridaceae phylogenies (Prado et al. 2007, Schuettpelz et al. 2007, Zhang et al. 2007) with the data of the present study; it is possible to make the best inferences yet, regarding the relationships of the New Zealand Pteridaceae species to their overseas relatives.

New Zealand and other areas of the South Pacific are under-represented in previous DNA sequence sampling, as the present study is the first molecular investigation to be conducted on New Zealand Pteridaceae phylogenetics. 
Previous studies of New Zealand Asplenium ferns suggest that regional biodiversity exists in areas of the South Pacific and Australasia (Perrie and Brownsey 2005) where hybridizing New Zealand species formed a closely related "Austral" group. The five genera of Pteridaceae native to New Zealand are Anogramma (one species), Pteris (four), Adiantum (eight), Cheilanthes (two), and Pellaea (three). Within New Zealand, most of these ferns are distributed throughout the country, although a few are quite rare and confined to certain areas (e.g., Pellaea falcata and Adiantum formosum). While most of New Zealand's native Pteridaceae species are also found in Australia and elsewhere, three Adiantum, two Pteris and, one Pellaea are endemic to New Zealand (Brownsey and Smith-Dodsworth 2000).

Increased taxonomic sampling with individual and combined analyses of multiple genes in this study offered insight into the following questions: 1) What are the relationships and affinities of the New Zealand Pteridaceae to the overseas members of this family? 2) Does the addition of the New Zealand species change the Pteridaceae phylogeny as it is has been reported in previous studies? 3) In the Pteridaceae, is there conflict between single gene phylogenies and combined gene phylogenies and is resolution gained with multiple gene analyses? 4) Do estimated divergence times support longdistance dispersal for the origins of the New Zealand Pteridaceae?

\subsection{Material \& Methods}

\subsubsection{Sample collection}

A sample from each of the 17 Pteridaceae species native to New Zealand was included in the present study (Figure 2.2). A specimen referable to Adiantum 

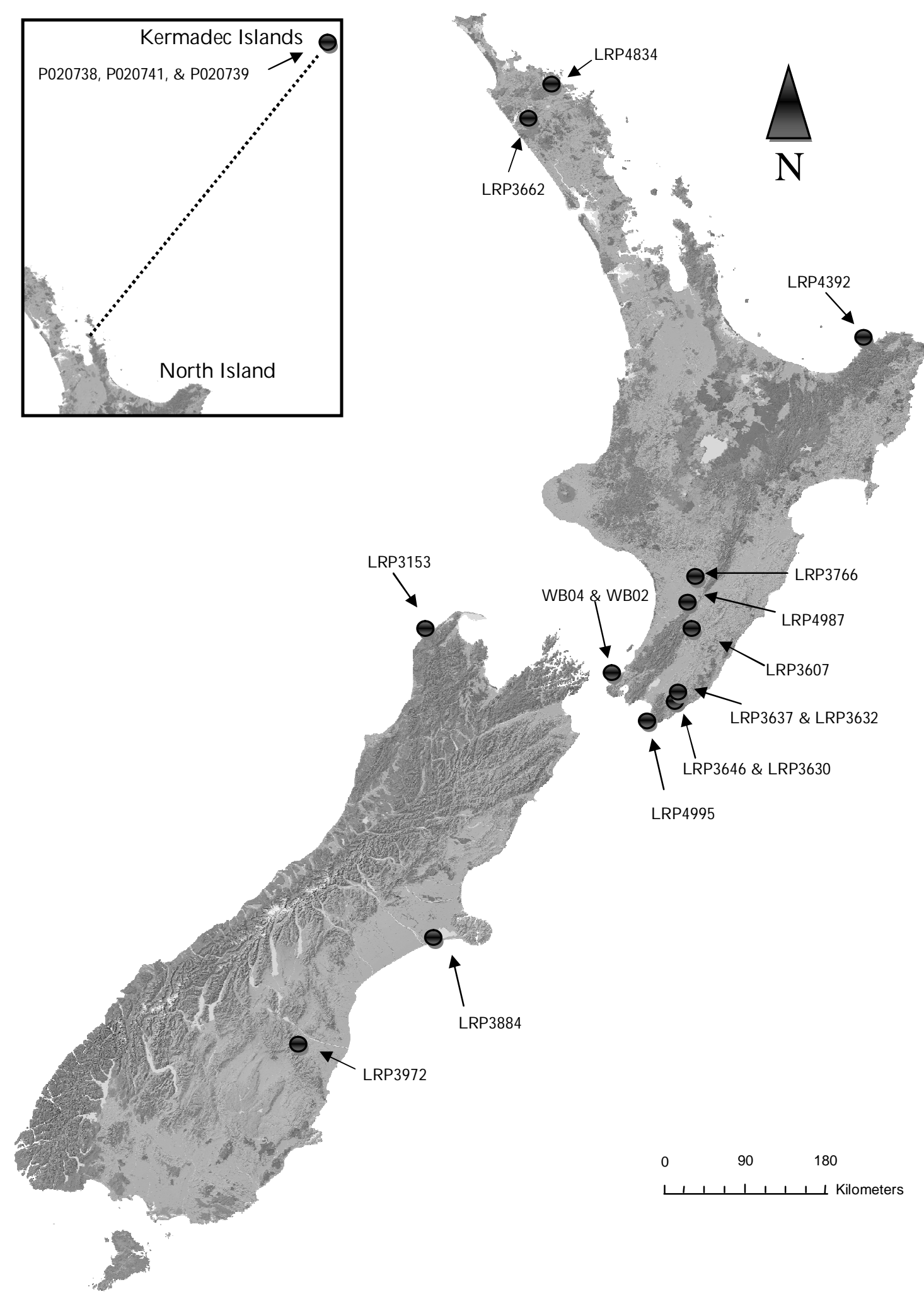

Figure 2.2. Distribution map of native New Zealand species collected for this study. The species collected from the Kermadec Islands are shown, in relation to New Zealand, in the top left. Samples beginning with P are in the WELT herbarium. WB and LRP are collection numbers for Whitney Bouma and Leon Perrie respectively. 
hispidulum Swartz var. pubescens (Schkuhr) Large et Braggins, sometimes treated as a distinct species (A. pubescens Schkuhr; Paris, 1980), was also sampled, as were two species adventive to New Zealand, Adiantum capillusveneris and A. raddianum. Samples were identified using Brownsey and Smith-Dodsworth (2000), and confirmed by sequencing the trnL-trnF locus for duplicate specimens for each native species (unpublished data; Chapters 3 and 4). The trnL-trnF locus is too variable for comparisons amongst the genera, but it supported the identification of the samples presented here.

\subsubsection{DNA isolation/PCR/sequencing}

Total DNA was extracted from dried silica gel tissue or fresh tissue, where available, according to a modified CTAB protocol (Doyle and Doyle 1990). Primers 1F (5'-ATGTCACCACAAACGGAGACTAAAGC-3') and 1361R (5'TCAGGACTCCACTTACTAGCTTCACG-3') were used for amplifying the rbcL chloroplast gene (Schuettpelz and Pryer 2007). PCR amplifications, in a total volume of $20 \mu \mathrm{l}$, were made with the following reagents: $1 \mathrm{M}$ betaine, $10 \mathrm{x}$ $\mathrm{NH}_{4}$ reaction buffer $\left(160 \mathrm{mM}\left(\mathrm{NH}_{4}\right)_{2} \mathrm{SO}_{4}, 670 \mathrm{mM}\right.$ Tris-HCI $\left(\mathrm{pH} 8.8\right.$ at $\left.25^{\circ} \mathrm{C}\right)$, 0.1\% Tween-20, BioLine), 1.5mM MgCl 2 (BioLine), 250 $\mu \mathrm{M}$ dNTPs (BioLine), 10 pmols of each forward and reverse primer, $1 \mathrm{U}$ of Taq DNA Polymerase (BioLine), and approximately 50ng of DNA template. Thermocycler conditions consisted of an initial denaturing of $95^{\circ} \mathrm{C}$ for 2 minutes, 34 cycles of $95^{\circ} \mathrm{C}$ for 1 minute, $50^{\circ} \mathrm{C}$ for 1 minute, $72^{\circ} \mathrm{C}$ for 1 minute, and a final $72^{\circ} \mathrm{C}$ for 5 minutes. Primers 672F (5'-TTGATACGGGAGCYCCTCTWAGTGT-3') and 384R (5'-GAATCCCAAACTATTCGATTAGG-3') were used to amplify the atpB gene (Schuettpelz and Pryer 2007). PCR amplification mix and thermocycler settings were the same as for $r b c L$. 
PCR products were visualized with agarose gel electrophoresis. Successfully amplified PCR products were purified with $0.2 \mathrm{U}$ of SAP (shrimp alkaline phosphatase, USB Corp., Cleveland, USA) and 1U EXO (exonuclease I, Exo I, USB Corp., Cleveland, USA) to remove residual reagents. Thermocycler conditions consisted of $37^{\circ} \mathrm{C}$ for 30 minutes followed by deactivation of enzymes at $80^{\circ} \mathrm{C}$ for 15 minutes. Cleaned products were sequenced at the Allan Wilson Center Genome Service with an ABI3730 Genetic Analyzers (Allan Wilson Centre Genome Service, Palmerston North, New Zealand). Newly obtained DNA sequences for the New Zealand Pteridaceae will be submitted to GenBank but sequence data and files can be found in the CD appendix.

\subsubsection{Phylogenetic analyses}

Three single-gene data sets (88-taxon $a t p B, 88$-taxon $r b c L$, and 220-taxon $r b c L$ with expanded sampling) and a combined two-gene (88-taxon $a t p B+r b c L$ ) data set were constructed. The single-gene data sets $(a t p B$ and $r b c L)$ and the combined data set contained 88 taxa, including the 17 species of Pteridaceae native to New Zealand, and 12 being assigned as outgroups. The same outgroups as Schuettpelz et al. (2007) were used because both atpB and $r b c L$ sequences were available on GenBank. The remaining 55 DNA sequences for other members of the Pteridaceae were sourced from GenBank, again because they had both $a t p B$ and $r b c L$ DNA sequences available to allow for a concatenated data set. The expanded $r b c L$ data set contained 220 taxa, again including the New Zealand species with the remainder being Pteridaceae samples from recent studies (Prado et al. 2007, Schuettpelz et al. 2007, Zhang et al. 2007) obtained from GenBank (Table 2.1). 
Newly generated DNA sequences for both $r b c L$ and $a t p B$ were edited by eye using BioEdit version 5.0.9 (Hall 1999). Alignments were constructed using Clustal X version 1.83 (Thompson et al. 1997). These alignments were imported into MEGA version 4.0 (Tamura et al. 2007) and combined with imported sequences from GenBank. Summary statistics on alignments were calculated using MEGA v.4.0 (Table 2.2). Pairwise comparisons determined the number of nucleotide differences, transitions, and transversions both within and between the major groups of the Pteridaceae (Table 2.3). DAMBE (Xia and Xie 2001) software was used to plot the number of transitions and transversions versus the number of nucleotide differences (Appendix B) to investigate whether the data sets had become saturated with transitions and thus were inappropriate for phylogenetic analyses (Page and Holmes 1998). Before combining $r b c L$ and $a t p B$ sequence data, a partition homogeneity test was run on PAUP* version 4.b10 (Swofford 2002) to test for conflict between the two data sets.

PAUP* v. 4.b10 was also used for implementing maximum parsimony and maximum likelihood analyses on all of the 88-taxon data sets. The heuristic searches under the parsimony criterion employed 10,000 replicates of random sequence addition and tree bisection-reconnection branch swapping. Support for the topology was assessed using bootstrapping, with 200 pseudoreplicates each using 100 replicates of random sequence addition. Maximum likelihood analyses were implemented using the appropriate model of evolution as assessed by ModelTest version 3.6 (Posada and Buckley 2004) according to the Akaike Information criteria. Maximum likelihood settings ran for 100 replicates of random sequence addition. Bootstrapping was again performed to assess the confidence with settings consisting of 100 pseudoreplicates, one random sequence addition, and, because of time constraints, branch swapping of nearest neighbor interchange (NNI). The 220-taxon $r b c L$ data set 
was subjected to maximum parsimony analysis using the same criteria as mentioned above. Maximum likelihood analyses were not run on this expanded data set because the time required would have been prohibitive.

MrBayes 3.1.2 (Huelsenbeck and Ronquist 2001) was used to carry out Bayesian inference (nst $=6$, rates=invgamma, and default priors) on all four of the data sets in this study. Analyses were run for 5,000,000 generations with sampling every 1000 generations and the initial 50\% discarded as burn-in. Standard deviations of split frequencies were checked at 2,500,000 generations to ensure a value of $\varangle 0.01$ (suggesting a convergence to stationary distribution had been achieved).

\subsection{Results}

\subsubsection{Data}

The alignment of the $r b c L$ and $a t p B$ gene sequences was straightforward, with no insertions or deletions. Summary statistics (Table 2.2; found at the end of the chapter) for the $r b c L$ data set showed that of the 1143 sites used, 496 were variable, with 413 being parsimony informative. The $a t p B$ data set comprised an alignment length of 1111 sites, of which 469 were variable and 384 were parsimony informative sites. Nucleotide composition for the $r b c L$ alignment averaged: $\mathrm{T}=26.3 \% \quad \mathrm{C}=22.0 \% \quad \mathrm{~A}=26.0 \% \quad \mathrm{G}=25.8 \%$. Average nucleotide composition for the $a t p B$ alignment showed: $\mathrm{T}=27.5 \% \mathrm{C}=19.9 \% \mathrm{~A}=28.2 \%$ and $\mathrm{G}=24.4 \%$. The observed differences between transitions and transversions are given in Table 2.3. Both $a t p B$ and $r b c L$ data sets had a similar number of observed transitions. However, the $r b c L$ data set had a much higher proportion of transversions 
Table 2.2.

Summary statistics for the four data sets analyzed in this study

\begin{tabular}{|c|c|c|c|c|c|c|}
\hline Data Set & $\begin{array}{l}\text { Alignment } \\
\text { Length } \\
\text { (bp) }\end{array}$ & $\begin{array}{c}\text { Variable } \\
\text { sites }\end{array}$ & $\begin{array}{l}\text { Parsimony } \\
\text { Informative } \\
\text { sites }\end{array}$ & $\begin{array}{l}\text { Best } \\
\text { fitting } \\
\text { Model } \\
\text { (AIC) }\end{array}$ & $\begin{array}{c}\text { Number } \\
\text { MP } \\
\text { Trees } \\
\text { (score) }\end{array}$ & $\begin{array}{l}\text { Score ML } \\
\text { tree }\end{array}$ \\
\hline $\begin{array}{c}\text { 88-taxon } \\
r b c L\end{array}$ & 1143 & 496 & 413 & $\mathrm{GTR}+\mathrm{I}+\mathrm{G}$ & $\begin{array}{c}270 \\
(2908)\end{array}$ & 15202.05189 \\
\hline $\begin{array}{c}\text { 88-taxon } \\
\text { atpB }\end{array}$ & 1111 & 469 & 384 & $\mathrm{TVM}+\mathrm{I}+\mathrm{G}$ & $\begin{array}{c}319 \\
(2284)\end{array}$ & 12283.04732 \\
\hline $\begin{array}{l}\text { 88-taxon } \\
r b c L+a t p B\end{array}$ & 2254 & 956 & 797 & $\mathrm{GTR}+\mathrm{I}+\mathrm{G}$ & 39 (5228) & 27717.61937 \\
\hline $\begin{array}{c}\text { Expanded } \\
r b c L\end{array}$ & 1143 & 594 & 483 & NA & $\begin{array}{l}10,000 \\
(4617)\end{array}$ & NA \\
\hline
\end{tabular}

AIC: Akaike Information Criteria MP: Maximum parsimony ML: Maximum likelihood

when compared with transition type changes suggesting a faster rate of evolution compared to atpB sequence data. Figures B1 and B2 in Appendix B show the rates of transitions and transversions versus the observed distance for each of the single gene 88-taxon $a t p B$ and 88-taxon $r b c L$ data sets, respectively, and showed no sign of saturation.

The partition homogeneity test reported a $\mathrm{P}$ value greater than 0.05 indicating that the two data sets could be combined for analyses $(\mathrm{P}=0.09)$. Summary statistics for the 88-taxon $a t p B+r b c L$ data set showed that of the 2254 characters used 956 were variable and 797 were parsimony informative. The 220-taxon $r b c L$ data set had the same amount of characters as the 88-taxon $r b c L$ data set, but, with the additional taxa, had 594 variable sites of which 483 were parsimony informative.

\subsubsection{Phylogenetic analyses}

Five major monophyletic groups or clades were resolved within the Pteridaceae in this study. They will be referred to by the Pteridaceae clade names as presented in Schuettpelz et al. (2007); i.e., the cryptogrammoids, ceratopteridoids, pteridoids, 
Table 2.3a Sequence difference matrix between major clades in single gene atpB data set.

Upper matrix corresponds to the percent difference and the lower is the total number of transitions over the number of transversions

\begin{tabular}{|c|c|c|c|c|c|c|c|c|}
\hline Groups & ceraptopteridoids & pteridoids & cheilanthoids & Adiantum $\mathbf{I}$ & Adiantum II & vittaroids & outgroups & cryptogrammoids \\
\hline ceratopteridoids & & 10.8 & 10.7 & 11.0 & 10.6 & 13.7 & 12.9 & 10.5 \\
\hline pteridoids & $63 / 13$ & & 8.7 & 8.2 & 7.7 & 12.7 & 12.0 & 8.9 \\
\hline cheilanthoids & $63 / 12$ & $53 / 9$ & & 7.9 & 7.8 & 12.0 & 12.3 & 7.6 \\
\hline Adiantum I & $62 / 14$ & $47 / 11$ & $48 / 7$ & & 6.3 & 10.9 & 12.1 & 9.1 \\
\hline Adiantum II & $59 / 12$ & $47 / 8$ & $48 / 4$ & $33 / 7$ & & 10.9 & 12.0 & 8.5 \\
\hline vittaroids & $69 / 26$ & $65 / 23$ & $61 / 21$ & $54 / 22$ & $53 / 20$ & & 15.4 & 13.2 \\
\hline outgroups & $72 / 17$ & $70 / 13$ & $74 / 11$ & $71 / 13$ & $71 / 11$ & $82 / 24$ & & 12.2 \\
\hline cryptogrammoids & $60 / 13$ & $53 / 9$ & $47 / 6$ & $54 / 9$ & $51 / 6$ & $69 / 22$ & $73 / 12$ & \\
\hline
\end{tabular}

Table 2.3b Sequence difference matrix between major clades in single gene rbcL data set

Upper matrix corresponds to the percent difference and the lower is the total number of transitions over the number of transversions.

\begin{tabular}{|c|c|c|c|c|c|c|c|c|}
\hline Groups & ceraptopteridoids & pteridoids & cheilanthoids & Adiantum I & Adiantum II & vittaroids & outgroups & cryptogrammoids \\
\hline ceratopteridoids & & 11.9 & 12.9 & 13.6 & 13.1 & 16.1 & 14.9 & 12.4 \\
\hline pteridoids & $58 / 42$ & & 9.3 & 10.6 & 10.6 & 13.8 & 12.9 & 9.3 \\
\hline cheilanthoids & $71 \beta 7$ & $56 / 22$ & & 9.9 & 10.1 & 13.6 & 12.7 & 9.9 \\
\hline Adiantum I & $76 / 38$ & $64 / 25$ & $68 / 15$ & & 9.0 & 13.2 & 13.6 & 10.4 \\
\hline Adiantum II & $72 \beta 7$ & $68 / 24$ & $70 / 14$ & $58 / 15$ & & 13.5 & 13.1 & 10.4 \\
\hline vittaroids & $82 / 53$ & $74 / 41$ & $78 \beta 6$ & $76 / 34$ & $78 ß 35$ & & 16.5 & 15.2 \\
\hline outgroups & $83 / 42$ & $79 / 29$ & $83 / 23$ & $87 / 27$ & $86 / 23$ & $94 / 44$ & & 11.9 \\
\hline cryptogrammoids & $69 / 35$ & $58 / 20$ & $69 / 14$ & $70 / 18$ & $72 / 15$ & $88 / 39$ & $79 / 20$ & \\
\hline
\end{tabular}


cheilanthoids, and adiantoids. Within the adiantoids, three groups (Adiantum I, Adiantum II, and the vittaroids) were consistently recovered in the 88-taxon atpB, 88taxon $r b c L$, and 88-taxon $a t p B+r b c L$ data sets. The group Adiantum I contained species with affinity to $A$. capillus-veneris (A. malesianum, A. pedatum, A. perumianum, A. tetraphyllum, and sometimes A. tenerum). Adiantum II contained all the New Zealand species with the addition of the non-native $A$. raddianum. Core phylogenies from all three tree-building analyses of each of the three 88-taxon data sets are presented in Figures 2.3a-i. Many of the inferred relationships amongst the major clades differed between tree-building analyses and between which sequence data set was used.

\section{Maximum Parsimony}

Figure 2.3a represents the 50\% majority rule consensus tree of 319 equally most parsimonious trees with a tree length of 2284 steps, for the 88-taxon atpB data set. There were 270 most parsimonious trees for the 88-taxon rbcL data set, of 2908 steps in length (Table 2.2). Figure $2.3 \mathrm{~d}$ represents the $50 \%$ majority rule consensus tree of the 270 trees recovered from this analysis. Figure $2.3 \mathrm{~g}$ represents the $50 \%$ majority rule consensus tree for the 36 recovered trees of the 88 -taxon $a t p B+r b c L$ data set with a tree length of 5228 steps.

The consensus parsimony trees for each of the 88-taxon data sets recovered the major Pteridaceae clades as recorded by Schuettpelz et al. (2007). However, incongruence was found in respect to the relationships between these clades. In all three of the 88taxon maximum parsimony analyses, the most parsimonious tree recovered the ceratopteridoids as sister to the rest of the Pteridaceae, which was not in agreement with the previous studies (Prado et al. 2007, Schuettpelz et al. 2007). The bootstrap analyses for the present study also recovered the ceratopteridoids as sister to the Pteridaceae but not supported with high bootstrap (BS) with the 88-taxon atpB (BS=60\%), and only moderately supported for the 88-taxon atpB+rbcL analyses 


\section{atpB}

$\begin{array}{lll}\text { MP } & \mathrm{BI} & \mathrm{ML}\end{array}$
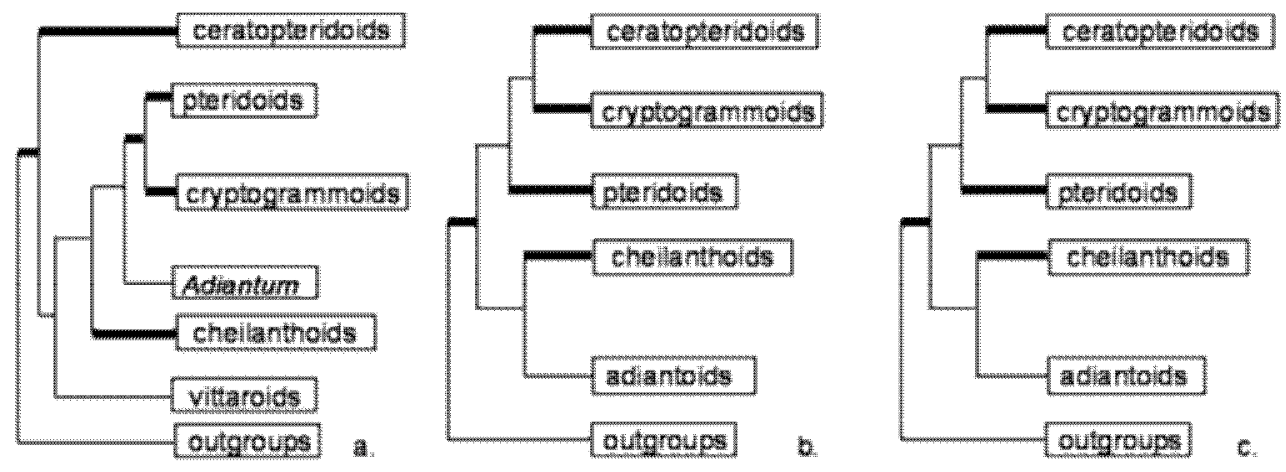

\section{$\mathrm{rbcL}$}
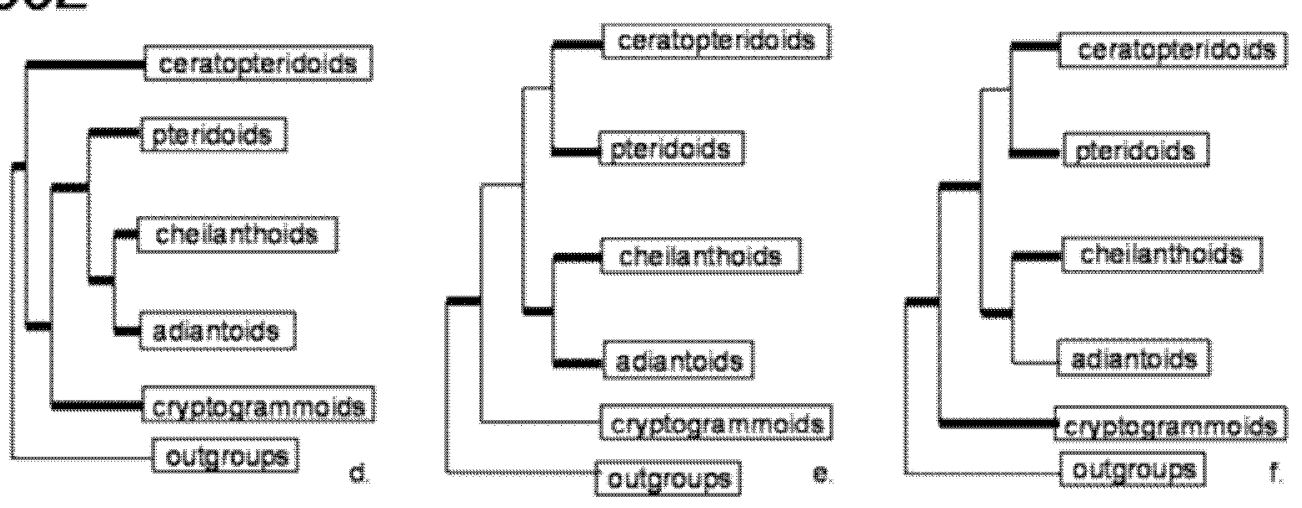

\section{$r b c L+a t p B$}
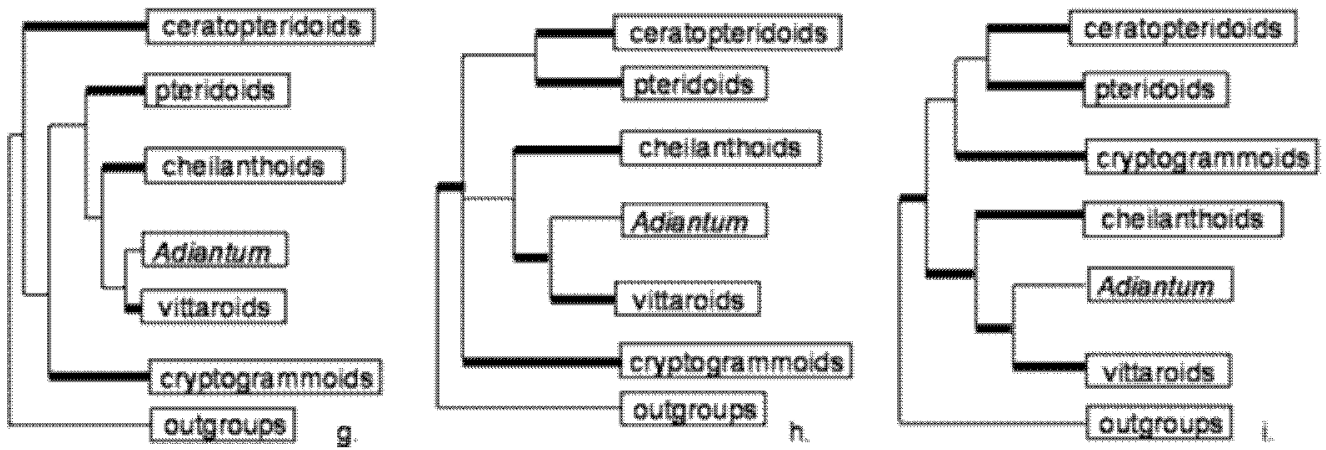

Figure 2.3a-3i.

Phylogenies for each of the three analyses; maximum parsimony (MP), Bayesian Inference (BI), and maximum likelihood (M L), for single gene atpB, rbcL, and combined atpB trbcL data sets. Thickened branches indicate well supported bootstrap values $(>70)$ and good posterior probabilities $(>0.95)$.

(BS=72\%). In contrast the bootstrap analysis of the 88-taxon $r b c L$ data set recovered the ceratopteridoids as sister to the pteridoids (bootstrap trees not shown). 
Other differences with past studies were produced in the maximum parsimony analyses. The 88-taxon at $p B$ data set produced a clade containing cryptogrammoids and pteridoids, which was then sister to Adiantum. The vittaroids, rather than being related to Adiantum, were placed sister to the remainder of Pteridaceae with the exception of the ceratopteridoids. None of these relationships were supported with high bootstrap values.

Also worth noting was the relationships recovered between Adiantum and vittaroids. Neither the 88-taxon $r b c L$ nor the 88-taxon $r b c L+a t p B$ data sets resolved Adiantum as a well supported monophyletic group. Adiantum was recovered as either paraphyletic with respect to the vittaroids with low support $(\mathrm{BS}=<50 \%$ ) in the 88-taxon $r b c L$, or a poorly supported monophyletic group $(\mathrm{BS}=55 \%)$ in the 88-taxon $r b c L+a t p B$ data set.

The maximum parsimony analysis for the 220-taxon $r b c L$ dataset (Figure 2.4a-c) also recovered the five major putative groups in the Pteridaceae. In contrast to the three 88-taxon parsimony analyses, the 220-taxon $r b c L$ data set produced a topology of the five major clades that was in agreement with previous studies with the cryptogrammoids as sister to the Pteridaceae. This expanded data set also recovered a monophyletic Adiantum (Figure 2.4c), though it received low bootstrap support (BS $=54 \%$ ).

\section{Bayesian Inference}

Bayesian Inference (BI) of the 88-taxon $r b c L$ data set (Figure 2.3e) produced a resolved tree with cryptogrammoids being sister to the rest of the Pteridaceae although receiving low posterior probability $(\mathrm{PP})$ support $(\mathrm{PP}=0.86)$. The remainder of the clades producing a topology in agreement with previous studies (Prado et al. 2007, Schuettpelz et al. 2007). The ceratopteridoids ( $P P=1.0)$ were sister to the pteridoids ( $\mathrm{PP}<0.50$ ) but the relationship did not receive good support ( $\mathrm{PP}=0.82$ ). 
The fully resolved but poorly supported cheilanthoid clade ( $\mathrm{P}=0.55)$ was sister to the fully resolved adiantoids $(\mathrm{PP}=1.0)$ and the relationship received high support $(\mathrm{PP}=1.0)$. The genus Adiantum was paraphyletic, with the vittaroids being more closely related to Adiantum I than to Adiantum II. Although grouping the vittaroids with Adiantum was well supported $(\mathrm{PP}=1.0)$, the paraphyletic relationship of Adiantum was not $(\mathrm{PP}=0.67)$.

The 88-taxon $a t p B$ BI produced a tree (Figure 2.3b) incongruent to that of the 88taxon $r b c L$ BI analyses with the major difference being the placement of cryptogrammoids. The cryptogrammoids $(\mathrm{PP}=1.0)$ were sister to the ceratopteridoids $(\mathrm{PP}=1.0)$ as opposed to the rest of the Pteridaceae but this was supported with low posterior probability $(\mathrm{PP}=0.74)$. This new clade was sister to the pteridoids $(\mathrm{PP}=1.0)$ as previously noted and was somewhat well supported ( $P P=0.91)$. The cheilanthoids were sister to the adiantoids. The adiantoids in this analysis was unresolved, with a trichotomy of the vittaroids, Adiantum I, and Adiantum II. The species A. tenerum, which consistently showed affinity for Adiantum I in the analyses 88-taxon $r b c L$, now had affinity to Adiantum II.

The BI of the 88-taxon $a t p B+r b c L$ data set recovered yet another different topology which was still incongruent with Schuettpelz et al. (2007). A basal trichotomy comprising the cryptogrammoids, the clade containing the ceratopteridoids and pteridoids, and the clade containing the adiantoids and cheilanthoids was recovered in the analysis. The relationship of the ceratopteridoids to the pteridoids ( $\mathrm{PP}=0.52$ ) was not well supported, and neither was a monophyletic Adiantum (PP=0.67).

Bayesian Inference of the 220-taxon $r b c L$ data set (tree not shown) resolved the five major Pteridaceae clades all with high support $(\mathrm{PP}=1.0)$. Their position was in agreement with previous studies and well supported with the exception of the position of the cryptogrammoids receiving low support $(\mathrm{PP}=0.85)$ as sister to the 
Pteridaceae. Also, Bayesian Inference failed to resolve a well supported monophyletic Adiantum $(\mathrm{PP}<0.50)$ as this analysis recovered a trichotomy comprising Adiantum I, Adiantum II, and the vittaroids.

\section{Maximum likelihood}

Maximum likelihood analyses for both the 88-taxon $r b c L$ and the 88-taxon atpB data sets produced almost identical topologies to their respective BI analyses. The relationships amongst the major clades in the 88-taxon $r b c L$ (Figure 2.3f) analyses were supported with high bootstrap (BS) values, with the exception of the relationship between the vittaroids and Adiantum (BS=56\%) and also the ceratopteridoids to the pteridoids (BS=54\%). Again, the 88-taxon atpB (Figure 2.3c) data set showed the cryptogrammoids form a clade with the ceratopteridoids which was sister then to the pteridoids but these relationships were not supported with high bootstrap values ( $\mathrm{BS}=59 \%$ and $\mathrm{BS}=62 \%$, respectively). The cheilanthoids and adiantoids were sister to one another as expected. Maximum likelihood analysis for the 88-taxon $a t p B+r b c L$ data set (Figure 2.3i) produced a more resolved topology to that of its Bayesian Inference, with the clade containing the ceratopteridoids and pteridoids recovered as sister to the cryptogrammoids but again this was not supported by high bootstrap values (BS $<50 \%$ ).

Within the adiantoids, incongruence was found among the relationships of the genus Adiantum and the members of the vittaroids. The 88-taxon rbcL and 88-taxon atpB analyses resolve Adiantum as paraphyletic with vittaroids grouping with Adiantum I and not Adiantum II. In the 88-taxon atpB data set, A. tenerum had affinities to the Adiantum II as opposed to the Adiantum I. A monophyletic Adiantum was resolved in the 88-taxon combined gene data set but did not receive high support from bootstrap values (BS<50\%). 


\subsubsection{Phylogenetic relationships of the New Zealand Pteridaceae species}

The New Zealand representatives mostly group together within their respective major clades. According to the 220-taxon rbcL data set the members of the New Zealand Cheilanthes (Figure 2.4a) group with one another and are sister to $C$. micropteris, the type species of Cheilanthes, in both the BI and MP analyses. The New Zealand species of the genus Pellaea (Figure 2.4a) form a monophyletic group that corresponds to Pellaea sect. Platyloma (Gastony and Rollo 1995, Kirkpatrick 2007). These species form a clade with some of the members of the genus Paragymnotperis rather than other members of the genus Pellaea. However, the New Zealand Pellaea and some Paragymnopteris are sister to a clade which contains the type species for Pellaea, P. atropurpurea. The New Zealand members of the genus Adiantum (Figure 2.4b) are paraphyletic with South American A. raddianum and A. cuneatum being more closely related to the New Zealand representatives rather than to other Adiantum species native to South America.

The members of the New Zealand Pteris (Figure 2.4c) are polyphyletic with Pteris tremula being grouped with the majority of the overseas Pteris species (excluding $P$. vittata). Pteris vittata, which is thought to have close affinity to the type species of Pteris, P. longifolia L., is not closely allied to the other sampled members of the genus Pteris, suggesting this genus is polyphyletic. It was not surprising, however, that the other native New Zealand representatives of Pteris (i.e., P. macilenta, P. saxatilis, and $P$. comans) are grouped together as they are part of what believed to be a hybrid complex where $P$. macilenta is an allopolyploid of $P$. saxatilis and P. comans (Braggins 1975, Brownsey and Smith-Dodsworth 2000). Lastly, the only New Zealand representative of the genus Anogramma (Figure 2.4c) was grouped with other members of the subfamily Taenitideae, in which it was grouped with other members of the genus Anogramma. It was, however, distinct from the duplicate sample of $A$. leptophylla from Mexico. 


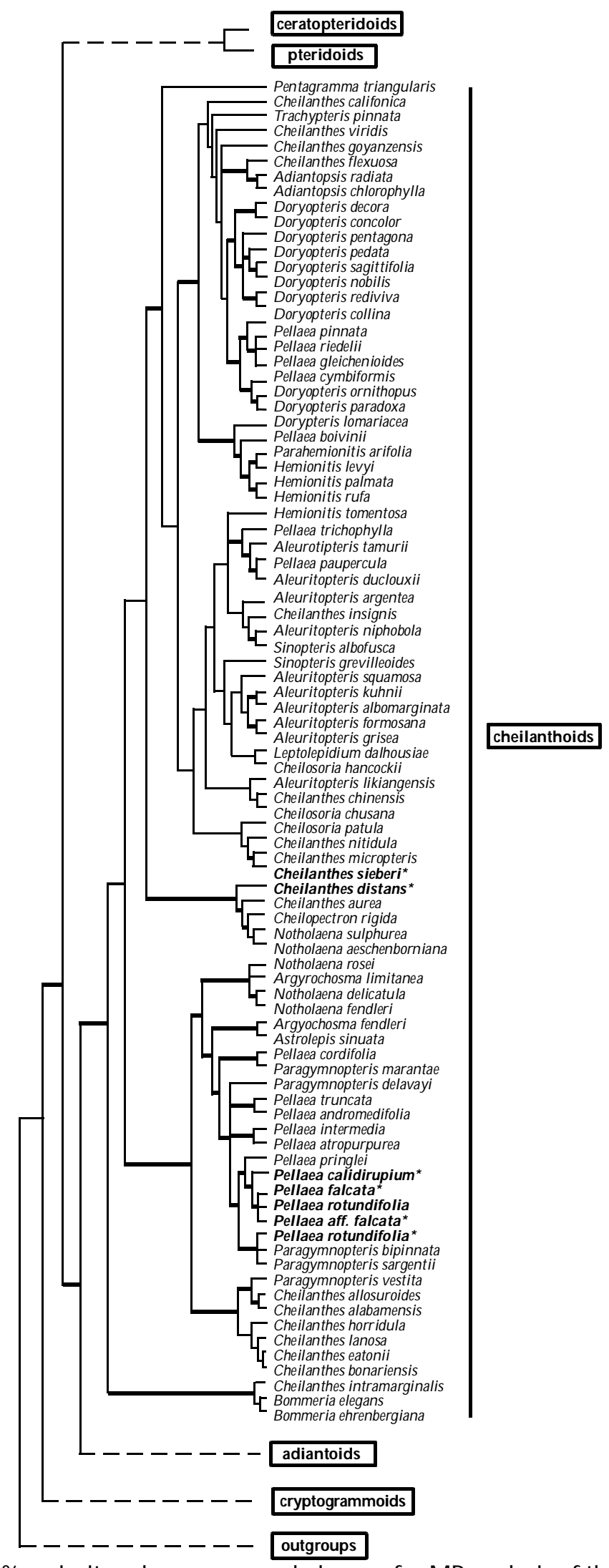

Figure $2.4 \mathrm{a}$. The $50 \%$ majority rule consensus phylogeny for M P analysis of the 220 -taxon rbcL data set. The five putative clades are shown but only the relationships within the cheilanthoids are represented here. Thickened branches indicate well supported bootstrap values (>70\%) and good posterior probabilities $(>0.95)$. New Zealand taxa are represented by an $*$ and bold text. 


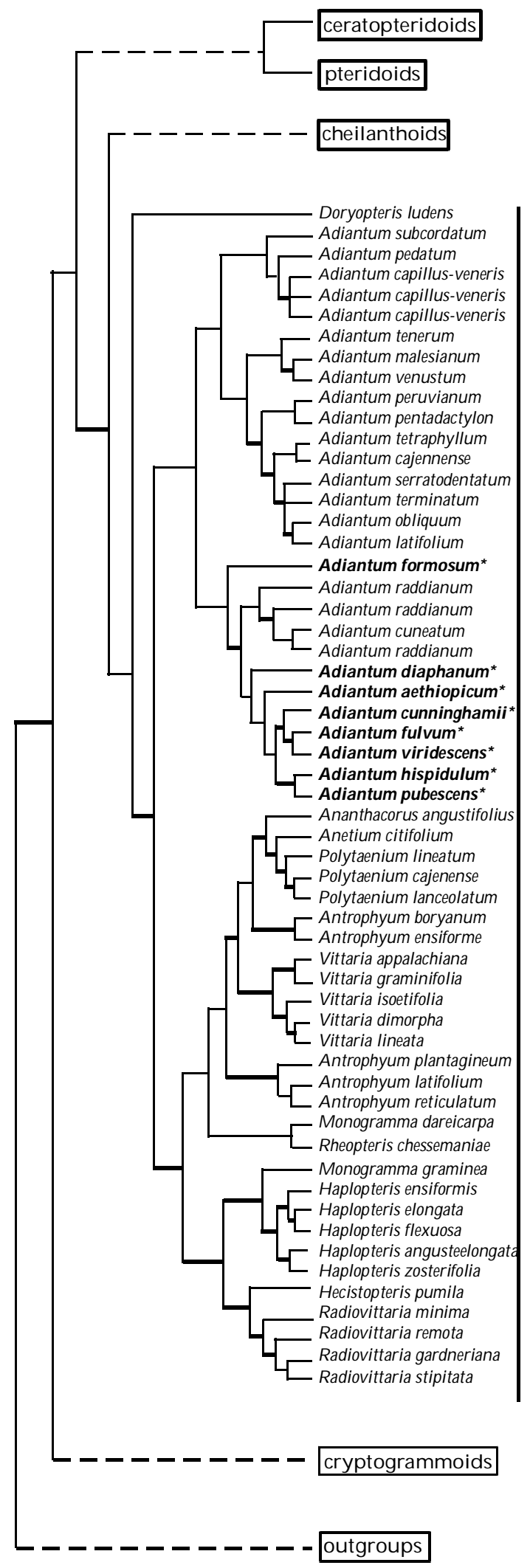

adiantoids

Figure $2.4 \mathrm{~b}$. The $50 \%$ majority rule concensus phylogeny for M P analyses of the 220 -taxon rbcL data set. The five putative clades are shown but only the relationships within the cheilanthoids are represented here. Thinckened branches indicate well supported bootstrap values (>70\%) and good posterior probabilities $(>0.95)$. New Zealand taxa are represented with an * and bold text. 


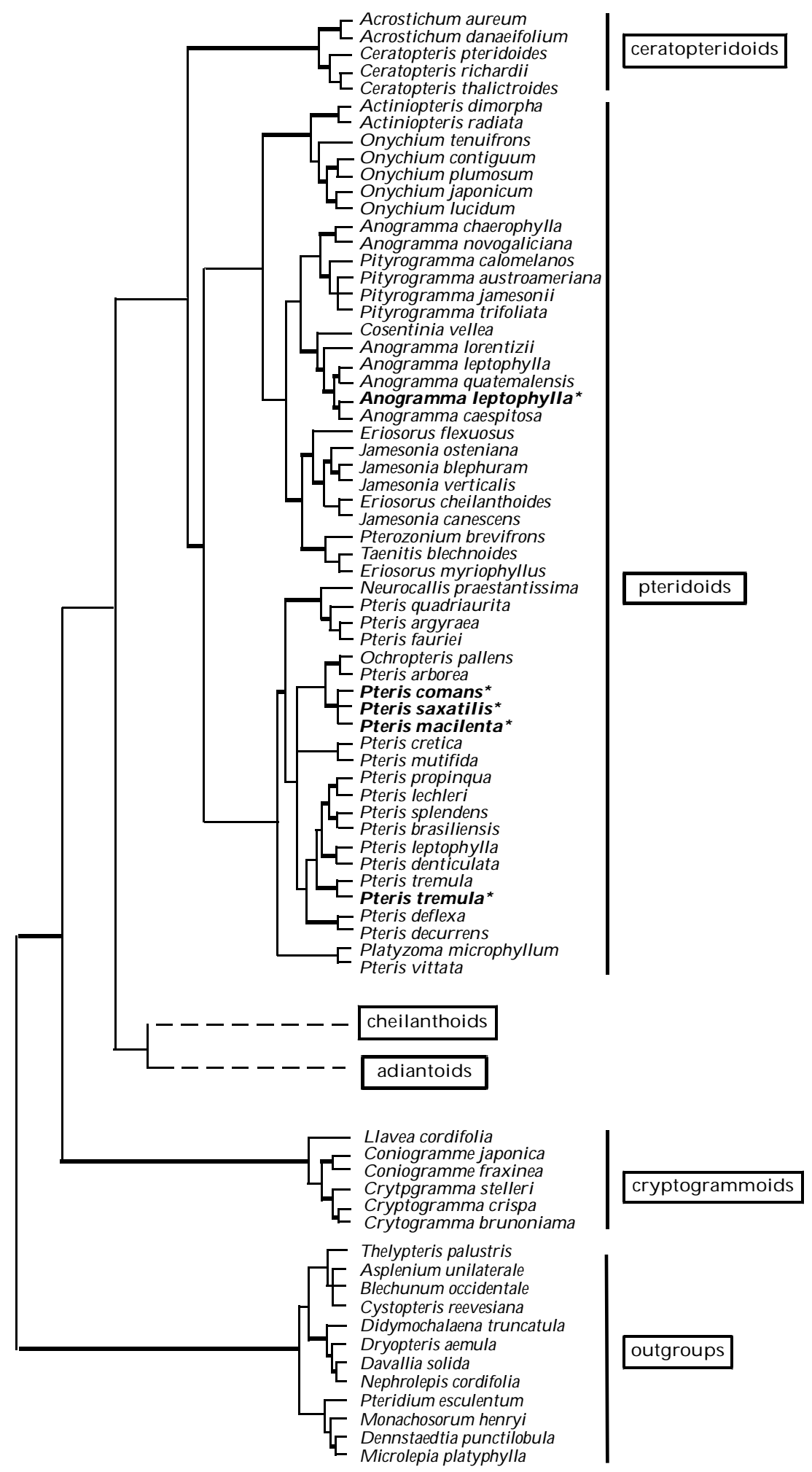

Figure $2.4 \mathrm{c}$. The $50 \%$ majority rule consensus phylogeny for M P analysis of the 220 -taxon rbcL data set. The five putative clades are shown but only the relationships within the pteridoids and represented here. Thickened branches indicate well supported bootstrap values (>70\%) and good posterior probabilities $(>0.95)$. New Zealand taxa are represented by an $*$ and bold text. 


\subsection{Discussion}

\subsubsection{Incongruence between single and combined gene phylogenies}

The consistent resolution of five major clades within the Pteridaceae in this study was in agreement with the results of Schuettpelz et al. (2007) and Prado et al. (2007). However, there were differences between the topologies of the individual and combined gene analyses. For example, the incongruence that exists among the relationship of the cryptogrammoids to the Pteridaceae between 88-taxon $r b c L$ and 88-taxon $a t p B$ data sets and also the 88-taxon atp+rbcL data set. Although the chloroplast genes, $r b c L$ and $a t p B$, code for different enzymatic functions, and hence, are subject to different evolutionary constraints, they are independent data sets representing the evolutionary history for that part of the chloroplast genome (Wolf 1997). However, these two genes are expected to reflect the same history as they are both located in the large single-copy region of the plastid genome (Wolf 1997, Savolainen et al. 2000).

The phylogenetic utility of $a t p B$ has been previously studied among plants (Wolf 1997, Savolainen et al. 2000, Guillon 2007). These studies reported a similar level of incongruence between the single gene analyses of $a t p B$ and $r b c L$, and they also reported the increased resolution with the combination of $a t p B$ with other genes. A study on the phylogeny of Equisetum compared DNA sequence data from atpB with three other chloroplast genes (Guillon 2007). Their results indicated incongruence only in topologies recovered from analyses of the $a t p B$ sequence data. Comparison of divergence rates and pairwise comparisons of the two genes suggests that $r b c L$ has a slightly faster rate of change, suggesting $a t p B$ could be more reliable at inferring relationships of older divergence than $r b c L$ (Wolf, 1997). 
These studies also reported that single $r b c L$ and combined gene data sets usually provided largely congruent phylogenies as well as increased support when the genes were combined (Wolf 1997, Savolainen et al. 2000). Surprisingly, in the present study there was a lack of resolution and a decrease in support for the placement of cryptogrammoids when the two data sets were combined (Figure 2.3gi). In both studies, Schuettpelz et al. (2007) and Prado et al. (2007), the rbcL data alone provides a poorly resolved (MP, Prado) or poorly supported (BI, Schuettpelz and Prado) position of the cryptogrammoids in the Pteridaceae phylogeny (Figure 2.1). This was concordant with results from this study. However, signal from the $a t p B$ sequence data, which favors the affinity of the cryptogrammoids to the ceratopteridoids, appeared strong enough to produce an unresolved position for cryptogrammoids (BI) or a poorly supported clade containing the cryptogrammoids and the pteridoid+ceratopteridoids clade (ML) when the atpB and $r b c L$ genes were combined.

The multi-gene analyses in Schuettpelz et al. (2007) included another chloroplast gene, $\operatorname{atp} A$, and they reported robust support for the relationships between the major Pteridaceae clades. The atp $A$ gene has been recently described as a particularly useful marker for detecting phylogenetic signal (Schuettpelz et al. 2006). It appears that the addition of $\operatorname{atp} A$ sequence data provided even more resolution than just atpB and $r b c L$ alone or even the combination of the two. It is generally agreed upon that multiple gene analyses aid in providing more resolution to phylogenetic relationships and that single gene phylogenies are that of the gene itself and not necessarily the organismal phylogeny (Wolf 1997, Savolainen et al. 2000, SànchesBaracaldo 2004, Smith et al. 2006, Guillon 2007, Schuettpelz et al. 2007, Zhang et al. 2007). The results from this study confirm that it is important to include different chloroplast loci when inferring relationships as each may yield incongruent phylogenies. 


\subsubsection{Parsimony analyses and Long Branch Attraction}

Maximum parsimony analyses produced incongruent results with regard to the relationship of the ceratopteridoids within the Pteridaceae. The 88-taxon $r b c L, 88$ taxon $a t p B$, and 88-taxon $a t p B+r b c L$ data set were not in agreement with phylogenies of previous studies (Prado et al. 2007, Schuettpelz et al. 2007) or with analyses employing different methods in the present study. This difference in topologies seems to be an issue in the methods of analysis and possibly also the taxon set used. The relationship of the ceratopteridoids as sister to the rest of the Pteridaceae as opposed to being sister to the pteridoids was different from the results of Schuettpelz et al. (2007) and Prado et al. (2007). However, incongruent relationships have been previously reported results from parsimony analyses. For example, a study focusing on tree ferns reported similar incongruent topologies when performing maximum parsimony analyses (Korall et al. 2006).

The phenomenon of long-branch attraction (LBA) was the most reasonable explanation for these relationships, as MP analyses are particularly susceptible to LBA (Kennedy et al. 2005). This occurs when taxa within a data set that have particularly long branches are attracted to distant outgroups. Although LBA tends to be a scapegoat for unexplainable topologies in many phylogenetic studies (Anderson and Swofford 2004, Bergsten 2005, Kennedy et al. 2005), there are certain indicators that imply a topology is experiencing LBA effects. It has been suggested that certain data sets under suspicion should be reanalyzed excluding the outgroups (Anderson and Swofford 2004, Bergsten 2005). If the exclusion of the outgroups resolves the correct ingroup topology, then there is a good chance that the data set is experiencing LBA, and furthermore the ingroup-alone topology is more likely to be accurate (Bergsten 2005). 
Other indicators that MP analyses are experiencing LBA are simple comparisons of topologies from MP to that of model based analyses such as maximum likelihood and Bayesian Inference (Bergsten 2005). In the present study, comparisons were made of the topologies recovered from MP analyses to the topologies from BI and ML. The comparisons indicate that maximum likelihood and Bayesian Inference, although not strongly supported, are in agreement with one another and topologies recovered from MP were largely incongruent. Given the suspicion of LBA, all three data sets were rerun with the same parsimony parameters but excluding the outgroups. The ceratopteridoids regained their expected affinity to the pteridoid clade. However, the cryptogrammoids tended to have affinity to the pteridoids and/or the ceratopteridoids when outgroups are excluded (unpublished data) even in the 88-taxon $r b c L$ data set.

The studies of Schuettpelz et al. (2007) and Prado et al. (2007) resolved the ceratopteridoids as being sister to the pteridoid clade. Schuettpelz et al. (2007) used similar genetic markers for DNA sequence data to that of the present study, yet did not run MP analyses. However, Prado et al. (2007) performed MP analyses and recovered topologies that were in agreement with Schuettpelz et al. (2007) with respect to the position of the ceratopteridoids, but they used different outgroups and different taxa in the data set. To investigate the effects of outgroup taxa on the topology in this study, each data set was rerun using the same parsimony settings but with the current outgroup taxa replaced by the outgroup taxa from Prado et al. (2007). The resulting topology was in agreement with the BI topologies from Schuettpelz et al. (2007). Furthermore, the data set from Prado et al. (2007) was run using the outgroup taxa from this study and the same correct ingroup topology was obtained suggesting that the taxonomic sampling used in Prado et al. (2007) was more conducive to filling in the branches and avoiding effects of LBA. Results from the MP analyses of the expanded $r b c L$ data set also suggest that increased taxonomic sampling helped avoid the effects of LBA. 


\subsubsection{Increased taxonomic sampling}

Creating taxonomic classifications that comprise monophyletic groups is regarded by many taxonomists as desirable (Potter and Freudenstein 2005, Stevens 2006). The results from this study indicated that the vittaroids are indeed included as part of the adiantoids. But the relationship between Adiantum and the vittaroids in this study remains unclear. The results from the 88-taxon $a t p B+r b c L$ BI and ML analyses indicate that Adiantum was monophyletic though it does not receive good support from either PP or BS values. This is in contrast to the paraphyletic relationship with respect to the vittaroids in the single gene analyses.

Both single gene $r b c L$ data from Schuettpelz et al. (2007) and Prado et al. (2007) recovered a paraphyletic relationship for the genus Adiantum. In contrast, the multigene analyses $(a t p B, r b c L$, and $a t p A)$ in Schuettpelz et al. (2007) recovered a monophyletic Adiantum, though this was not well supported (Figure 2.1). A latter study by Schuettpelz and Pryer (2007) used the same taxonomic sampling of the adiantoids and the same three chloroplast loci in a larger data set comprising representatives for all leptosporangiate ferns. Their results recovered Adiantum as paraphyletic showing the same relationships as those recovered from the single gene rbcL analyses in Schuettpelz et al. (2007).

The 220-taxon $r b c L$ data set also recovered a monophyletic Adiantum. The additional taxonomic sampling included in this data set provided resolution for the monophyly of Adiantum, suggesting that resolution and support for relationships can be improved by both increasing sequence data and increasing the number of sequence loci. Although, the 220-taxon $r b c L$ data set was a marked improvement on taxonomic sampling, it only sampled 25 of approximately 150 Adiantum species and 30 of the predicted 300 species of the vittaroids. As additional species are added to the data set, relationships of the adiantoids should become clearer, as the vast 
amount of present incongruence might be a reflection of insufficient sampling. Hence, until sufficient sampling is obtained, taxonomic revisions would be hasty.

\subsubsection{Phylogenetic relationships of the New Zealand Pteridaceae}

The topologies recovered from this study show that the species of Adiantum sampled form two distinct clades. New Zealand representatives of Adiantum fall into a clade with the addition of Brazilian A. raddianum and A. cuneatum. Tyron and Tryon (1982) suggested a classification for the genus Adiantum by dividing them into eight groups based loosely on morphological characters (Tryon and Tryon 1982). The New Zealand species were placed into three different groups. Adiantum aethiopicum, which also grows in Australia, Norfolk Island, and South Africa, was placed in a group with the type species of Adiantum, A. capillus-veneris. Also included in this group were $A$. raddianum and $A$. cuneatum. Adiantum diaphanum, which also grows in Australia, areas of south-western Asia, and Pacific Islands as far east as Fiji, was placed in a group with $A$. pedatum, which according to the results of the 220-taxon $r b c L$ data set, had affinity to A. capillus-veneris. The remainder of the New Zealand species, excluding the endemic species $A$. viridescens and A. cunninghamii, were placed in a group with A. pectinatum (not sampled in this study) which has a distribution predominately in South America. It was clear that this classification based on morphology was not concordant with molecular data, and intense sampling is needed to produce a phylogeny-based classification. However, it is beginning to be apparent that there is support for a possible South West Pacific group within Adiantum, and this group appears distinct from that group with affinity to the type, A. capillus-veneris.

The New Zealand members of Pteris are situated in separate positions within the clade containing the majority of the species in the genus. Pteris tremula was grouped with the other P. tremula sample and other sampled Pteris species, most of which are 
from South America. The other three New Zealand species, P. macilenta, P. saxatilis, and P. comans were sister to a clade containing P. arborea from South America and Ochropteris pallens from Madagascar. The majority of the samples of Pteris were placed in a clade separate from $P$. vittata. It has been suggested, though not confirmed by molecular data, that the type specimen for Pteris (P. longifolia L.) would have affinity to Pteris vittata (Tryon and Tryon 1982, Schuettpelz et al. 2007), suggesting polyphyly in the genus. Like the genus Adiantum, only a small number of Pteris species were sampled for this study. There are approximately 300 species in the genus Pteris, and with increased sampling a better understanding of the relationships among the genus would become clearer, particularly amongst the species of Pteris that have affinity to $P$. vittata.

The New Zealand Pellaea form a monophyletic group within the cheilanthoid clade. This group corresponds to the Pellaea section Platyloma as described by Tryon and Tryon (1982). Other representatives of the section Platyloma include the Australian P. paradoxa and P. nana. Though not sampled here, they group with the New Zealand representatives (unpublished data Chapter 3). Pellaea sect. Platyloma is nested within the clade consisting of members of Pellaea sect. Pellaea, which comprises ferns mostly occurring in South America (Gastony and Rollo 1995, Kirkpatrick 2007). Asian ferns from the genus Paragymnopteris had the closest affinity to the New Zealand Pellaea. Based on results from Kirkpatrick (2007), Australian Paraceterach muelleria is also grouped with members of New Zealand Pellaea.

Paraphyletic and polyphyletic relationships are rampant in the cheilanthoid ferns particularly in the genus Pellaea, as the representatives of Pellaea sampled for this study are highly polyphyletic, being situated in several different positions within the tree. These results support claims that convergent morphologies have complicated generic circumscriptions for these ferns (Tryon and Tryon 1982, 
Gastony and Rollo 1995, Kirkpatrick 2007, Zhang et al. 2007). Taxonomic revisions for these ferns have previously been suggested (Kirkpatrick 2007). However, additional sampling will be required in order to accurately represent Pellaea ferns and their relationships to the other cheilanthoid ferns on a global level.

The New Zealand species of Cheilanthes also occur in Australia and other islands of the South Pacific. Their affinity to the type species for Cheilanthes was supported in both the MP and BI of the 220-taxon rbcL data set. However, there are approximately 13 other species of Cheilanthes that occur in Australia and the South Pacific, none of which were sampled for this study. The inclusion of the South Pacific Cheilanthes to this data set would provide a better picture of the relationships of these Cheilanthes to the type specimen and hence, other members of the cheilanthoid ferns.

Lastly, the only species of the genus Anogramma occurring in New Zealand, $A$. leptophylla (the type species for Anogramma), showed affinity for other members in the genus, but it was, however, distinct from the other sample of A. leptophylla, from Mexico. The New Zealand sample was more closely related to the African $A$. caespitosa than to the central American A. guatemalensis and Mexican A. leptophylla. Tryon and Tryon (1982) commented that A. leptophylla was the most widely distributed and also the most polymorphic species of the genus (Tryon and Tryon 1982). They also commented that several robust morphological characters of $A$. leptophylla have caused confusion with distinguishing it from A. guatemalensis and $A$. caespitosa. The genus was also paraphyletic with members of the genus Pityrogramma being nested within the members of Anogramma. 


\subsubsection{Estimated divergence times}

The Pteridaceae family is a lineage of polypod ferns within the core leptosporangiate ferns (Pryer et al. 2004). Pryer et al. (2004) inferred the divergence of the core leptosporangiate ferns to have occurred during the Triassic period ( 220 mya). The polypod lineage began to diversify in the Jurassic ( 183 mya to 160 mya) and contains some of the most species diverse lineages, specifically the Pteridaceae. According to Pryer et al. (2004), this lineage diverged during the late Cretaceous ( 76 mya). In addition, Perrie and Brownsey (2007) investigated the divergence times a New Zealand species of each of Adiantum and Pteris with respect to their closest (available) non-New Zealand relative. Their inferred divergence times were approximately 20 and 30 mya, respectively (Perrie and Brownsey 2007).

Thoughts on the origins for the flora of New Zealand are centered on two main hypotheses. Either the flora in New Zealand has been isolated since New Zealand's separation from Gondwana ( $\sim 80$ mya) or the flora has arrived in New Zealand as a result of long-distance dispersal. The recent divergence of the Pteridaceae ferns supported both by Pryer et al. (2004) and Perrie and Brownsey (2007) imply that they are the result of long-distant dispersal. Although long-distant dispersal has been suggested by several studies (Brownsey 2001, Winkowrth et al. 2002, Perrie et al. 2007, Perrie and Brownsey 2007), the direction of dispersal could not be determined because of the lack of a phylogeny containing large amounts of overseas relatives. The 220-taxon $r b c L$ data set shows that the New Zealand Pteridaceae species are nested within the overseas diversity, indicating their respective groups have originated elsewhere and immigrated to New Zealand. 


\subsubsection{Conclusions}

As new taxa from the Pteridaceae family are sequenced from around the world and as new DNA sequence markers are developed, the resolution of the relationships in this family will continue to improve. Large scale analyses, coupled with studies focusing on particular segregates (e.g., Pellaea, Cheilanthes, Pteris, and Adiantum) will help to provide a robust phylogeny of the Pteridaceae, not only between the subfamilies, but the relationships among the genera within these subfamilies. The New Zealand Pteridaceae species are representatives from a previously undersampled part of the world. Their inclusion particularly provided a better picture for the relationships among the genus Adiantum, as well as representing the members of Pellaea sect. Platyloma among the cheilanthoid ferns. The Pteridaceae is a large and diverse family of ferns and quite possibly could continue to grow with regard to size and diversity as new species are continually being discovered (Prado 2006). There are several genera that require taxonomic revision. However it is clear now that until adequate taxonomic sampling is achieved, a revision, based on the currently available data, would be premature. 


\subsection{References}

Anderson, F. E., and D. L. Swofford. 2004. Should we be worried about long-branch attraction in real data sets? Investigations using metazoan $18 \mathrm{~S}$ rDNA. Molecular Phylogenetics and Evolution 33:440-451.

Bergsten, J. 2005. A review of long-branch attraction. Cladistics 21:163-193.

Braggins, J. E. 1975. Studies on the New Zealand, and some related, species of Pteris L. University of Auckland.

Brownsey, P. J. 2001. New Zealand's pteridophyte flora--- plants of ancient lineage but recent arrival? Brittonia 53:284-303.

Brownsey, P. J., and J. C. Smith-Dodsworth. 2000. New Zealand Ferns and Allied Plants. 2nd edition. David Bateman Ltd., Auckland, New Zealand.

Ching, R. C. 1940. On natural classification of the family "Polypodiaceae". Sunyatesenia 5:201-268.

Copeland, E. B. 1947. Genera Filicum, Waltham, Mass.

Doyle, J. J., and J. D. Doyle. 1990. Isolation of plant DNA from fresh tissue. Focus 12.

Gastony, G. J., and D. R. Rollo. 1995. Phylogeny and Generic Circumscriptions of Cheilanthoid Ferns (Pteridaceae: Cheilanthoideae) Inferred from $r b c \mathrm{~L}$ Nucleotide Sequences. American Journal of Botany 85:341-360.

Guillon, J.-M. 2007. Molecular phylogeny of horsetails (Equisetum) including chloroplast atpB sequences. Journal of Plant Research 120:569-574.

Hall, T. A. 1999. BioEdit: a user-friendly biological sequence alignment editor and analysis program for Windows 95 98/NT. Nucleic Acids Symp. Ser. 41:95-98.

Hasebe, M., W. P.G., K. M. Pryer, K. Ueda, M. Ito, R. Sano, G. J. Gastony, J. Yokoyama, J. R. Manhart, N. Murakami, E. H. Crane, C. H. Haufler, and W. D. Hauk. 1995. Fern Phylogeny Based on rbcL Nucleotide Sequences. American Journal of Botany 85:134-181.

Huelsenbeck, J. P., and F. R. Ronquist. 2001. MrBayes: Bayesian inference of phylogeny. Biometrics 17:754-755. 
Kennedy, M., B. R. Holland, R. D. Gray, and H. G. Spencer. 2005. Untangling Long Branches: Identifying Conflicting Phylogenetic Signals Using Spectral Analysis, Neighbor-Net, and Consensus Networks. Systematic Biology 54:620-633.

Kirkpatrick, R. E. B. 2007. Investigating the monophyly of Pellaea (Pteridaceae) in the context of a phylogenetic analysis of Cheilantoid Ferns. Systematic Botany 32:504-518.

Korall, P., K. M. Pryer, J. S. Metzgar, H. Schneider, and D. S. Conant. 2006. Tree ferns: Monophyletic groups and their relationships as revealed by four protein-coding plastid loci. Molecular Biology and Evolution 39:830-845.

Page, R. D. M., and E. C. Holmes. 1998. Molecular Evolution: A Phylogenetic Approach. Blackwell Science Ltd.

Perrie, L. R., M. J. Bayly, C. A. Lehnebach, and P. J. Brownsey. 2007. Molecular phylogenetics and molecular dating of the New Zealand Gleicheniaceae. Brittonia 59:129-141.

Perrie, L. R., and P. J. Brownsey. 2005. Insights into the biogeography and polyploid evolution of New Zealand Asplenium from chloroplast DNA sequence data. American Journal of Botany 95:1-21.

Perrie, L. R., and P. J. Brownsey. 2007. Molecular evidence for long-distance dispersal in the New Zealand pteridophyte flora. Journal of Biogeography 34:2028-2038.

Pichi Sermolli, R. E. G. 1977. Tentamen pteridophytorum genera in taxonomicum ordinem ridigendi. Webbia 31:313-512.

Posada, D., and T. R. Buckley. 2004. Model selection and model averaging in phylogenetics: advantages of Akaike information criterion and Bayesian approaches over likelihood ratio tests. Systematic Biology 53:793-808.

Potter, D., and J. V. Freudenstein. 2005. Character-based phylogenetic Linnaean classification: taxa should be both ranked and monophyletic. TAXON 54:1033-1035.

Prado, J. 2006. Three new species of Adiantum (Pteridaceae) from Bolivia and Peru. Brittonia 58:379-384. 
Prado, J., C. Del Nero Rodrigues, A. Salatino, and M. L. F. Salatino. 2007.

Phylogenetic relationships among Pteridaceae, including Brazilian species, inferred from $r b c \mathrm{~L}$ sequences. TAXON 56:355-368.

Pryer, K. M., E. Schuettpelz, P. G. Wolf, H. Schneider, A. R. Smith, and R. Cranfill. 2004. Phylogeny and evolution of ferns (monilophytes) with a focus on the early leptosporangiate divergences. American Journal of Botany 91:1582-1598.

Sànches-Baracaldo, P. 2004. Phylogenetics and biogeography of the neotropical fern genera Jamesonia and Eriosorus (Pteridaceae). American Journal of Botany 91:274-284.

Savolainen, V., M. W. Chase, S. B. Hoot, C. M. Morton, D. E. Soltis, C. Bayer, M. F. Fay, A. Y. De Bruijn, S. Sullivan, and Y. Qiu. 2000. Phylogenetics of Flowering Plants Based on Combined Analysis of Plastid $a t p B$ and $r b c L$ Gene Sequences. Systematic Biology 49:306-362.

Schuettpelz, E., P. Korall, and K. M. Pryer. 2006. Plastid atpA data provide improved support for deep relationships among ferns. TAXON 55:897-906.

Schuettpelz , E., and K. M. Pryer. 2007. Fern phylogeny inferred from 400 leptosporangiate species and three plastid genes. TAXON 56:1037-1050.

Schuettpelz , E., H. Schneider, L. Huiet, M. D. Windham, and K. M. Pryer. 2007. A molecular phylogeny of the fern family Pteridaceae: Assessing overall relationships and the affinities of previously unsampled genera. Molecular Phylogenetics and Evolution 44:1172-1185.

Smith, A. R., Pryer, K.M.,, E. Schuettpelz, P. Korall, H. Schneider, and P. G. Wolf. 2006. A classification for extant ferns. TAXON 55:705-731.

Stevens, P. F. 2006. An end to all things? -- plants and their names. Australian Systematic Botany 19:115-133.

Swofford, D. L. 2002. PAUP* Phylogenetic analysis using parsimony (* and other methods). Sinauer Associates, Sunderland.

Tamura, K., J. Dudley, M. Nei, and S. Kumar. 2007. MEGA4: Molecular Evolutionary Genetics Analysis (MEGA) software version 4.0. . Molecular Biology and Evolution 24:1596-1599. 
Tryon, R. M., and A. F. Tryon. 1982. Ferns and Allied Plants With Special Reference to Tropical America. Springer-Verlag New York Inc., New York.

Tyron, R. M., A. F. Tyron, and K. U. Kramer. 1990. Pteridaceae. Pages 230-256 The Families and Genera of Vascular Plants Vol. 1. Pteridophytes and Gymnosperms. Springer-Verlag, Berlin.

Winkowrth, R. C., S. J. Wagstaff, D. Glenny, and P. J. Lockhart. 2002. Plant dispersal N.E.W.S from New Zealand. Trends in Ecology and Evolution 17:514-520.

Wolf, P. G. 1997. Evaluation of atpB nucleotide sequences for phylogenetic studies of ferns and other pteridophytes. American Journal of Botany 84:1429-1440.

Xia, X., and Z. Xie. 2001. DAMBE: Data analysis in molecular biology and evolution. Journal of Heredity 92:371-373.

Zhang, G., X. Zhang, Z. Chen, H. Liu, and W. Yang. 2007. First insights in the phylogeny of Asian cheilanthoid ferns based on sequences of two chloroplast markers. TAXON 56:369-378. 
Table 2.1. List of taxonomic sampling from the current study, including available voucher information and accession numbers. The New Zealand taxa will have collection numbers until voucher information is available. - indicates where no accession numbers are available.

\begin{tabular}{|c|c|c|c|}
\hline Species Name & Voucher information & $\begin{array}{l}r b c L \\
\text { GenBank } \\
\text { Accession }\end{array}$ & $\begin{array}{c}\text { atpB } \\
\text { GenBank } \\
\text { Accession }\end{array}$ \\
\hline \multicolumn{4}{|c|}{ New Zealand taxa } \\
\hline Adiantum aethiopicum $\mathrm{L}$. & LRP3637 & -- & -- \\
\hline Adiantum capillus-veneris $\mathrm{L}$. & WB10 & -- & -- \\
\hline Adiantum cunninghamii Hook. & LRP3153 & -- & -- \\
\hline Adiantum diaphanum Blume & LRP4392 & -- & -- \\
\hline Adiantum formosum R.Br. & LRP4987 & -- & -- \\
\hline Adiantum fulvum Raoul & WB02 & -- & -- \\
\hline Adiantum hispidulum Sw. & LRP4834 & -- & -- \\
\hline Adiantum pubescens Shukhur & PO20741 & -- & -- \\
\hline Adiantum raddianum C.Presl & WB09 & -- & -- \\
\hline Adiantum viridescens Colenso & WB04 & -- & -- \\
\hline Anogramma leptophylum (L.) Link & LRP3632 & -- & -- \\
\hline Cheilanthes distans (R.Br.) Mett. & LRP3646 & -- & -- \\
\hline Cheilanthes sieberi Kunze & LRP3630 & -- & -- \\
\hline Pellaea calidirupium Brownsey et Lovis & LRP3884 & -- & -- \\
\hline Pellaea aff. falcata & LRP3607 & -- & -- \\
\hline Pellaea falcata (R.Br.) Fee & PO20738 & -- & -- \\
\hline Pellaea rotundifolia (G.Forst.) Hook. & LRP3972 & -- & -- \\
\hline Pteris macilenta A.Rich. & LRP4995 & -- & -- \\
\hline Pteris comans G.Forst. & PO20739 & -- & -- \\
\hline Pteris tremula R.Br. & LRP3766 & -- & -- \\
\hline Pteris saxatilis Carse & LRP3662 & -- & -- \\
\hline \multicolumn{4}{|c|}{ Other Pteridaceae taxa sourced from GenBank } \\
\hline Acrostichum aureum $\mathrm{L}$. & Masuyama et al. (2002) & AB059586 & -- \\
\hline Acrostichum danaeifolium Langsd. et Fisch. & Schuettpelz 616 (B) & EF452129 & EF452008 \\
\hline Actiniopteris dimorpha Pic. Serm. & Schneider s.n. (GOET) & EF452130 & EF452009 \\
\hline Actiniopteris radiata (Sw.) Link & $\begin{array}{l}\text { Gastony and Johnson } \\
\text { (2001) }\end{array}$ & AF336100 & -- \\
\hline Adiantopsis chlorophylla (Sm.) Fee & Prado and Yano 1047 & EF473684 & -- \\
\hline Adiantopsis radiata (L.) Fee & Christenhusz 4033 (TUR) & EF452131 & EF452010 \\
\hline Adiantum cajennense Willd. & Prado et al. 1201 & EF473765 & -- \\
\hline Adiantum capillus-veneris $\mathrm{L}$. & Hasebe et al. (1993) & D14880 & -- \\
\hline Adiantum capillus-veneris $\mathrm{L}$. & Wolf et al. (2003) & AY178864 & AY178864 \\
\hline Adiantum cuneatum Langsd. et Fisch. & Prado and Yano 1078 & EF473676 & -- \\
\hline Adiantum latifolium Lam. & Prado et al. 1294 & EF473677 & -- \\
\hline Adiantum malesianum J. Ghatak & Huiet 111 (UC) & EF452132 & EF452011 \\
\hline Adiantum obliquum Willd. & Prado et al. 1345 & EF473678 & -- \\
\hline Adiantum pedatum $\mathrm{L}$. & $\begin{array}{l}\text { Hasebe et al. (1994), Huiet } \\
117 \text { (UC) }\end{array}$ & U05602 & EF452012 \\
\hline Adiantum pentadactylon Langsd. et Fisch. & Prado et al. 1085 & EF473679 & -- \\
\hline
\end{tabular}




\begin{tabular}{|c|c|c|c|}
\hline Species Name & Voucher information & $\begin{array}{l}r b c L \\
\text { GenBank } \\
\text { Accession }\end{array}$ & $\begin{array}{c}a t p B \\
\text { GenBank } \\
\text { Accession }\end{array}$ \\
\hline Adiantum peruvianum Klotzsch & Huiet 103 (UC) & EF452133 & EF452013 \\
\hline Adiantum raddianum C. Presl & Prado and Yano 1077 & EF473680 & -- \\
\hline Adiantum raddianum C. Presl & $\begin{array}{l}\text { Wolf et al. (1994), Wolf } \\
\text { (1997), Wolf } 717 \text { (UTC) }\end{array}$ & U05906 & U93840 \\
\hline $\begin{array}{l}\text { Adiantum serratodentatum Humb. et Bonpl. } \\
\text { ex Willd. }\end{array}$ & Prado et al. 1545 & EF473681 & -- \\
\hline Adiantum subcordatum Sw. & Prado and Yano 1075 & EF473682 & -- \\
\hline Adiantum terminatum Kunze ex Miq. & Prado et al. 1354 & EF473683 & -- \\
\hline Adiantum tenerum Sw. & Huiet 107 (UC) & EF452134 & EF452014 \\
\hline $\begin{array}{l}\text { Adiantum tetraphyllum Humb. et Bonpl. ex } \\
\text { Willd. }\end{array}$ & Huiet 105 (UC) & EF452135 & EF452015 \\
\hline Adiantum venustum D.Don & Huiet 116 (UC) & EF452136 & -- \\
\hline $\begin{array}{l}\text { Aleuritopteris albomarginata (C.B.Clarke) } \\
\text { Ching }\end{array}$ & Zhang et al (2005) & AY266411 & -- \\
\hline Aleuritopteris argentea (S.G.Gmelin) Fee & Yatskievych 01-23 (MO) & EF452137 & EF452016 \\
\hline Aleuritopteris duclouxii (Christ) Ching & Gastony and Rollo (1995) & U27447 & -- \\
\hline Aleuritopteris formansana (Hayata) Tagawa & Gangmin Zhang 458 & DQ432643 & -- \\
\hline Aleuritopteris grisea (Blanf.) Panigrahi & Zhang et al. (2005) & AY299653 & -- \\
\hline Aleuritopteris kuhii (Milde) Ching & Zhang et al. (2005) & AY266412 & -- \\
\hline Aleuritopteris likiangensis Ching & Gangmin Zhang 278 & DQ432645 & -- \\
\hline Aleuritopteris niphobola (C.Chr.) Ching & Zhang et al. (2005) & AY266409 & -- \\
\hline $\begin{array}{l}\text { Aleuritopteris squamosa (Hope et } \\
\text { C.H.Wright) Ching }\end{array}$ & Shiyong Dong 28 & DQ432642 & -- \\
\hline Aleuritopteris tamburii (Hook) Ching & Gangmin Zhang 434 & DQ732644 & -- \\
\hline $\begin{array}{l}\text { Ananthacorus angustifolius Underw. et } \\
\text { Maxon }\end{array}$ & Crane et al. (1995) & U20932 & -- \\
\hline Anetium citrifolium (L.) Splitg. & $\begin{array}{l}\text { Crane et al. (1995), } \\
\text { Christenhusz } 4076 \text { (TUR) }\end{array}$ & U21284 & EF452017 \\
\hline Anogramma caespitosa Pic.Serm. & $\begin{array}{l}\text { Nakazato and Gastony } \\
\text { (2003) }\end{array}$ & AY168718 & -- \\
\hline Anogramma chaerophylla (Desv.) Link & $\begin{array}{l}\text { Nakazato and Gastony } \\
\text { (2003) }\end{array}$ & AY168712 & -- \\
\hline Anogramma quatemalensis (Domin) C. Chr. & $\begin{array}{l}\text { Nakazato and Gastony } \\
\text { (2003) }\end{array}$ & AY168716 & -- \\
\hline Anogramma leptophylla (L.) Link & $\begin{array}{l}\text { Nakazato and Gastony } \\
\text { (2003) }\end{array}$ & AY168715 & -- \\
\hline Anogramma lorentzii (Hieron.) Diels & $\begin{array}{l}\text { Gastony and Johnson } \\
\text { (2001) }\end{array}$ & AF336102 & -- \\
\hline Anogramma novogaliciana Mickel & $\begin{array}{l}\text { Nakazato and Gastony } \\
\text { (2003) Ruanker } 1774 \\
\text { (COLO) }\end{array}$ & AY168714 & -- \\
\hline Antrophyum boryanum (Willd.) E.H.Crane & Crane et al. (1995) & U20930 & -- \\
\hline Antrophyum ensiforme Hook. & Crane et al. (1995) & U20931 & -- \\
\hline Antrophyum latifolium Blume & Ranker 1774 (COLO) & EF452138 & EF452018 \\
\hline Antrophyum plantagineum (Cav.) Kaulf. & Crane et al. (1995) & U21285 & \\
\hline Antrophyum reticulatum (G.Forst.) Kaulf. & Hasebe et al. (1994) & U05604 & -- \\
\hline Argyrochosma fendleri (Kunze) Windham & Gastony and Rollo (1995) & $\mathrm{U} 27727$ & -- \\
\hline
\end{tabular}




\begin{tabular}{|c|c|c|c|}
\hline Species Name & Voucher information & $\begin{array}{l}r b c L \\
\text { GenBank } \\
\text { Accession }\end{array}$ & $\begin{array}{c}\text { atpB } \\
\text { GenBank } \\
\text { Accession }\end{array}$ \\
\hline Argyrochosma limitanea (Maxon) Windham & Schuettpelz 472 (DUKE) & EF452139 & EF452019 \\
\hline Asplenium unilaterale Lam. & Ranker 2072 (COLO) & EF452140 & EF452020 \\
\hline $\begin{array}{l}\text { Astrolepis sinuate (Lag. ex Sw.) D.M. } \\
\text { Benham et Windham }\end{array}$ & Schueettpelz 310 (DUKE) & EF452141 & EF452021 \\
\hline Blechnum occidentale L. & $\begin{array}{l}\text { Wolf et al. (1994), Wolf } \\
\text { (1997), Wolf } 289 \text { (UTC) }\end{array}$ & U05910 & U93838 \\
\hline Bommeria ehrenbergiana (Kotzsch) Underw. & Gastony and Rollo (1995) & U19497 & -- \\
\hline $\begin{array}{l}\text { Bommeria elegans (Davenp.) Ranker \& } \\
\text { Haufler }\end{array}$ & Gastony \& Rollo (1995) & U27729 & -- \\
\hline Bommeria hispida (Mett. ex Kuhn) Underw. & Schuettpelz 467 (DUKE) & EF452142 & EF452022 \\
\hline Ceratopteris pteridoides (Hook.) Hieron. & Masuyama et al. (2002) & AB059584 & -- \\
\hline Ceratopteris richardii Brongn. & $\begin{array}{l}\text { Masysyama et al. (2002), } \\
\text { Pryer et al. (2004), Killip } \\
44595 \text { (GH) }\end{array}$ & AB059585 & AY612691 \\
\hline Ceratopteris thalictroides (L.) Brongn. & Masuyama etal. (2002) & AB059573 & -- \\
\hline Cheilanthes alabamensis (Buckley) Kunze & Schuettpelz 319 (DUKE) & EF452143 & EF452023 \\
\hline Cheilanthes allosuroides Mett. & Gastony and Rollo (1995) & U27239 & -- \\
\hline Cheilanthes aurea Baker & Gastony and Rollo (1995) & U28786 & -- \\
\hline Cheilanthes bonariensis (Willd.) Proctor & Gastony and Rollo (1995) & U19499 & -- \\
\hline Cheilanthes califonica (Hook.) Mett. & $\begin{array}{l}\text { Gastony and Johnson } \\
\text { (2001) }\end{array}$ & AF336101 & -- \\
\hline Cheilanthes chinensis (Baker) Domin & Gangmin Zhang 227 & DQ432651 & -- \\
\hline Cheilanthes eatonii Baker & Schuettpelz 323 (DUKE) & EF452144 & EF452024 \\
\hline Cheilanthes flexuosa Kunze & $\begin{array}{l}\text { Forza and Mello-Silva } \\
1503\end{array}$ & EF473686 & -- \\
\hline Cheilanthes goyazensis (Taub.) Domin & $\begin{array}{l}\text { Prado and B.-Blubaugh } \\
1403\end{array}$ & EF473687 & -- \\
\hline Cheilanthes horridula Maxon & Gastony and Rollo (1995) & U27448 & -- \\
\hline Cheilanthes insignis Ching & Zhang et al. (2005) & AY166413 & -- \\
\hline $\begin{array}{l}\text { Cheilanthes intramarginalis (Kaulf. ex Link) } \\
\text { Trevis. }\end{array}$ & Gastony and Rollo (1995) & U27449 & -- \\
\hline Cheilanthes lanosa (Michx.) D.C.Eaton & Gastony and Rollo (1995) & U27205 & -- \\
\hline Cheilanthes micropteris Sw. & Deginani $1363(\mathrm{MO})$ & EF452145 & -- \\
\hline Cheilanthes nitidula Hook. & Schneider s.n. (GOET) & EF452146 & EF452025 \\
\hline Cheilanthes viridis Sw. & Janssen $2701(\mathrm{P})$ & EF452147 & EF452026 \\
\hline Cheiloplecton rigidum (Sw.) Fee & Gastony and Rollo (1995) & U29133 & -- \\
\hline $\begin{array}{l}\text { Cheilosoria chusana (Hook.) Ching et K.H. } \\
\text { Shing }\end{array}$ & Gangmin Zhang 641 & DQ432650 & -- \\
\hline $\begin{array}{l}\text { Cheilosoria hancockii (Baker) Ching et K.H. } \\
\text { Shing }\end{array}$ & Gangmin Zhang 282 & DQ432649 & -- \\
\hline Cheilosoria patula (Baker) P.S.Wang & Gangmin Zhang 228 & DQ432663 & -- \\
\hline Coniogramme fraxinea (D.Don) Fee ex Diels & $\begin{array}{l}\text { Korall et al. (2006), Pryer } \\
\text { et al. (2004), Korall et al. } \\
(2006)\end{array}$ & AM177359 & AY612693 \\
\hline Coniogramme japonica (Thunb.) Diels & Hasebe et al. (1994) & U05611 & -- \\
\hline Cosentinia vellea (Aiton) Tod. & $\begin{array}{l}\text { Nakazato and Gastony } \\
\text { (2003) }\end{array}$ & AY168720 & -- \\
\hline
\end{tabular}




\begin{tabular}{|c|c|c|c|}
\hline Species Name & Voucher information & $\begin{array}{l}r b c L \\
\text { GenBank } \\
\text { Accession } \\
\end{array}$ & $\begin{array}{c}a t p B \\
\text { GenBank } \\
\text { Accession } \\
\end{array}$ \\
\hline $\begin{array}{l}\text { Cryptogramma brunoniana Wall. ex Hook. } \\
\text { et Grev. }\end{array}$ & Zhang et al. (2005) & AY266407 & -- \\
\hline Cryptogramma stelleri Prantl & Gangmin Zhang 306 & DQ432660 & -- \\
\hline Cryptogramma crispa (L.) R.Br. ex Hook. & Christenhusz 3871 (TUR) & EF452148 & EF452027 \\
\hline Cystopteris reevesiana Lellinger & Schuettpelz 419 (DUKE) & EF452149 & EF452028 \\
\hline Davallia solida (G.Forst.) Sw. & $\begin{array}{l}\text { Tsutsumi and Kato (2005), } \\
\text { Schuettpelz } 300 \text { (DUKE) }\end{array}$ & AB212712 & EF452029 \\
\hline $\begin{array}{l}\text { Dennstaedtia punctiolobula (Michx.) } \\
\text { T.Moore }\end{array}$ & $\begin{array}{l}\text { Wolf et al. (1994), Wolf, } \\
\text { 1997, Paris s.n. (UTC) }\end{array}$ & U05918 & U93836 \\
\hline Didymochlaena truncatula (Sw.) J.Sm. & $\begin{array}{l}\text { Smith and Cranfill (2002), } \\
\text { Schuettpelz } 267 \text { (DUKE) }\end{array}$ & AF425105 & EF452030 \\
\hline Dorypteris collina (Raddi) J.Sm. & $\begin{array}{l}\text { Prado and B.-Blubaugh } \\
1402\end{array}$ & EF472688 & -- \\
\hline $\begin{array}{l}\text { Doryopteris concolor (Langsd. et Fisch.) } \\
\text { Kuhn }\end{array}$ & Zhang et al. (2005) & AY266414 & -- \\
\hline Doryopteris decora Brack. & Gastony and Rollo (1995) & U27446 & -- \\
\hline Doryopteris lomariacea Klotzsch & Prado and Yano 1045 & EF473689 & -- \\
\hline Doryopteris ludens (Wall. ex. Hook.) J.Sm. & Schneider s.n. (GOET) & EF452150 & EF452031 \\
\hline Doryopteris nobilis (T.Moore) C.Chr. & Prado et al. 1119 & EF473690 & -- \\
\hline Doryopteris ornithopus (Hook. et Baker) & Prado and B.-Blubaugh & EF473691 & -- \\
\hline J.Sm. & 1399 & & \\
\hline Doryopteris paradoxa (Fee) Chirst. & Prado et al. 1131 & EF473692 & -- \\
\hline Doryopteris pedata $(\mathrm{L}$.$) Fee$ & Gastony and Rollo (1995) & U27206 & -- \\
\hline Doryopteris pentagona Pic. Serm. & Prado et al. 1100 & EF473693 & -- \\
\hline Doryopteris rediviva Fee & Prado et al. 1107 & EF473694 & -- \\
\hline Doryopteris sagittifolia (Raddi) J.Sm. & Schuettpelz 562 (GOET) & EF452151 & EF452032 \\
\hline Dryopteris aemula (Aiton) Kuntze & $\begin{array}{l}\text { Geiger and Ranker (2005), } \\
\text { Christenhusz } 3866 \text { (TUR) }\end{array}$ & AY268881 & EF452033 \\
\hline Eriosorus cheilanthoides (Sw.) A.F.Tyron & Moran $7579(\mathrm{NY})$ & EF452152 & EF452034 \\
\hline $\begin{array}{l}\text { Eriosorus flexuosus (Humb. et Bonpl.) } \\
\text { Copel. }\end{array}$ & $\begin{array}{l}\text { Nakazato and Gastony } \\
\text { (2003) }\end{array}$ & AY168709 & -- \\
\hline Eriosorus myriophyllus (Sw.) Copel. & Prado and Yano 1033 & EF473710 & -- \\
\hline $\begin{array}{l}\text { Haplopteris anguste-elongata (Hayata) } \\
\text { E.H.Crane }\end{array}$ & Crane et al. (1995) & U21291 & -- \\
\hline Haplotperis elongata (Sw.) E.H.Crane & Hueit 122 (UC) & EF452153 & EF452035 \\
\hline Haplopteris ensiformis (Sw.) E.H.Crane & Crane et al. (1995) & U21290 & -- \\
\hline Haplopteris flexuosa (Fee) E.H.Crane & Hasebe et al. (1994) & U05656 & -- \\
\hline Haplotperis zosterifolia (Willd.) E.H.Crane & Crane et al. (1995) & U21296 & -- \\
\hline Hecistopteris pumila (Spreng.) J.Sm. & 3976 (TUR) & U21286 & EF452036 \\
\hline Hemionitis levyi E.Fourn. & Gastony and Rollo (1995) & U27725 & -- \\
\hline Hemionitis palmata $\mathrm{L}$. & $\begin{array}{l}\text { Ranker and Geiger } \\
\text { (unpublished), Schuettpelz } \\
297 \text { (DUKE) }\end{array}$ & AY357708 & EF452037 \\
\hline Hemionitis rufa (L.) Sw. & $\begin{array}{l}\text { Ranker and Geiger } \\
\text { (unpublished) }\end{array}$ & AY357707 & -- \\
\hline Hemionitis tomentosa (Lam.) Raddi & $\begin{array}{l}\text { Ranker and Geiger } \\
\text { (unpublished) }\end{array}$ & AY357709 & -- \\
\hline
\end{tabular}




\begin{tabular}{|c|c|c|c|}
\hline Species Name & Voucher information & $\begin{array}{l}r b c L \\
\text { GenBank } \\
\text { Accession }\end{array}$ & $\begin{array}{c}\text { atpB } \\
\text { GenBank } \\
\text { Accession }\end{array}$ \\
\hline Jamesonia blepharum A.F.Tryon & Schuettpelz 269 (DUKE) & EF452154 & -- \\
\hline Jamesonia canescens Kunze & $\begin{array}{l}\text { Nakazato and Gastony } \\
\text { (2003) }\end{array}$ & AY168710 & -- \\
\hline Jamesonia osteniana (Dutra) Gastony & $\begin{array}{l}\text { Nakazato and Gastony } \\
\text { (2003) }\end{array}$ & AY168711 & -- \\
\hline Jamesonia verticalis Kunze & Moran 7593 (NY) & EF452155 & EF452038 \\
\hline $\begin{array}{l}\text { Leptolepidium dalhousiae (Hook.) K.H.Shing } \\
\text { \& S.K.Wu }\end{array}$ & Gangmin Zhang 328 & DQ432646 & -- \\
\hline Llavea cordifolia Lag. & $\begin{array}{l}\text { Gastony and Rollo (1995), } \\
\text { Schuettpelz } 377 \text { (DUKE) }\end{array}$ & U27726 & EF452039 \\
\hline Microlepia platyphylla (D.Don) J.Sm. & $\begin{array}{l}\text { Wolf (1995), Wolf (1997), } \\
\text { Wolf } 596 \text { (UTC) }\end{array}$ & U18642 & U93832 \\
\hline Monachosorum henryi Christ & $\begin{array}{l}\text { Wold et al. (1994), Pryer et } \\
\text { al. (2004), Korall et al. } \\
\text { (2006) }\end{array}$ & U05932 & AY612706 \\
\hline Monogramma sp. (dareicarpa) & Ranker 1778 (COLO) & EF452156 & -- \\
\hline Monogramma graminea (Poir.) Schkuhr & Janssen $2692(\mathrm{P})$ & EF452157 & EF4522040 \\
\hline Nephrolepis cordifolia (L.) C.Presl & $\begin{array}{l}\text { Wolf et al. (1994), Wolf } 309 \\
\text { (UTC) }\end{array}$ & U05933 & EF452041 \\
\hline Neurocallis praestantissima Bory ex Fee & Christenhusz 3997 (TUR) & EF452158 & EF452042 \\
\hline Notholaena aschenborniana Klotzsch & Schuettpelz 476 (DUKE) & EF452159 & EF452043 \\
\hline Notholaena delicatula Maxo et Weath. & Gastony and Rollo (1995) & U19500 & -- \\
\hline Notholaena fendleri Kunze & Gastony and Rollo (1995) & U27727 & -- \\
\hline Notholaena rosei Maxon & Gastony and Rollo (1995) & U27728 & -- \\
\hline Notholaena sulphurea (Cav.) J.Sm. & Gastony and Rollo (1995) & U28254 & -- \\
\hline Ochropteris pallens (Sw.) J.Sm. & Janssen $2677(\mathrm{P})$ & EF452160 & EF452044 \\
\hline Onychium contiguum Wall. ex C.Hope & Zhang et al. (2005) & AY266416 & -- \\
\hline Onychium japonicum (Thunb.) Kunze & $\begin{array}{l}\text { Hasebe et al. (1994), } \\
\text { Schneider s.n. (GOET) }\end{array}$ & U05641 & EF452045 \\
\hline Onychium lucidum (D.Don) Spreng. & $\begin{array}{l}\text { Gastony and Johnson } \\
\text { (2001) }\end{array}$ & AF360359 & -- \\
\hline Onychium plumosum Ching & Zhang et al. (2005) & AY266408 & -- \\
\hline Onychium tenuifrons Ching & Zhang et al. (2005) & AY266415 & -- \\
\hline $\begin{array}{l}\text { Paragymnopteris bipinnata (H.Christ) K.H. } \\
\text { Shing }\end{array}$ & Gangmin Zhang 292 & DQ432254 & -- \\
\hline $\begin{array}{l}\text { Paragymnopteris dalavayi (Baker) } \\
\text { K.H.Shing }\end{array}$ & Gangmin Zhang 268 & DQ432654 & -- \\
\hline Paragymnopteris marantae (L.) K.H.Shing & Yatskievych 02-35 (KUN) & EF452161 & EF452046 \\
\hline $\begin{array}{l}\text { Paragymnopteris sargentii (H.Christ) K.H. } \\
\text { Shing }\end{array}$ & Gangmin Zhang 341 & DQ432653 & -- \\
\hline $\begin{array}{l}\text { Paragymnopteris vestita (Wall. ex Presl) } \\
\text { K.H. Shing }\end{array}$ & Gangmin Zhang 640 & DQ432652 & -- \\
\hline Parahemionitis arifolia (Burm.f.) Panigrahi & $\begin{array}{l}\text { Ranker and Geiger } \\
\text { (unpublished) }\end{array}$ & AY357706 & -- \\
\hline Pellaea andromedifolia (Kaulf.) Fee & Gastony and Rollo (1995) & U19501 & -- \\
\hline Pellaea atropurpurea (L.) Link & Schuettpelz 312 (DUKE) & EF452162 & -- \\
\hline Pellaea boivinii Hook. & Gastony and Rollo (1995) & U29132 & -- \\
\hline
\end{tabular}




\begin{tabular}{|c|c|c|c|}
\hline Species Name & Voucher information & $\begin{array}{l}r b c L \\
\text { GenBank } \\
\text { Accession }\end{array}$ & $\begin{array}{c}a t p B \\
\text { GenBank } \\
\text { Accession }\end{array}$ \\
\hline Pellaea cordifolia (Sesse et Moc.) A.R.Sm. & Gastony and Rollo (1995) & U28253 & -- \\
\hline Pellaea cymbiformis J. Prado & $\begin{array}{l}\text { Prado and B.-Blubaugh } \\
1404\end{array}$ & EF473697 & -- \\
\hline Pellaea gleichenioides (Hook.) Christ & $\begin{array}{l}\text { Prado and B.-Blubaugh } \\
1398\end{array}$ & EF473698 & -- \\
\hline Pellaea intermedia Mett. ex Kuhn & Schuettpelz 481 (DUKE) & EF452163 & EF452047 \\
\hline $\begin{array}{l}\text { Pellaea paupercula (H.Christ) Hall et } \\
\text { Lellinger }\end{array}$ & Gangmin Zhang 260 & DQ432640 & -- \\
\hline Pellaea pinnata (Kaulf.) Prantl & $\begin{array}{l}\text { Prado and B.-Blubaugh } \\
1407\end{array}$ & EF473699 & -- \\
\hline Pellaea pringlei Davenp. & Gastony and Rollo (1995) & U28787 & -- \\
\hline Pellaea riedilii Baker & $\begin{array}{l}\text { Forza and Mello-Silva } \\
1515\end{array}$ & EF473703 & -- \\
\hline Pellaea rotundifolia (G.Forst.) Hook. & Gastony and Rollo (1995) & U28788 & -- \\
\hline Pellaea trichophylla (Baker) Ching & Gangmin Zhang 266 & DQ432639 & -- \\
\hline Pellaea truncata Goodd. & Schuettpelz 430 (DUKE) & EF452164 & EF452048 \\
\hline $\begin{array}{l}\text { Pentagramma triangularis (Kaulf.) Yatsk., } \\
\text { Windham et E.Wollenw. }\end{array}$ & Schuettpelz 445 (DUKE) & EF452165 & EF452049 \\
\hline Pityrogramma austroamericana Domin & Schuettpelz 301 (DUKE) & EF452166 & EF452050 \\
\hline Pityrogramma calomelanos (L.) Link & $\begin{array}{l}\text { Gastony and Johnson } \\
\text { (2001) }\end{array}$ & AF336103 & -- \\
\hline Pityrogramma jamesonii (Baker) Domin & Moran $7592(\mathrm{NY})$ & EF452167 & -- \\
\hline Pityrogramma trifoliata (L.) R.M.Tryon & $\begin{array}{l}\text { Gastony and Johnson } \\
\text { (2001) }\end{array}$ & AF336104 & -- \\
\hline Platyzoma microphyllum R.Br. & $\begin{array}{l}\text { Nakazato and Gastony } \\
\text { (2003), Kato } 303 \text { (TI) }\end{array}$ & AY168721 & EF452051 \\
\hline Polytaenium cajenense (Desv.) Benedict & $\begin{array}{l}\text { Crane et al. (1995), } \\
\text { Schuettpelz } 211 \text { (DUKE) }\end{array}$ & U20934 & EF452052 \\
\hline Polytaenium lanceolatum (L.) Benedict & Crane et al. (1995) & U21287 & -- \\
\hline Polytaenium lineatum (Sw.) J.Sm. & Crane et al. (1995) & U20935 & -- \\
\hline Pteridium esculentum (G.Forst.) Nakai & $\begin{array}{l}\text { Wolf et al. (1994), Wolf } \\
\text { (1997), Smith s.n. (UC) }\end{array}$ & U05940 & U93834 \\
\hline Pteris arborea $\mathrm{L}$. & Christenhusz 4050 (TUR) & EF452168 & EF452053 \\
\hline Pteris argyraea T.Moore & Schuettpelz 542 (GOET) & EF42169 & EF452054 \\
\hline Pteris brasiliensis Raddi & Prado et al. 1086 & EF473702 & -- \\
\hline Pteris cretica L. & Schuettpelz 597 (DUKE) & EF452170 & EF452055 \\
\hline Pteris decurrens C.Presl. & Prado and Yano 1082 & EF473703 & -- \\
\hline Pteris deflexa Link & Prado et al. 1089 & EF473704 & -- \\
\hline Pteris denticulata Sw. & Prado et al. 1084 & EF473705 & -- \\
\hline Pteris fauriei Hieron. & Hasebe et al. (1994) & U05647 & -- \\
\hline Pteris lechleri Mett. & Prado et al. 1093 & EF473706 & -- \\
\hline Pteris leptophylla Sw. & Boldrin et al. 160 & EF473707 & -- \\
\hline Pteris multifida Poir. & Schuettpelz 591 (GOET) & EF452171 & EF452056 \\
\hline Pteris propinqua J.Agardh & Schuettpelz 268 (GOET) & EF452172 & EF452057 \\
\hline Pteris quadriaurita Retz. & Schuettpelz 546 (GOET) & EF452173 & EF452058 \\
\hline Pteris splendens Kaulf. & Prado 1131a. & EF473708 & -- \\
\hline Pteris tremula R.Br. & Schuettpelz 620 (B) & EF452174 & EF452059 \\
\hline
\end{tabular}




\begin{tabular}{|c|c|c|c|}
\hline Species Name & Voucher information & $\begin{array}{l}r b c L \\
\text { GenBank } \\
\text { Accession }\end{array}$ & $\begin{array}{c}a t p B \\
\text { GenBank } \\
\text { Accession }\end{array}$ \\
\hline Pteris vittata $\mathrm{L}$. & $\begin{array}{l}\text { Wolf et al. (1994), } \\
\text { Schuettpelz } 249 \text { (DUKE) }\end{array}$ & U05941 & EF452060 \\
\hline Pterozonium brevifrons (A.C.Sm.) Lellinger & Schuettpelz 285 (DUKE) & EF452175 & EF452061 \\
\hline Radiovittaria gardneriana (Fee) E.H.Crane & $\begin{array}{l}\text { Crane et al. (1995), } \\
\text { Schuettpelz } 249 \text { (DUKE) }\end{array}$ & U21294 & EF452062 \\
\hline Radiovittaria minima (Baker) E.H.Crane & Crane et al. (1995) & U21288 & -- \\
\hline Radiovittaria remota (Fee) E.H.Crane & Crane et al. (1995) & U21289 & -- \\
\hline Radiovittaria stipitata (Kunze) E.H.Crane & Crane et al. (1995) & U21293 & -- \\
\hline Rheopteris cheesmaniae Alston & Croft $1749(\mathrm{~A}, \mathrm{~K})$ & EF452176 & EF452063 \\
\hline Sinopteris albofusca (Baker) Ching & Gastony and Rollo (1995) & U19498 & -- \\
\hline $\begin{array}{l}\text { Sinopteris grevilleoides (H.Christ) C. Chr. et } \\
\text { Ching }\end{array}$ & Gangmin Zhang 639 & DQ432648 & -- \\
\hline Taenitis blechnoides (Willd.) Sw. & Hasebe et al. (1994) & U05654 & -- \\
\hline Thelypteris palustris Schott & $\begin{array}{l}\text { Wolf et al. (1994), Pryer et } \\
\text { al. (2004), Wolf } 284 \text { (UTC) }\end{array}$ & U05947 & AY612713 \\
\hline Trachypteris pinnata (Hook.f.) C.Chr. & Gastony and Rollo (1995) & $\mathrm{U} 27450$ & -- \\
\hline Vittaria appalachiana Farrar et Mickel & Crane (1997) & U88961 & -- \\
\hline Vittaria dimorpha Mull. & Crane et al. (1995) & U21292 & -- \\
\hline Vittaria graminifolia Kaulf. & $\begin{array}{l}\text { Crane et al. (1995), } \\
\text { Schuettpelz } 227 \text { (DUKE) }\end{array}$ & $\mathrm{U} 21295$ & -- \\
\hline Vittaria isoetifolia Bory & Crane et al. (1995) & U20936 & -- \\
\hline Vittaria lineata (L.) Sm. & Crane et al. (1995) & U20937 & -- \\
\hline
\end{tabular}




\section{Chapter 3}

\section{Morphological intermediates cause taxonomic confusion in New Zealand Pellaea}

\subsection{Introduction}

The genus Pellaea, as defined by Tryon and Tryon (1982), comprises approximately 40 species. It is centered mainly in the United States, Mexico and South America, but it also extends through India and into the Pacific including Australia and New Zealand. Tryon and Tryon (1982) divided the genus into four sections: Pellaea (20 species in America and one in Africa), Ormopteris (five to seven species of South America, mostly in Brazil), Holcochlaena (about 10 species from Africa and three extending to India and Sri Lanka), and Platyloma (three species distributed in India, Sri Lanka, Tasmania, Australia, New Zealand, and New Caledonia. Pellaea sect. Platyloma has recently been expanded to include the new species $P$. calidirupium (Brownsey and Lovis 1990) and P. nana (Bostock et al. 1998). The 
phylogenetic position of Pellaea sect. Platyloma is nested within Pellaea sect. Pellaea, with an affinity to the Australian Paraceterach muelleri and Asian species of the genus Paragymnopteris, according to Kirkpatrick (2007).

The New Zealand representatives of Pellaea sect. Platyloma are Pellaea rotundifolia (Forst.) Hook., P. falcata (R. Br.) Fee and P. calidirupium Brownsey et Lovis, as recorded in Brownsey and Smith-Dodsworth (2000). Pellaea rotundifolia is endemic to New Zealand and is quite commonly found throughout the North and South Islands. The distribution of P. calidirupium is predominately on the South Island although it has also been found in areas around Wellington and Auckland on the North Island (Brownsey and Lovis 1990). The rarer P. falcata is thought to grow on off shore islands (e.g., Kermadec Islands, Three Kings Island) and coastal patches on the mainland north of Auckland, according to Brownsey and Smith-Dodsworth (2000). However, its distribution throughout New Zealand is uncertain (for distribution maps see Appendix A).

Both Pellaea calidirupium and P. falcata are found growing outside of New Zealand. In Australia, these species are mostly restricted to the east coast in Queensland, New South Wales and Victoria, and Tasmania. Pellaea falcata is also found in New Caledonia, Lord Howe Island and the Kermadec Islands; on the latter it is the only Pellaea species present (Sykes et al. 2000). The other members of section Platyloma growing outside of New Zealand include $P$. nana, and P. paradoxa. Both of these occur in Australia and the latter is also found on Lord Howe Island (Bostock et al. 1998). Interestingly, the species shared between New Zealand and Australia, New Zealand plants are tetraploid whereas Australian plants are diploid (Kokubugata et al. 2006). 
The genus Pellaea is characterized as terrestrial or rupestral ferns with scaly creeping rhizomes. Their fronds are pinnate, scaly and the veins are free. The sori are continuous along pinnae margins though often absent at apices. Brownsey and Smith-Dodsworth (2000) also note that this genus is distinct in New Zealand with pinnate fronds with unprotected sori on pinnae margins and that the three species are not clearly defined and require further investigation.

The three species in New Zealand are most often differentiated from one another by three main morphological characteristics: extent of marginal sori, nature of rachis scales, and pinnule length and shape. Pellaea rotundifolia typically has sori absent from the pinnae apices, spreading scales on the rachis, and round to oblong shaped pinnae, 8 to $20 \mathrm{~mm}$ in length. Pellaea falcata also has sori absent from the pinnae apices, spreading scales, but mostly oblong shaped pinnae 15 to $40 \mathrm{~mm}$ in length. Plants of P. calidirupium differ in having sori continuous around their margins and appressed scales, with round to oblong pinnae 8 to $40 \mathrm{~mm}$ in length (Brownsey and SmithDodsworth 2000).

Although P. calidirupium is usually easily distinguished by its appressed rachis scales, it is often difficult to distinguish $P$. rotundifolia from $P$. falcata particularly because of plants with intermediate morphologies. In New Zealand intermediate plants, which will hereafter be referred to as $P$. aff. falcata, have caused taxonomic confusion and led to the suspicion of P. falcata growing beyond its distribution as recognized in Brownsey and SmithDodsworth (2000). These $P$. aff. falcata plants more often identified as $P$. falcata than $P$. rotundifolia on herbarium specimens, have been reported from as far south as Geraldine on the South Island according to herbarium records held in CHR (e.g., CHR 510910; herbarium abbreviations follow Holmgren et 
al. 1990). Morphologically, they have pinnae ranging from 15 to $40 \mathrm{~mm}$ and their pinnules are mostly oblong rather than round. It is unknown whether these $P$. aff. falcata plants are more closely related to $P$. falcata, $P$. rotundifolia, or whether they are a new Pellaea species.

DNA sequence data from non-coding $\operatorname{trn} L-\operatorname{trn} F$ locus ( $\operatorname{trn} L$ intron, $\operatorname{trn} L 3^{\prime}$ exon, and trnL-trnF intergenic spacer), rps4 gene, and the rps4-trnS intergenic spacer (IGS) were obtained and analysed to determine the relationships between the New Zealand Pellaea species. A specific goal was to determine the relationships of $P$. aff. falcata to the other New Zealand Pellaea species. The trnL-trnF locus evolves quickly and is particularly useful for investigating interspecific variation (Perrie and Brownsey 2005b). The rps4 and the rps4trnS IGS are another widely used gene and spacer for phylogenetic studies (Sànches-Baracaldo 2004, Kirkpatrick 2007). Both of these regions had DNA sequence data available on GenBank for many species, for the basis of comparison and the use as outgroups. This coupled with their phylogenetic properties make them ideal markers for studying the New Zealand Pellaea.

Using morphology to classify cheilanthoid ferns has been misleading as shown by recent molecular based studies of these ferns (Gastony and Rollo 1995, Kirkpatrick 2007, Zhang et al. 2007). The cause of this morphological homoplasy has been attributed to convergent adaptation to xeric habitats (Copeland 1947, Tyron et al. 1990, Gastony and Rollo 1995). Though the members making up the New Zealand Pellaea are few, this explanation appears opposite to what is observed in New Zealand, where plants with a wide range of pinnule morphologies are found growing in the same population. 
Because clear species boundaries are lacking for the majority of the members of Pellaea sect. Platyloma, accurate identification of these species can be difficult. It has been suggested that problems identifying Pellaea members extends beyond New Zealand and it is a trans-Tasman problem with the genus (Peter de Lange, personal communication). Furthermore, it is clear that in New Zealand traditional taxonomic characters are inadequate for consistently discerning $P$. aff. falcata from either $P$. rotundifolia or $P$. falcata. Finding a character for consistent species identification in New Zealand and between the other members of Pellaea sect. Platyloma is desirable, as utilizing molecular data to positively confirm identifications is not always feasible.

The aim of this study is to determine the relationships of the New Zealand Pellaea species through the use of DNA sequence data. The following questions were addressed: 1) What are the relationships of the morphologically intermediate $P$. aff. falcata plants? 2) How does morphological variation correspond to the variation found with the molecular data? 3) What are the relationships of the New Zealand members to the overseas representative of Pellaea sect. Platyloma?

\subsection{Materials \& Methods}

\subsubsection{Sample collection}

This study examines 35 exemplars from the genus Pellaea in New Zealand. Twenty samples of Pellaea rotundifolia and five samples of P. calidirupium were collected from several wild populations from both the North and South Islands (Figure 3.1). Samples of P. rotundifolia were collected to encompass the diversity found in pinnule morphology. Five of these samples had a 


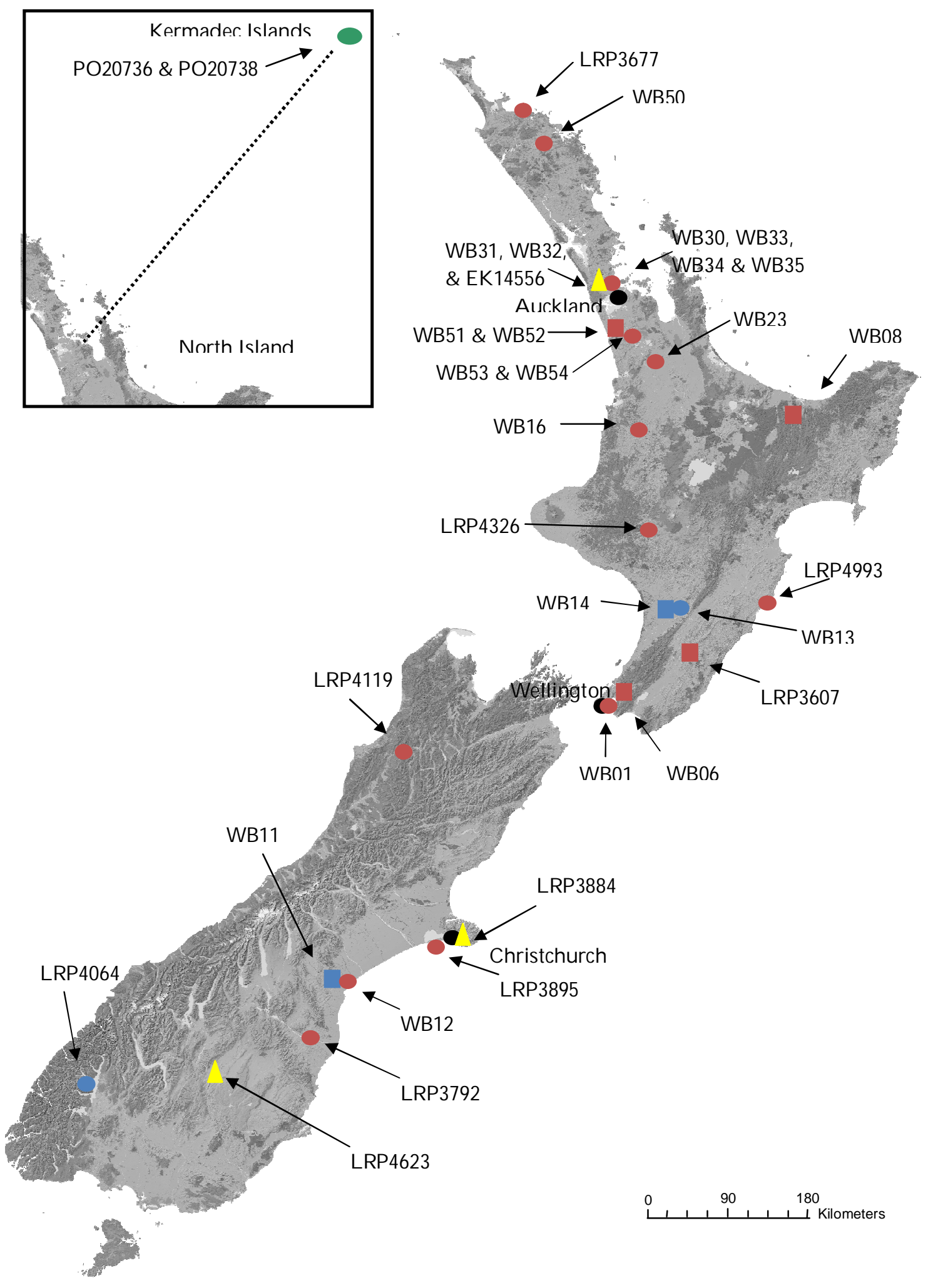

Figure 3.1. Distribution map of Pellaea samples collected for this study. Colors represent the haplotype: red $=1$, blue $=2$, yellow $=3$, and green $=4$. The shapes correspond to pinnule morphology: circle $=P$. rotundifolia, square $=P$. aff. falcata, triangle $=P$. calidirupium, and oval =P. falcata. Samples beginning with $\mathrm{P}$ are in the WELT herbarium. WB, LRP, and EK are collection numbers for Whitney Bouma, Leon Perrie, and Ewen Cameron respectively. 
Table 3.1. List of taxa collected for this study. Collection numbers, morphology, and haplotype are included as it corresponds to Figure 3.1. Collection number prefixes represent the collector's initials: WB- Whitney Bouma, LRP- Leon Perrie, and EK - Ewen Cameron, respectively.

\begin{tabular}{|c|c|c|c|}
\hline $\begin{array}{c}\text { Collection } \\
\text { No. }\end{array}$ & Species & haplotype & Collection Location \\
\hline WB14 & Pellaea aff. falcata & 2 & Kitchener Park, Fielding \\
\hline WB51 & Pellaea aff. falcata & 1 & Waiuku Forest \\
\hline WB52 & Pellaea aff. falcata & 1 & Waiuku Forest \\
\hline LRP3607 & Pellaea aff. falcata & 1 & Wairarapa \\
\hline WB06 & Pellaea aff. falcata & 1 & Trentham Park, Upper Hutt, Barton's Bush \\
\hline WB08 & Pellaea aff. falcata & 1 & Otari Wilton Bush, Karori Wellington \\
\hline WB12 & Pellaea aff. falcata & 1 & Talbot Forest Scenic Reserve, Geraldine \\
\hline WB31 & Pellaea calidirupium & 3 & Mt. Wellington, Auckland \\
\hline WB32 & Pellaea calidirupium & 3 & Mt. Wellington, Auckland \\
\hline LRP3884 & Pellaea calidirupium & 3 & Port Hills, Christchurch \\
\hline LRP4623 & Pellaea calidirupium & 3 & Alexandra \\
\hline EK14556 & Pellaea calidirupium & 3 & Mt. Wellington, Auckland \\
\hline P020736 & Pellaea falcata & 4 & Kermadec Islands \\
\hline P020738 & Pellaea falcata & 4 & Kermadec Islands \\
\hline WB55 & Pellaea falcata & 1 & Tasmania \\
\hline WB01 & Pellaea rotundifolia & 1 & Wellington \\
\hline WB11 & Pellaea rotundifolia & 2 & Talbot Forest Scenic Reserve, Geraldine \\
\hline WB13 & Pellaea rotundifolia & 2 & Kitchener Park, Fielding \\
\hline WB16 & Pellaea rotundifolia & 1 & Waitomo Walkway, Waitomo \\
\hline WB23 & Pellaea rotundifolia & 1 & Pukemokemoke, Hamilton \\
\hline WB30 & Pellaea rotundifolia & 1 & Mt. Wellington, Auckland \\
\hline WB33 & Pellaea rotundifolia & 1 & Mt. Wellington, Auckland \\
\hline WB34 & Pellaea rotundifolia & 1 & Mt. Wellington, Auckland \\
\hline WB35 & Pellaea rotundifolia & 1 & Mt. Wellington, Auckland \\
\hline WB50 & Pellaea rotundifolia & 1 & Kawiti Caves \\
\hline WB53 & Pellaea rotundifolia & 1 & Waiuku Forest \\
\hline WB54 & Pellaea rotundifolia & 1 & Waiuku Forest \\
\hline LRP4119 & Pellaea rotundifolia & 1 & Rotoroa \\
\hline LRP3972 & Pellaea rotundifolia & 1 & Kelceys Bush, Hunters \\
\hline LRP4064 & Pellaea rotundifolia & 2 & Livingstone \\
\hline LRP3895 & Pellaea rotundifolia & 1 & Banks Peninsula, Herbert \\
\hline LRP3677 & Pellaea rotundifolia & 1 & Whangaroa \\
\hline LRP4326 & Pellaea rotundifolia & 1 & Ohakune \\
\hline LRP4993 & Pellaea rotundifolia & 1 & Eastern Wairarapa, Pongaroa \\
\hline EK14557 & Pellaea rotundifolia & 1 & Mt. Wellington, Auckland \\
\hline
\end{tabular}

pinnule length longer than that typical for $P$. rotundifolia, while two other samples were within the range of typical $P$. rotundifolia but had strongly oblong pinnules. These seven samples were treated here as $P$. aff. falcata. Two samples of the rarer $P$. falcata were obtained from the Kermadec Islands, as collection efforts found no populations growing on mainland New 
Zealand. Positive identifications were made using Brownsey and SmithDodsworth (2000). Dried silica gel tissue of P. falcata from Tasmania was obtained for comparison with P. falcata from New Zealand.

\subsubsection{Morphology}

Morphological measurements were taken from all Pellaea samples collected for this study and an additional 53 Pellaea samples held in WELT Herbarium. The three longest pinnules, typically towards the middle of the lamina, were measured. Measurements consisted of pinnule length and pinnule width. Measurements were averaged and plotted to determine the extent to which separate taxonomic groups differed with respect to pinnule measurements.

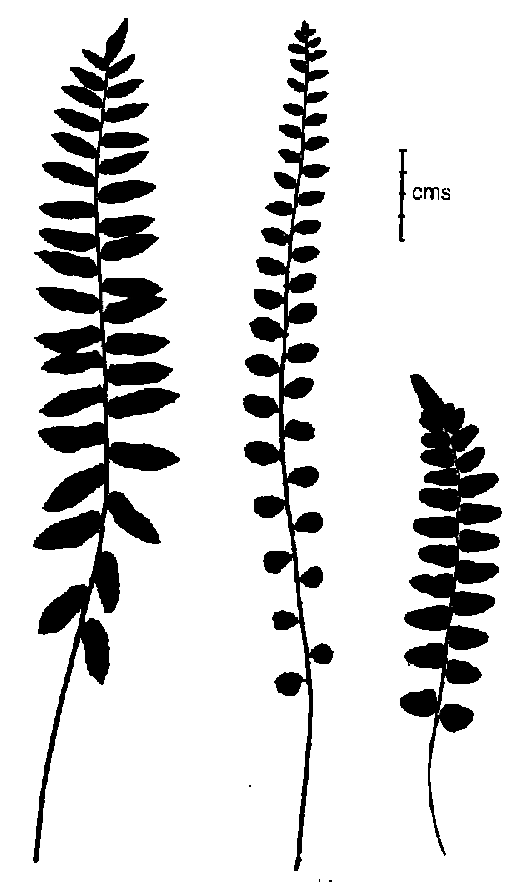

Figure 3.2. Fronds typical of $P$. falcata, P. rotundifolia, and $P$. calidirupium, respectively. silhouettes are by Patrick Brownsey as shown in Brownsey and Smith-Dodsworth (2000). 

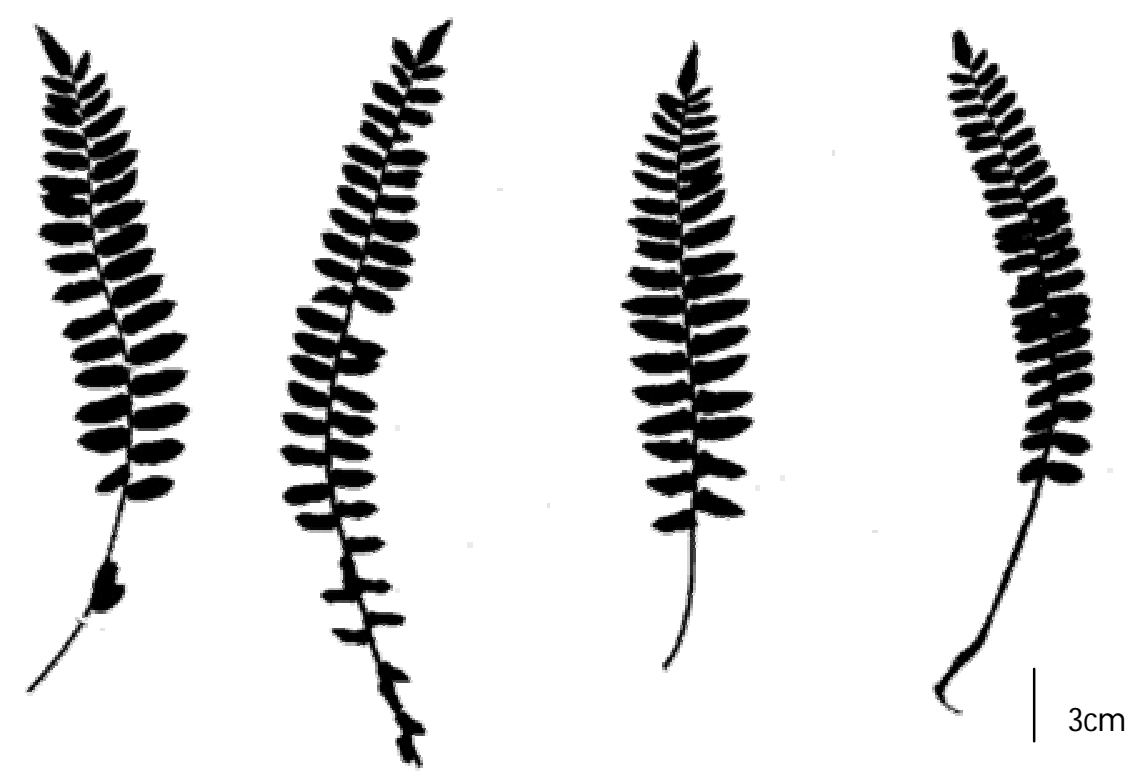

Figure 3.3. Frond silhouettes representing the variation in frond length and shape of those plant recognized as Pellaea aff. falcata.

Measurements were also taken of spore size from New Zealand and Australian Pellaea specimens for a preliminary comparison of spore size and ploidy level. The spores from two P. rotundifolia samples with typical rotundifolia-like pinnule morphology and one with $P$. aff. falcata morphology were measured. In addition, spores from two New Zealand and one Australian P. calidirupium, and one New Zealand and two Australian P. falcata were measured. The length and width of the exine of ten spores from each sample were measured under oil immersion in 50:50 glycerol: water (magnification $\times 1000)$.

\subsubsection{DNA isolation/PCR/sequencing}

Total DNA was extracted from silica dried tissue, or fresh when available, according to a modified CTAB protocol (Doyle \& Doyle, 1990).

The trnL-trnF locus was amplified with the primers, Fern1 (5'GGCAGCCCCCARATTCAGGGRAACC-3) and F ( 5'ATTTGAACTGGTGACACGAG-3') in $20 \mu \mathrm{l}$ total volume PCR mixtures 
(Taberlet et al. 1991, Trewick et al. 2002). PCR mixtures consisted of the following reagents: 1M betaine, 10X NH4 reaction buffer (BioLine), 1.5mM $\mathrm{MgCl}$ (BioLine), 250 $\mathrm{MM}$ dNTPs (BioLine), 10pmols of each forward and reverse primer, $1 \mathrm{U}$ of Taq DNA Polymerase (BioLine), and 50ng of DNA template. Thermocycler conditions consisted of an initial denaturing of $95^{\circ} \mathrm{C}$ for 2 minutes, 34 cycles of $95^{\circ} \mathrm{C}$ for 1 minute, $56^{\circ} \mathrm{C}$ for 1 minute, $72^{\circ} \mathrm{C}$ for 1 minute, and a final $72{ }^{\circ} \mathrm{C}$ extension for 5 minutes.

The rps4 gene and rps4-trnS IGS were amplified using the primers T1, (5'ATGTCMCGTTAYCGAGGRCCTCGT-3'), and F1, (5'TACCGAGGGTTCGAATC-3'), in $20 \mu \mathrm{l}$ total volume PCR mixtures (Nadot et al. 1994, Souza-Chies et al. 1997) . PCR mixtures consisted of the following reagents: $1 \mathrm{M}$ betaine, 10X NH4 reaction buffer (BioLine), $2.0 \mathrm{mM} \mathrm{MgCl}$ (BioLine), 250 $\mu \mathrm{M}$ dNTPs (BioLine), 10pmols of each forward and reverse primer, 1U of Taq DNA Polymerase (BioLine) taq, and 50ng of DNA template. PCR thermocycler conditions followed the protocol from Small et al. (2005), consisting of 30 cycles of $95^{\circ} \mathrm{C}$ for 1 minute, $50^{\circ} \mathrm{C}$ for 1 minute followed by a slow ramp $\left(1^{\circ} \mathrm{C} / 8 \mathrm{~s}\right)$ to $65^{\circ} \mathrm{C}$, and finally $65^{\circ} \mathrm{C}$ for 4 minutes (Small et al. 2005).

PCR products were visualized with agarose gel electrophoresis. Successfully amplified PCR products were purified with 0.2U of SAP (shrimp alkaline phosphatase, USB Corp., Cleveland, USA) and 1U EXO (exonuclease I, USB Corp., Cleveland, USA) to remove any residual reagents. Thermocycler conditions consisted of $37^{\circ} \mathrm{C}$ for 30 minutes and $80^{\circ} \mathrm{C}$ for 15 minutes. Cleaned products were sequenced at the Allan Wilson Center Genome Service with an ABI3730 Genetic Analyzer (Allan Wilson Centre Genome Service, Palmerston North, New Zealand). Newly obtained DNA sequences for the New Zealand Pellaea and the Tasmanian P. falcata will be submitted to GenBank (species 
and collection information are found in Table 3.1; newly generated DNA sequence data is in the $\mathrm{CD}$ appendix).

\subsubsection{DNA sequence alignments}

DNA sequence data was organized into four data sets for phylogenetic analyses. The chloroplast $t m L-t r n F$ locus was amplified and sequenced for each sample collected. The trnL-trnF locus data set contained the $35 \mathrm{New}$ Zealand Pellaea exemplars aligned with P. falcata from Tasmania. The most closely related cheilanthoid ferns to the New Zealand Pellaea, Paragymnopteris bipinnata and Paragymnopteris vestita, were chosen as outgroups, selected from topologies presented in Kirkpatrick (2007). These outgroups had both the $\operatorname{trnL-trnF}$ locus as well as the $r p s 4$ gene and rps4 IGS DNA sequences available for this study.

A second data set was created from the trnL-trnF IGS for which sequences of Australian P. falcata and P. nana, referred to as P. falcata var. nana in Kirkpatrick (2007), were available on GenBank. This alignment contained a representative for each of the four different haplotypes present in $\mathrm{New}$ Zealand Pellaea, combined with the Australian P. falcata and P. nana. This data set had a total of six ingroup sequences and the two Paragymnopteris outgroup sequences.

A third data set was constructed consisting of the DNA sequence data from the rps4 and rps4-trnS IGS. This data set included the same taxa used in the trnL-trnF IGS data set. This dataset again, had a total of six ingroup sequences and the two Paragymnopteris outgroup sequences. A partition homogeneity test using PAUP* version 4.b10 (Swofford 2002) was conducted to test for conflict between the three loci. A concatenated data set containing 
the trnL-trnF IGS, rps4 gene, and rps4-trnS IGS sequence data was also constructed including the same six taxa and two Paragymnopteris outgroups.

Newly generated DNA sequences for both trnL-trnF locus and rps4 gene and rps4-trnS IGS were edited by eye using BioEdit version 5.0.9 (Hall 1999).

Edited alignments were constructed using Clustal $X$ version 1.83 (Thompson et al. 1997). These alignments were imported into MEGA version 4.0 (Tamura et al. 2007) and combined with imported sequences from GenBank. Summary statistics on alignments were calculated using MEGA v 4.0 (Table 3.2).

\subsubsection{Phylogenetic analysis}

PAUP* version 4.b10 was used to implement maximum parsimony analyses on each of the four data sets. The relationships among the Pellaea trnL-trnF locus, the rps4 gene, and rps4-trnS IGS sequence data were inferred using an exhaustive search under a parsimony criterion. Gaps in the alignment were treated as missing data. For each of the four DNA sequence data sets, networks were constructed using the program TCS with statistical parsimony (Clement et al. 2000) and Splitstree 4.b4 with neighbor-net (Huson 1998); http://wwwab.informatik.unituebingen.de/software/jsplits/welcome_en.html. Settings in TCS consisted of treating gaps as missing.

\subsection{Results}

\subsubsection{Morphology}

Examples of the pinnule morphology of Pellaea in New Zealand are represented in Figure 3.2 and 3.3. Of the 82 Pellaea specimens measured, 
results showed that there is an overlap with respect to the pinnule morphology of the different taxa (Figure 3.4). Exemplars labeled P. falcata in the WELT herbarium along with P. falcata specimens from the Kermadec Islands had average pinnule length measurements ranging from $14 \mathrm{~mm}$ to $39 \mathrm{~mm}$. WELT herbarium records that were unidentified were considered exemplars of $P$. aff. falcata. These, along with $P$. aff. falcata collected for this study, had average pinnule measurement of $14 \mathrm{~mm}$ to $34 \mathrm{~mm}$. Specimens of $P$. rotundifolia had a range of $7 \mathrm{~mm}$ to $23 \mathrm{~mm}$.

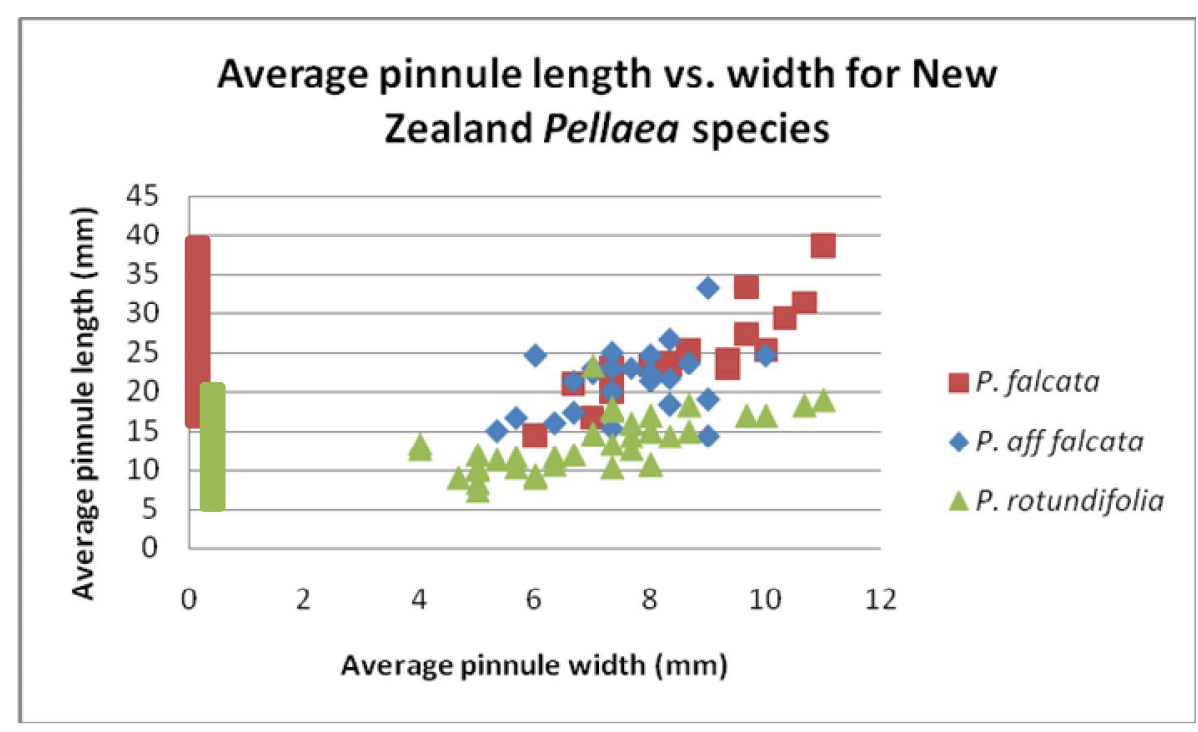

Figure 3.4. Graph representing pinnule measurements of length and width for New Zealand Pellaea. The red and green bars on the left represent the currently recognized range for pinnule length of $P$. falcata and $P$. rotundifolia.

The spore measurement of New Zealand and Australian Pellaea specimens showed that New Zealand spores were on average larger than Australian spores though some overlap exists when New Zealand P. rotundifolia is included. Figure 3.5 shows that although the spores of the New Zealand $P$. falcata sample were larger, there was just as much difference between the average measurements of the two Australian samples (length/width $=33.9$ $\mu \mathrm{m} / 30.2 \mu \mathrm{m}, 38.5 \mu \mathrm{m} / 34.9 \mu \mathrm{m})$ than between that of the spores of the New Zealand sample $(43.6 \mu \mathrm{m} / 40.9 \mu \mathrm{m})$. The measurements of spores from $P$. 
calidirupium consisted of only one Australian sample; however, its average size of spores $(31.2 \mu \mathrm{m} / 30.0 \mu \mathrm{m})$ was considerably smaller than the two New Zealand samples measured $(46.5 \mu \mathrm{m} / 42.3 \mu \mathrm{m}, 39.3 \mu \mathrm{m} / 36.5 \mu \mathrm{m})$.

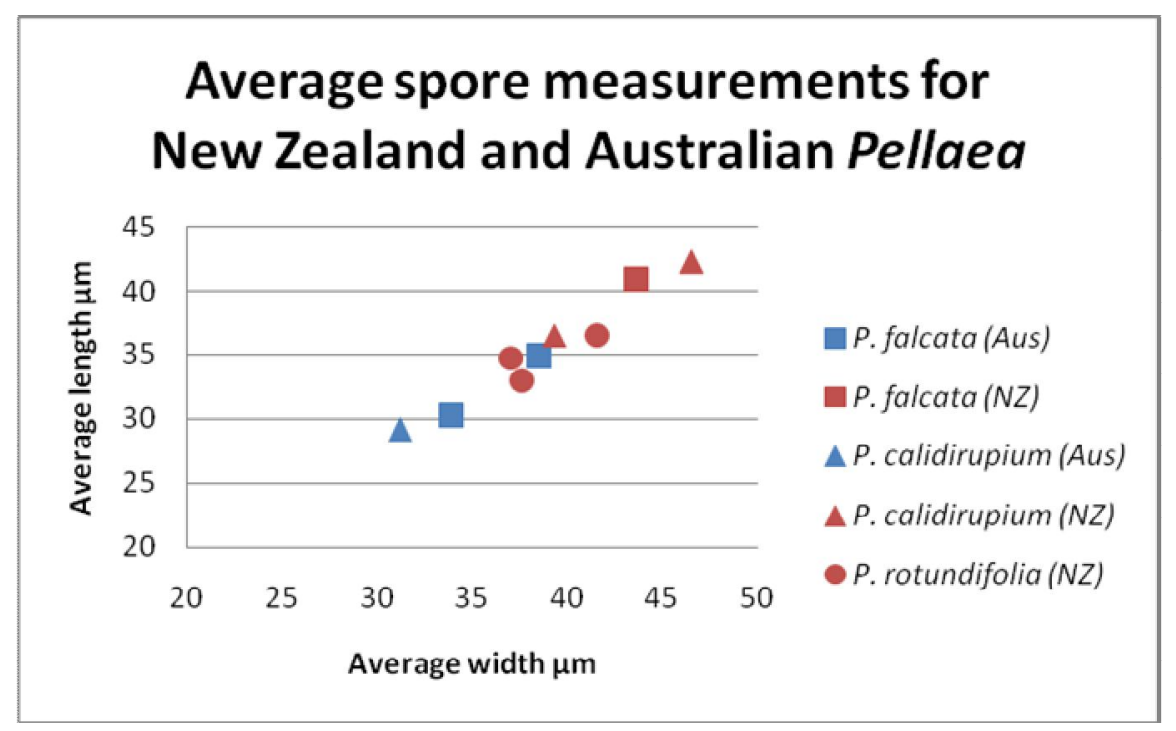

Figure 3.5. Graph of average spore length and width measurements for New Zealand Pellaea and their Australian counterparts.

\subsubsection{Alignments}

Summary statistics (Table 3.2) for the trnL-trnF locus produced an alignment length of 892 base pairs. The ingroup taxa exhibited nine variable sites of which all were also parsimony informative. The $\operatorname{trn} L-\operatorname{trnF}$ locus sequence data (tree not shown) showed one base pair transversion among all the representatives of $P$. rotundifolia signifying haplotype variation among this species (Figure 3.9). The P. falcata sample obtained from Tasmania was identical to the most common of the haplotypes of New Zealand $P$. rotundifolia. However, the samples of $P$. falcata from the Kermadec Island differed at six base pair positions to the rest of the alignment. The samples of P. calidirupium differed at four positions, sharing two derived characters with P. falcata from the Kermadec Islands. The morphologically intermediate 
samples labeled $P$. aff. falcata had identical haplotypes to those found in $P$. rotundifolia.

Table 3.2. Summary statistics for the four data sets analyzed in this study by maximum parsimony analysis.

\begin{tabular}{cccccc}
\hline Data set & $\begin{array}{c}\text { Alignment } \\
\text { Length } \\
(\mathbf{b p})\end{array}$ & $\begin{array}{c}\text { Variable } \\
\text { sites }\end{array}$ & $\begin{array}{c}\text { Parsimony } \\
\text { Informative } \\
\text { sites }\end{array}$ & $\begin{array}{c}\text { No. of } \\
\text { MP } \\
\text { trees }\end{array}$ & $\begin{array}{c}\text { MP } \\
\text { Tree } \\
\text { length }\end{array}$ \\
\hline trnL-trnF locus & 892 & 9 & 9 & NA & NA \\
trnL-trnF IGS & 350 & 9 & 2 & 5 & 43 \\
rps4+rps4 IGS & 989 & 13 & 5 & 2 & 98 \\
trnL-trnF+rps4 & 1339 & 22 & 7 & 10 & 142 \\
\hline
\end{tabular}

The trnL-trnF IGS data set alignment was 350 base pairs in length. The ingroup taxa had nine variable sites with two of them being parsimony informative. The network (Figure 3.6) produced similar relationships compared to the trnL-trnF locus despite the addition of Australian P. falcata and P. nana. However, conflict was detected in the alignment as Australian $P$. falcata shared one derived character, G at position 9, with the New Zealand $P$. calidirupium.

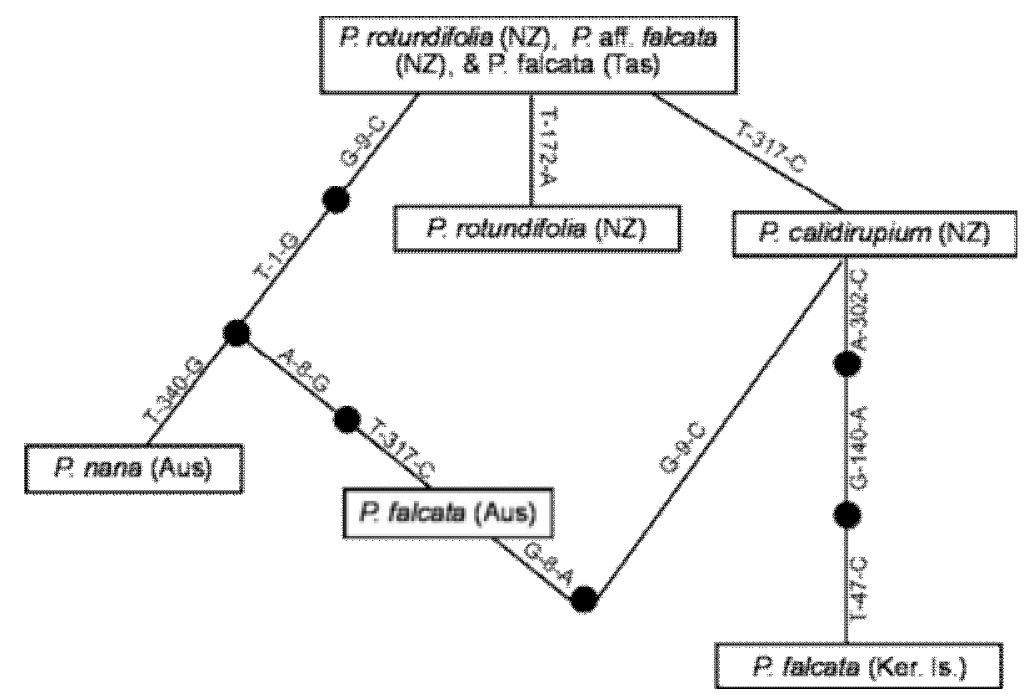

Figure 3.6. Neighbornet network representing the trnL-trnF IGS sequence data. Each substitution is labeled in its respective node. Note the conflict between Australian P. falcata and New Zealand P. calidirupium. 
The rps4 gene and rps4-trnS IGS alignment was 989 base pairs in length. The ingroup taxa contained 13 variable sites and five parsimony informative sites. Figure 3.7 represents the network obtained from TCS. It shows a base pair substitution distinguished haplotypes among the exemplars of P. rotundifolia. The relationships differed from the trnL-trnF IGS in that $P$. falcata from Australia has affinity to P. calidirupium from New Zealand as opposed to Australian P. nana.

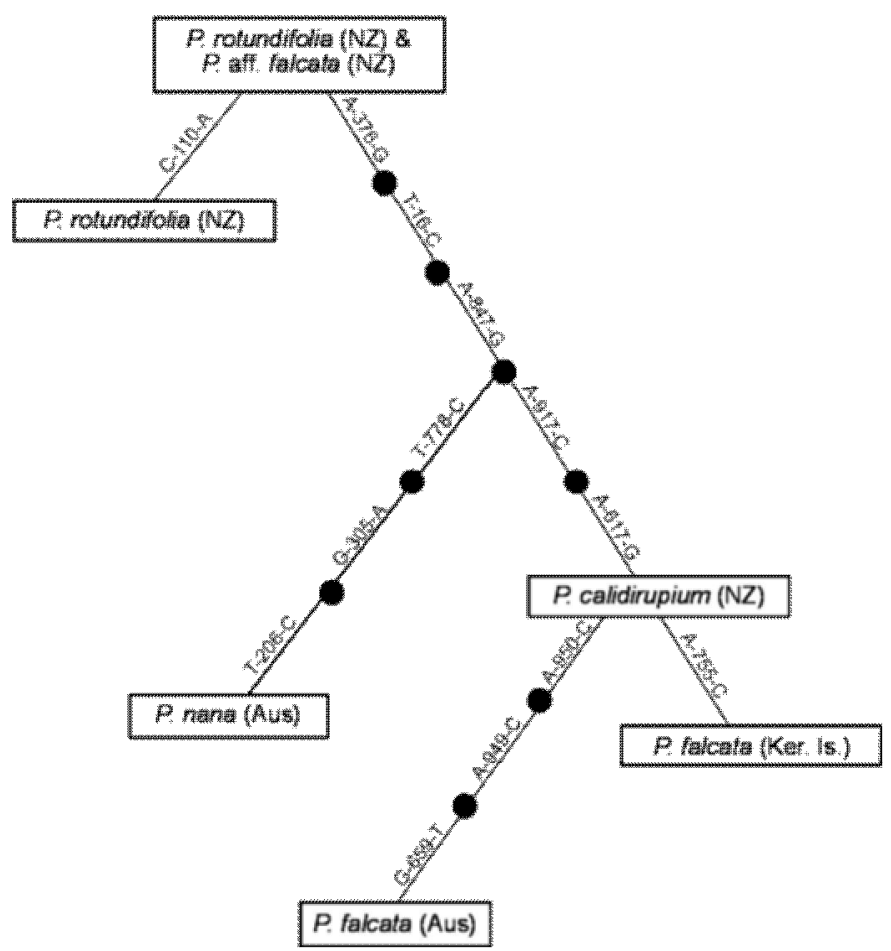

Figure 3.7. Neighbornet network representing the rps4 and rps4-trnS IGS sequence data. Each substitution is labeled in its respective node.

The results of the partition homogeneity test $(\mathrm{p}<0.36)$ allowed for a concatenated data set. The alignment was 1339 base pairs in length and the ingroup taxa contained 22 variable sites and seven parsimony informative sites. Figure 3.8 represents the TCS network for the concatenated data set. The relationships are congruent with that of the rps4 gene and rps4-trnS IGS 


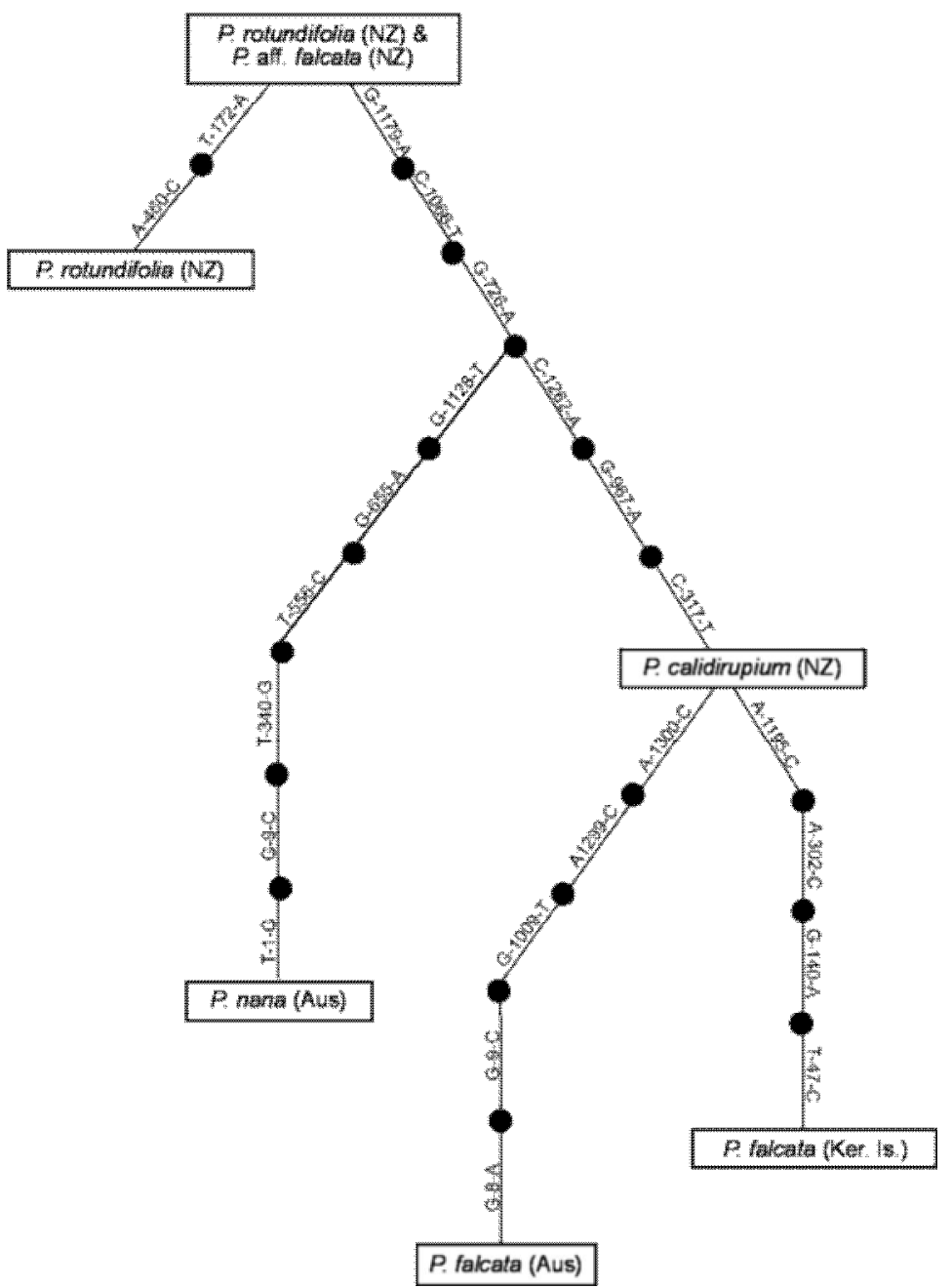

Figure 3.8. Neighbornet network representing the concatenated sequence data. Each substitution is labeled in its respective node.

network. Again, P. falcata from Australia has affinity to P. calidirupium from New Zealand as opposed to P. nana from Australia.

\subsubsection{Phylogenetic analyses}

Exhaustive parsimony searches on the trnL-trnF IGS data set produced five trees of 43 steps in length. The rps4 gene and rps4-trnS IGS data set recovered two trees 98 steps in length. The concatenated data set recovered ten trees, 142 steps in length. Similar relationships among the Pellaea haplotypes were inferred from maximum parsimony, statistical parsimony, and neighbor-net 
with each of the data sets. The relationships inferred from the different data sets were mostly in agreement. Differences were observed between the rps4 gene and rps4-trnS IGS to that of the trnL-trnF IGS where it was unclear if Australian P. falcata were more closely related to Australian P. nana or to New Zealand's $P$. calidirupium. However, these relationships were further resolved in the analyses of the concatenated data set, where Australian P. falcata was more closely related to New Zealand's P. calidirupium than to Australian P. nana (Figure 3.9).

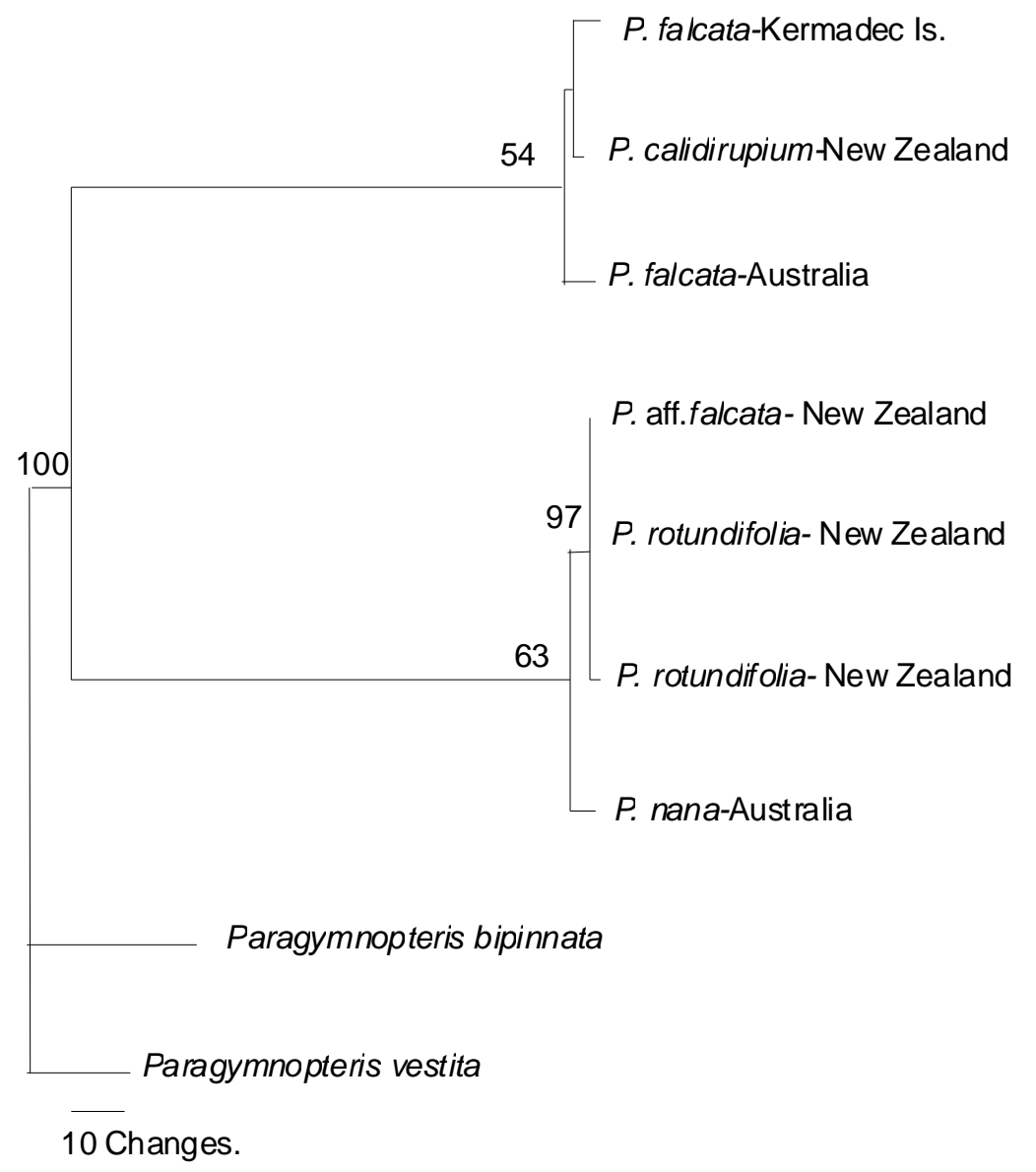

Figure 3.9. One of the two most parsimonious trees from maximum parsimony analyses of the concatenated data set. Bootstrap values are shown above the branches. 


\subsection{Discussion}

\subsubsection{Morphological vs. molecular data}

Plants of Pellaea rotundifolia and P. falcata exhibit a wide range of pinnule morphologies throughout New Zealand, where plants intermediate in morphology between $P$. rotundifolia and $P$. falcata occur with plants more typical of $P$. rotundifolia. Where this occurs, suspicion is raised that these intermediate plants constitute different species. The results from pinnule measurements confirm that specimens identified according to Brownsey and Smith-Dodsworth (2000) cannot be separated by pinnule length. However, chloroplast DNA sequence data of the trnL-trnF locus and rps4 gene and rps4trnS IGS suggest that these morphologically intermediate plants are molecularly identical to $P$. rotundifolia and distinct by 10 base pairs from $P$. falcata from the Kermadec Islands.

It is not uncommon for morphological characters to disagree with molecular data as has been the case in studies on cheilanthoid ferns (Gastony and Rollo 1995, Zhang et al. 2007) and also other New Zealand ferns. Studies of New Zealand Asplenium hookerianum also displayed pinnule morphology not concordant with variation in the trnL-trnF locus. This study found nine distinct haplotypes among the sampled specimens of Asplenium hookerianum, but no clear pattern grouping narrow or broad-pinnuled individuals with any of the haplotypes. Hence, recognizing two distinct species, one with narrow pinnules and the other with broad, was not justified (Perrie and Brownsey 2005a). The potential for morphological differences in pinnule length corresponding to the two haplotypes found among the plants of P. rotundifolia was investigated, but again, there was no pattern between the two characters. It is clear that pinnule morphology is insufficient for discriminating $P$. falcata 
and $P$. rotundifolia. The average pinnule length measurement of $P$. falcata from the Kermadec Islands (23mm) is shorter than P. falcata from Tasmania (35mm) and many of the $P$. aff. falcata specimens $(33 \mathrm{~mm})$ that were molecularly determined to be more closely related or identical to $P$. rotundifolia.

Further investigations into the haplotype variation present in Asplenium hookerianum found a total of 25 haplotypes throughout New Zealand. Those haplotypes corresponded to specific geographical regions (Shepherd et al. 2007). Although the sample set for this study includes $P$. rotundifolia samples from throughout the country, more thorough sampling is required to assess whether additional haplotypes exist among this species and whether the haplotypes are linked to geographic regions. Rather, it seems according to the results of the current study, $P$. rotundifolia is a polymorphic species with a diverse range of pinnule morphologies that do not necessarily signify separate evolutionary lineages.

An issue with the polymorphic $P$. rotundifolia arises when plants are misidentified as P. falcata. The New Zealand Department of Conservation currently has labeled $P$. falcata as chronically threatened and subject to gradual decline (de Lange et al. 2004). For species conservation it is important to find a reliable way to determine identities for these plants and to ensure that appropriate action is being taken for the correct species. The collection efforts for this study found no populations of P. falcata on the mainland. Therefore, the confirmation that the $P$. aff.falcata plants were more closely related or possibly identical to $P$. rotundifolia raises concern that $P$. falcata might be rarer than previously believed.

Results from trnL-trnF locus and rps4 gene and rps4-trnS IGS sequence data revealed that Pellaea falcata from Tasmania is molecularly identical to $P$. 
rotundifolia compounds the problem of circumscribing $P$. falcata. It also suggests that problems identifying $P$. falcata plants extend beyond New Zealand to other regions of the South Pacific where P. falcata is known to grow. Pellaea rotundifolia is believed to be endemic to New Zealand. The specimen from Tasmania with identical chloroplast sequences to $P$. rotundifolia suggests the latter may actually extend outside New Zealand. Whether or not this has been a recent introduction or a case of misidentifying $P$. rotundifolia in Tasmania, due to the variability of its pinnule morphology, remains unknown. Unfortunately, the extent of this issue could not be resolved in the current study as the problem has only become apparent. Clearly though, this section of Pellaea warrants further investigations.

\subsubsection{Pellaea falcata and Pellaea sect. Platyloma}

The networks from the trnL-trnF IGS data set recovered conflict in the data set over whether Australian P. falcata was more closely related to P. calidirupium or to Australian P. nana. However, maximum parsimony analyses and networks of the rps4 gene and rps4-trnS IGS and the concatenated data sets resolved the relationship supporting Australian P. falcata as more closely related to the New Zealand P. calidirupium than to P. nana from Australia. Furthermore, exhaustive parsimony searches support that P. falcata from the Kermadec Islands is more closely related to $P$. calidirupium from New Zealand than to P. falcata from Australia.

It might be expected that $P$. falcata from Australia would be more closely related to its New Zealand counterpart. However, P. falcata from the Kermadec islands differs from Australian $P$. falcata by nine base pairs, four of which uniquely characterize $P$. falcata from the Kermadec Islands. This suggests it may be a distinct species, although it remains unknown if it is 
restricted to the Kermadec Islands or if it occurs in other areas of the South Pacific. Extensive collecting and sequencing will be necessary to determine these relationships, but nonetheless these results compound the problem of circumscribing P. falcata.

Also investigated in this study were the relationships between the other members of Pellaea sect. Platyloma. Australian P. nana was previously considered a variety of $P$. falcata (Bostock et al. 1998). These results showed that $P$. nana is quite distinct from Australian P. falcata and confirmed that should it be treated as a distinct species. Indeed, relationships inferred from the concatenated data sets show that $P$. nana is actually more closely related to New Zealand P. rotundifolia than to the other members of Pellaea.

Not included in this study were Australian samples of $P$. calidirupium and $P$. paradoxa. It is uncertain whether the Australian P. calidirupium would group with New Zealand P. calidirupium according to DNA sequence data. It has been noted that $P$. calidirupium lacks continual sori around pinnule margins and that morphologically it appears intermediate between $P$. paradoxa and $P$.

falcata (Bostock et al. 1998). Pellaea paradoxa would be expected to group with representatives of $P$. calidirupium according to morphological descriptions. However, it has become quite clear that morphology is often not a reliable means of inferring relationships between the members of Pellaea sect. Platyloma.

\subsubsection{Future directions}

It had been mentioned before that the distinction between the members of the New Zealand Pellaea are not clearly defined and are in need of redefinition (Brownsey and Smith-Dodsworth 2000). With only three known species 
present in New Zealand, this task was deemed straightforward. With the results of DNA sequence data combined with preliminary morphological analyses, it is now clear that the problem is far greater than anticipated. Furthermore, the problem of recovering clear evolutionary lines between the members of Pellaea no doubt extends beyond those in New Zealand to include the entire Pellaea section Platyloma of the South Pacific. Several issues should be addressed in future studies of New Zealand Pellaea and also Pellaea sect. Platyloma in general.

The species Pellaea falcata appears to be ill-defined and its distribution is unclear not only in New Zealand but in the South Pacific. Additional sampling is required in areas that report having $P$. falcata to determine if they are in fact allied to P. falcata (the type locality is Sydney, Australia), "P. falcata" from the Kermadec Islands, $P$. rotundifolia (including morphologically intermediate $P$. aff. falcata plants), P. nana, or some additional taxon.

It should be determined if other molecular markers (chloroplast and additional genomes, e.g., mtDNA or rDNA) are in agreement with the trnLtrnF locus and rps4 gene and rps4-trnS IGS sequence data, in suggesting that $P$. aff. falcata plants with longer pinnules are the same species as $P$. rotundifolia. An intron of the nuclear LEAFY locus was sequenced to determine if data from the nuclear genome inferred the same relationships as the chloroplast genome. Unfortunately, the LEAFY intron offered no insights to the relationships as the sequences generated showed an immense amount of heterozygosity among the exemplars of New Zealand P. rotundifolia (unpublished data). The extent of the distribution of $P$. rotundifolia in the Pacific region (i.e. its endemism) should also be determined with sampling in locations where P. falcata grows or is said to grow, i.e., Tasmania, Australia, Lord Howe Island, New Caledonia, Kermadec Islands. 
To accurately infer the relationships among the members of Pellaea sect. Platyloma, Australian samples of P. calidirupium and P. paradoxa should be incorporated into further phylogenetic analyses. In addition to molecular analyses, morphological investigations should be conducted to determine if a viable character exist to aid in identifying members of Pellaea sect. Platyloma. In the current study, preliminary spore measurements were made to determine if they would be a helpful character in discerning the diploid Australian species of Pellaea from the tetraploid New Zealand species. The measurement averages suggest that New Zealand spores are larger than Australian spores, which is consistent with previous studies reporting that spore size corresponds to ploidy level where larger spores are indicative of a higher ploidy level (Barrington et al. 1986, Huang et al. 2006). Future investigations of spore size will require a larger sample set to determine if this difference is statistically significant and is thus an appropriate character that will help discern the relationships amongst the Australasian Pellaea.

In conclusion, preliminary results from morphological and chloroplast DNA sequence data suggest that the morphologically intermediate Pellaea aff. falcata is molecularly identical or very closely related to P. rotundifolia. P. aff. falcata appears to have a distribution that extends outside of New Zealand, questioning the endemic status of $P$. rotundifolia. Pellaea falcata, as a species, is ill-defined, both morphologically and with respect to its distribution, and is in need of extensive sampling and taxonomic revisions. The plants labeled $P$. falcata from the Kermadec Islands appear to be a distinct species of Pellaea, but again, further sampling in other areas of the South specific are required to confirm this. Taxonomic and phylogenetic issues with the cheilanthoid ferns apparently are not just an issue at generic levels, and clearly extend to groups comprising only a handful of species. Establishing sound species-level 
classifications is a necessary step for resolving the higher-level taxonomy of contentious fern groups such as Pellaea. 


\subsection{References}

Barrington, D. S., C. A. Paris, and T. A. Ranker. 1986. Systematic inferences from spore and stomate size in the ferns. American Fern Journal 76:149-159.

Bostock, P. D., T. C. Chambers, and P. A. Farrant. 1998. Adaintaceae. Flora of Australia. CSIRO Publishing, Collingwood.

Brownsey, P. J., and J. D. Lovis. 1990. Pellaea calidirupium -- a new fern species from New Zealand. New Zealand Journal of Botany 28:197-205.

Brownsey, P. J., and J. C. Smith-Dodsworth. 2000. New Zealand Ferns and Allied Plants. 2nd edition. David Bateman Ltd., Auckland, New Zealand.

Clement, M., D. Posada, and K. A. Crandall. 2000. TCS: a computer program to estimate gene genealogies. Molecular Ecology 9:1657-1659.

Copeland, E. B. 1947. Genera Filicum, Waltham, Mass.

de Lange, P. J., D. A. Norton, P. B. Heenan, S. P. Courtney, P. B. J. Molloy, C. C. Ogle, B. D. Rance, P. N. Johnson, and R. Hitchmough. 2004. Threatened and uncommon plants of New Zealand. New Zealand Journal of Botany 42:45-76.

Gastony, G. J., and D. R. Rollo. 1995. Phylogeny and Generic Circumscriptions of Cheilanthoid Ferns (Pteridaceae: Cheilanthoideae) Inferred from $r b c L$ Nucleotide Sequences. American Journal of Botany 85:341-360.

Hall, T. A. 1999. BioEdit: a user-friendly biological sequence alignment editor and analysis program for Windows $95 / 98$ NT. Nucleic Acids Symp. Ser. 41:95-98.

Holmgren, P. K., N. H. Holmgren, and L. C. Branett. 1990. Index herbariorum. Part 1, The herbaria of the world, ed. 8. Regnum Vegetabile 120:1-693.

Huang, Y. M., H. M. Chou, T. H. Hsieh, J. C. Wang, and W. L. Chiou. 2006. Cryptic characteristics distinguish diploid and triploid varieties of 
Pteris fauriei (Pteridaceae). Canadian Journal of Botany-Tevue Canadienne De Botanique 84:261-268.

Huson, D. H. 1998. SplitsTree: a program for analyzing and visualizing evolutionary data. . Bioinformatics 14:68-73.

Kirkpatrick, R. E. B. 2007. Investigating the monophyly of Pellaea (Pteridaceae) in the context of a phylogenetic analysis of Cheilantoid Ferns. Systematic Botany 32:504-518.

Kokubugata, G., P. D. Bostock, and P. I. Forster. 2006. Chromosome records for four species of Pellaea section Platyloma (J.Sm.) Hook. \& Baker (Adiantaceae) from Australia. Austrobaileya 7:341-345.

Nadot, S., R. Bajon, and L. B. 1994. The chloroplast gene rps4 as a tool for the study of Poaceae phylogeny. Plant Systematics and Evolution 191:2738.

Perrie, L. R., and P. J. Brownsey. 2005a. Genetic variation is not concordant with morphological variation in the fern Asplenium hookerianum sensu lato (Aspleniaceae). American Journal of Botany 92:1559-1564.

Perrie, L. R., and P. J. Brownsey. 2005b. Insights into the biogeography and polyploid evolution of New Zealand Asplenium from chloroplast DNA sequence data. American Journal of Botany 95:1-21.

Sànches-Baracaldo, P. 2004. Phylogenetics and biogeography of the neotropical fern genera Jamesonia and Eriosorus (Pteridaceae). American Journal of Botany 91:274-284.

Shepherd, L. D., L. R. Perrie, and P. J. Brownsey. 2007. Fire and ice: volcanic and glacial impacts on the phylogeography of the New Zealand forest fern Asplenium hookerianum. Molecular Ecology 16:4536-4549.

Small, R. L., E. B. Lickey, J. Shaw, and W. D. Hauk. 2005. Amplification of noncoding chloroplast DNA for phylogenetic studies in lycophytes and monilophytes with a comparative example of relative phylogenetic utiltity from Ophioglossaceae. Molecular Phylogenetics and Evolution 36:509-522. 
Souza-Chies, T. T., G. Bittar, S. Nadot, L. Carter, E. Besin, and B. Lejeune. 1997. Phylogenetic analysis of Iridaceae with parsimony and distance methods using the plastid gene rps4. Plant Systematics and Evolution 204:109-123.

Swofford, D. L. 2002. PAUP* Phylogenetic analysis using parsimony (* and other methods). Sinauer Associates, Sunderland.

Sykes, W. R., C. J. West, J. E. Beever, and A. J. Fife. 2000. Kermadec Island Flora - Special Edition. Manaaki Whenua Press, Lincoln, Canterbury.

Taberlet, P., L. Gielly, G. Pautou, and J. Bouvet. 1991. Universal primers for amplification of three non-coding regions of chloroplast DNA. Plant Molecular Biology 17:1105-1109.

Tamura, K., J. Dudley, M. Nei, and S. Kumar. 2007. MEGA4: Molecular Evolutionary Genetics Analysis (MEGA) software version 4.0. . Molecular Biology and Evolution 24:1596-1599.

Trewick, S. A., M. Morgan-Richards, S. J. Russell, S. Henderson, F. J. Rumsey, I. Pinter, J. A. Barrett, M. Gibby, and J. C. Vogel. 2002. Polyploidy, phylogeography and Pleistocene refugia of the rockfern Asplenium ceterach: evedence from chloroplast DNA. Molecular Ecology 11:20032012.

Tyron, R. M., A. F. Tyron, and K. U. Kramer. 1990. Pteridaceae. Pages 230-256 The Families and Genera of Vascular Plants Vol. 1. Pteridophytes and Gymnosperms. Springer-Verlag, Berlin.

Zhang, G., X. Zhang, Z. Chen, H. Liu, and W. Yang. 2007. First insights in the phylogeny of Asian cheilanthoid ferns based on sequences of two chloroplast markers. TAXON 56:369-378. 


\section{Chapter 4}

\section{A molecular phylogeny for New Zealand's Adiantum ferns from analyses of chloroplast DNA sequences and another look at the Adiantum hispidulum Swartz complex.}

\subsection{Introduction}

The genus Adiantum comprises over 200 species within the Pteridaceae family. It has a global distribution except in areas of extreme cold and dry climates (Tryon and Tryon 1982). This genus is characterized by tufted or creeping scaly rhizomes. The fronds are pinnate to 4-pinnate, also being glabrous or hairy. The sori are borne abaxially on strongly reflexed, usually kidney- 
shaped marginal lobes, called false indusia (Brownsey and Smith-Dodsworth 2000).

Adiantum has been recognized as an old and isolated genus with its evolutionary ties to the Pteridaceae based on soral characters and chromosome number (Tryon and Tryon 1982). Although this genus is one of the better understood within the family Pteridaceae, no comprehensive infrageneric classification has been generated for Adiantum. Previous studies on the genus have been focused on specific segregates (Parris and Croxall 1974, Parris 1980, Paris and Windham 1988, Large and Braggins 1993, Korpelainen et al. 2005). The last effort to classify Adiantum on a global scale was by Tryon and Tryon in 1982 where the genus was split into eight groups on the basis of morphological characters. The authors admitted that although the groups in their classification brought together related species, some species were doubtfully placed and the relationships of the groups to one another were uncertain (Tryon and Tryon 1982).

In New Zealand, seven native Adiantum species are recognized: $A$. aethiopicum L., A. diaphanum Blume, A. formosum R.Br., A. hispidulum Sw., A. cunninghamii Hook., A. fulvum Raoul, and A. viridescens Colenso. The latter three are endemic to New Zealand (Brownsey and Smith-Dodsworth 2000). Previously only A. cunninghamii and A. fulvum were recognized as endemic in New Zealand, but the discovery of an Adiantum intermediate between $A$. cunninghamii and A. fulvum, with respect to indumentum, was morphologically determined by Parris (1974) to be a distinct species, $A$. viridescens. The endemic status of A. cunninghamii was questioned because of a morphologically similar fern growing in Australia. Recently, the Australian counterpart was included under the name A. silvaticum (Bostock et al. 1998). 
However, it has been noted that it is strikingly similar to New Zealand's $A$. viridescens (Parris and Croxall 1974).

Most of the native species are distributed on both the North and South Islands. However, some species are rarer and are restricted to the North Island. Adiantum formosum is very common in Australia, but is the rarest of the New Zealand Adiantum, surviving only around the Manawatu Gorge. It has been recorded from Northland, but no longer occurs there (Brownsey and Smith-Dodsworth 2000). Two other Adiantum species, A. capillus-veneris (type species for Adiantum) and A. raddianum, have become naturalized in New Zealand and although they are included in this study, the focus is directed towards the native species.

Also restricted to the North Island in New Zealand is Adiantum hispidulum. This fern is found growing in coastal areas and is one of the few ferns to grow well in open sunny conditions (Brownsey and Smith-Dodsworth 2000). Outside of New Zealand, this fern grows in Africa, India, south-east Asia, Australia, and various Pacific Islands (Bostock et al. 1998). Adiantum hispidulum has been previously termed a polymorphic species with two morphs growing in New Zealand as part of the Adiantum hispidulum complex, consisting of Adiantum hispidulum sensu stricto and A. pubescens Schkuhr (Parris 1980, Large and Braggins 1993). These two taxa were considered distinct by the degree of indumentum and also frond formation.

A study by Parris in 1980 analyzed the two taxa morphologically. Based on her findings on differences in hair type and length and frond formation, she suggested recognizing two distinct species: A. hispidulum having short, stout, rigid hairs and fronds that were either 2-3 pinnate or pedate; and A. pubescens having longer, thin, sub-rigid hairs and fronds that were always pedate. 
Parris (1980) also stated that recognizing only a single polymorphic species would be a step backwards.

Large and Braggins (1993) carried out a much more extensive morphological analysis of Adiantum hispidulum and A. pubescens. Of all the morphological characters considered in the study, the only consistent character distinguishing the two ferns was hair length and type (Large and Braggins 1993). Another character, frond shape, had been previously utilized for separating the two taxa by Parris (1980). However, A. pubescens and A. hispidulum were found to be present in either pinnate or pedate form. This study characterized the two taxa by the following criteria: Adiantum hispidulum had short stiff hairs $63-815 \mu \mathrm{m}$ in length, with pigmented enlarged basal cells, and most often pinnate frond formation; whereas, A. pubescens had long lax hairs, $251-1003 \mu \mathrm{m}$ in length, with narrow basal cells, and most often pedate frond formation.

Large and Braggins (1993) concluded that there was a distinction between the two taxa in New Zealand. However, because it was based on only one character and there was a lack of information based on foreign material, $A$. pubescens should be considered a variety of A. hispidulum; A. hispidulum var. pubescens (Schukuhr) Large et Braggins. Yet, since the publication of both of these studies, neither A. pubescens or A. hispidulum var. pubescens have been widely adopted in New Zealand and still only A. hispidulum is recognized (Brownsey and Smith-Dodsworth 2000).

With the advent of molecular techniques it is possible to further investigate classifications previously based on morphological characters. The chloroplast trnL-trnF locus ( $\operatorname{trnL}$ intron, $t r n L$ 3'exon, and $\operatorname{trnL}$ - $\operatorname{trnF}$ intergenic spacer), rps4 gene and $r p s 4$-trnS intergenic spacer (IGS), $r b c L$ gene, and $a t p B$ gene were 
selected for investigations of the relationships among the members of the New Zealand Adiantum. For a detailed investigation of the A. hispidulum Swartz complex, the trnL-trnF locus was selected based on its phylogenetic properties. This region evolves relatively quickly and accumulates base pair substitutions and indels, making it an ideal locus for detecting variation at the interspecific and intraspecific taxonomic levels.

The aim of this study was to determine the relationships of the New Zealand Adiantum using DNA sequence data. The following questions were addressed: 1) What are the relationships between the New Zealand members of the genus Adiantum? 2) Does DNA sequence data show genetic variation between the representatives of the Adiantum hispidulum complex? 3) Does hair length and type correspond to molecular variation amongst the members of the A. hispidulum complex?

\subsection{Materials and Methods}

\subsubsection{Data collection}

This study examines 28 exemplars from the genus Adiantum as it is represented in New Zealand. Duplicate samples of each species were collected from several wild populations from both the North and South Islands (Figure 4.1) to confirm positive identification of the species. A total of 11 exemplars of the A. hispidulum complex were collected for the investigation of morphological and genetic variation. Positive identifications were made using Brownsey and Smith-Dodsworth (2000). 


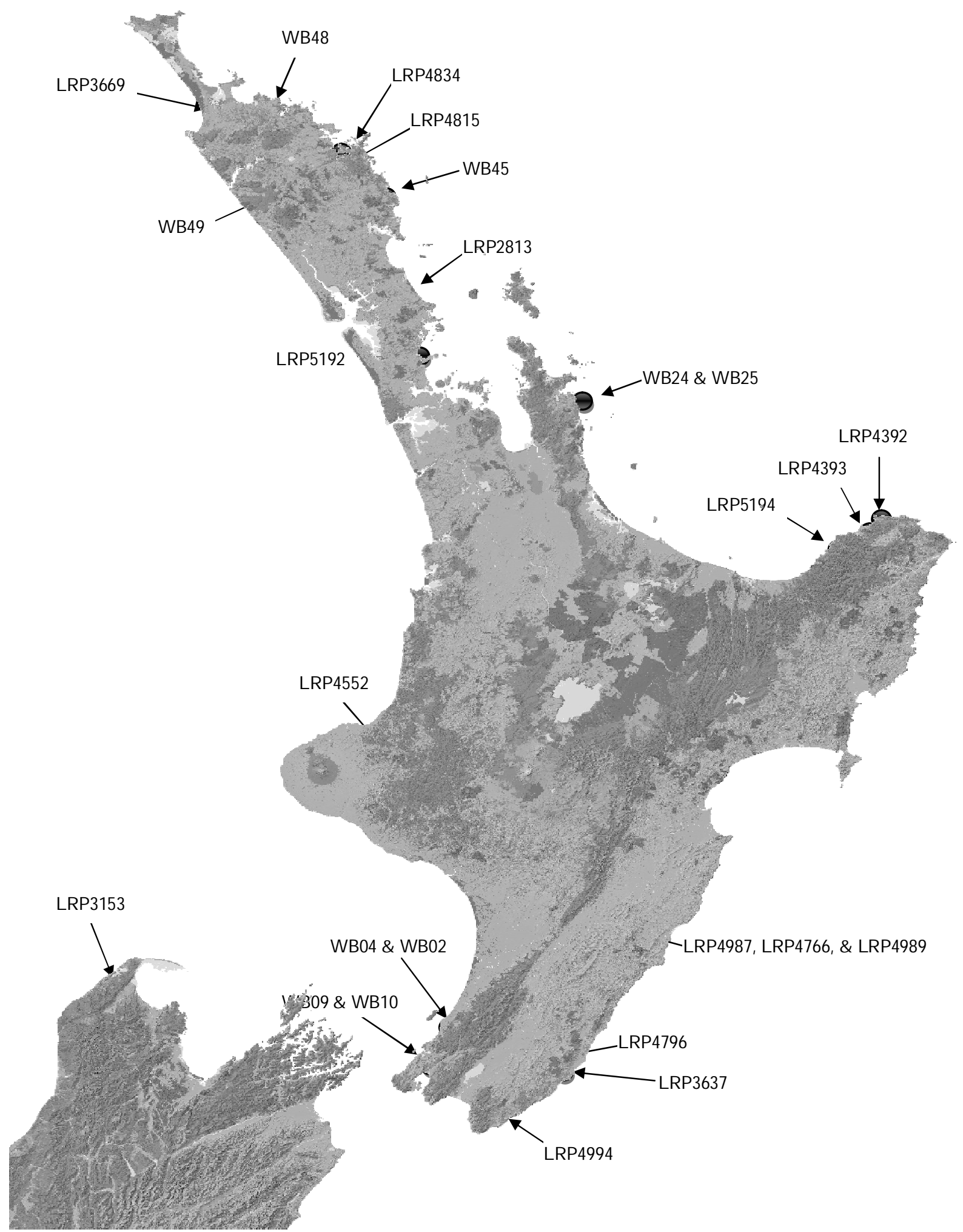

Figure 4.1. Distribution of the Adiantum species collected for this study. Not shown on this map is sample P020141, A. hipidulum (var. pubescens), which was collected from the Kermadec Islands which can be found in Figure 2.2 in this study. WB and LRP prefixes refer to collection numbers for Whitney Bouma and Leon Perrie, respectively. 


\subsubsection{Morphology}

Using the morphological descriptions from Large and Braggins (1993), regarding length and rigidity of hairs between $A$. hispidulum and $A$.

(hispidulum var.) pubescens, all A. hispidulum samples collected for this study as well as the A. hispidulum specimens held in the WELT Herbarium were visually examined and categorized as having hispidulum-like or pubescens-like hairs.

\subsubsection{DNA isolation/PCR/sequencing}

Total DNA was extracted from silica gel dried or fresh when available, tissue, according to a modified CTAB protocol (Doyle \& Doyle, 1990).

The trnL-trnF locus was amplified with the Fern 1 (5'-

GGCAGCCCCCARATTCAGGGRAACC-3') and F (5'ATTTGAACTGGTGACACGAG-3') primers in 20 $\mu$ l total volume reactions (Taberlet et al. 1991, Trewick et al. 2002). PCR mixtures consisted of the following reagents: $1 \mathrm{M}$ betaine, $10 \mathrm{X} \mathrm{NH} 4$ reaction buffer $\left(160 \mathrm{mM}\left(\mathrm{NH}_{4}\right)_{2} \mathrm{SO}_{4}\right.$, $670 \mathrm{mM}$ Tris-HCI ( $\mathrm{pH} 8.8$ at $25^{\circ} \mathrm{C}$ ), $0.1 \%$ Tween-20, BioLine), $1.5 \mathrm{mM} \mathrm{MgCl} 2$ (BioLine), 250 $\mu \mathrm{M}$ dNTPs (BioLine), 10pmols of each forward and reverse primer, 1U of Taq DNA Polymerase (BioLine), and approximately 50ng of DNA template. Thermocycler conditions consisted of an initial denaturing of $95^{\circ} \mathrm{C}$ for 2 minutes, $34^{\circ} \mathrm{C}$ cycles of $95^{\circ} \mathrm{C}$ for 1 minute, $56^{\circ} \mathrm{C}$ for 1 minute, $72^{\circ} \mathrm{C}$ for 1 minute, and a final $72^{\circ} \mathrm{C}$ for 5 minutes.

The rps4 gene and rps4-trnS intergenic spacer were amplified using the following primers: T1 (5'-ATGTCMCGTTAYCGAGGRCCTCGT-3') and F1 (5'-TACCGAGGGTTCGAATC-3') primers, in 20 $\mu$ l total volume mixtures (Taberlet et al. 1991). PCR mixtures consisted of the following reagents: 1M 
betaine, 10X NH4 reaction buffer (BioLine), 2.0mM MgCl 2 (BioLine), 250 $\mu \mathrm{M}$

dNTPs (BioLine), 10pmols of each forward and reverse primer, 1U of Taq DNA Polymerase (BioLine), and approximately 50ng of DNA template. PCR thermocycler conditions were selected according to Small et al, (2005) of 30 cycles of $95^{\circ} \mathrm{C}$ for 1 minute, $50^{\circ} \mathrm{C}$ for 1 minute followed by a slow ramp $\left(1^{\circ} \mathrm{C} / 8\right.$ s) to $65^{\circ} \mathrm{C}$, and finally $65^{\circ} \mathrm{C}$ for 4 minutes.

Primers 1F (5'-ATGTCACCACAAACGGAGACTAAAGC-3') and 1361R (5'TCAGGACTCCACTTACTAGCTTCACG-3') were used for amplifying the rbcL chloroplast gene (Nadot et al. 1994, Souza-Chies et al. 1997). PCR amplifications, in a total volume of $20 \mu \mathrm{l}$, were made with the following reagents: $1 \mathrm{M}$ betaine, $10 \mathrm{X} \mathrm{NH}_{4}$ reaction buffer (BioLine), $1.5 \mathrm{mM} \mathrm{MgCl}_{2}$ (BioLine), 250 $\mu \mathrm{M}$ dNTPs (BioLine), 10pmols of each forward and reverse primer, $1 \mathrm{U}$ of Taq DNA Polymerase (BioLine), and approximately 50ng of DNA template. Thermocycler conditions consisted of an initial denaturing of $95^{\circ} \mathrm{C}$ for 2 minutes, 34 cycles of $95^{\circ} \mathrm{C}$ for 1 minute, $50^{\circ} \mathrm{C}$ for 1 minute, $72^{\circ} \mathrm{C}$ for 1 minute, and a final $72^{\circ} \mathrm{C}$ for 5 minutes. The $a t p B$ gene was amplified using the primers 672F (5'-TTGATACGGGAGCYCCTCTWAGTGT-3') and 384R (5'GAATCCCAAACTATTCGATTAGG-3') PCR amplification mix and thermocycler settings were the same as for $r b c L$ (Schuettpelz and Pryer 2007).

PCR products were visualized by agarose gel electrophoresis. Successfully amplified PCR products were purified with $0.2 \mathrm{U}$ of SAP (shrimp alkaline phosphatase, SAP, USB Corp., Cleveland, USA) and 1 U EXO (exonuclease I, Exo I, USB Corp., Cleveland, USA) to remove any residual reagents. Thermocycler conditions consisted of $37^{\circ} \mathrm{C}$ for 30 minutes followed by inactivation of enzymes at $80^{\circ} \mathrm{C}$ for 15 minutes. Cleaned products were sequenced at the Allan Wilson Centre Genome Service with an ABI3730 Genetic Analyzers (Allan Wilson Centre Genome Service, Palmerston North, 
New Zealand). Newly obtained DNA sequences for the New Zealand Adiantum will be submitted to GenBank (species collection information is available in Table 4.1 and DNA sequence detail are in the CD appendix).

Table 4.1. List of Adiantum taxa collected for this study including collection location. Duplicate samples were collected for each of the native species for trnL-trnF locus DNA sequencing. The native Adiantum indicated with an * have trnL-trnF locus, rps4 and rps4trnS IGS, atpB, and rbcL DNA sequence data available in the CD appendix. Collections beginning with $P$ are held in the WELT herbarium. WB and LRP prefixes are collection numbers for Whitney Bouma and Leon Perrie respectively.

\begin{tabular}{|c|c|c|}
\hline $\begin{array}{l}\text { Collection } \\
\text { No. }\end{array}$ & Species & Collection Location \\
\hline LRP3637* & Adiantum aethiopicum & $\begin{array}{l}\text { Pahaoa Valley, } \\
\text { Wairarapa }\end{array}$ \\
\hline LRP2813 & Adiantum aethiopicum & Logues Bush, Wellsford \\
\hline WB10 & Adiantum capillus-veneris & Hataitai, Wellington \\
\hline LRP4815* & Adiantum cunninghamii & Opua, Bay of Islands \\
\hline LRP3153 & Adiantum cunninghamii & $\begin{array}{l}\text { Golden Bay, North-West } \\
\text { Nelson }\end{array}$ \\
\hline LRP4989 & Adiantum diaphanum & Woodville \\
\hline LRP4392* & Adiantum diaphanum & $\begin{array}{l}\text { Whanarua Bay, } \\
\text { Northland }\end{array}$ \\
\hline LRP4766 & Adiantum formosum & Manawatu Gorge \\
\hline LRP4987* & Adiantum formosum & Woodville, Wairarapa \\
\hline LRP3669 & Adiantum fulvum & Whangaroa \\
\hline WB02* & Adiantum fulvum & Plimmerton, Wellington \\
\hline WB24 & Adiantum hispidulum & $\begin{array}{l}\text { Cathedral Cove, } \\
\text { Coromandel }\end{array}$ \\
\hline WB25 & Adiantum hispidulum & $\begin{array}{l}\text { Cathedral Cove, } \\
\text { Coromandel }\end{array}$ \\
\hline WB45 & Adiantum hispidulum & Whale Bay, Northland \\
\hline WB48 & Adiantum hispidulum & Whangaroa, Northland \\
\hline WB49 & Adiantum hispidulum & Kawakawa, Northland \\
\hline LRP4393 & Adiantum hispidulum & Te Kaha, East Cape \\
\hline LRP4834 & $\begin{array}{l}\text { Adiantum hispidulum sens. } \\
\text { lat. }\end{array}$ & Opua, Bay of Islands \\
\hline LRP4994* & $\begin{array}{l}\text { Adiantum hispidulum sens. } \\
\text { lat. }\end{array}$ & $\begin{array}{l}\text { Aorangi Range, } \\
\text { Wairarapa }\end{array}$ \\
\hline P020741 & $\begin{array}{l}\text { Adiantum hispidulum sens. } \\
\text { lat. }\end{array}$ & Kermadec Islands \\
\hline
\end{tabular}




\begin{tabular}{lll}
\hline LRP5195 & $\begin{array}{l}\text { Adiantum hispidulum sens. } \\
\text { lat. }\end{array}$ & Hawai, Bay of Plenty \\
LRP5192 & $\begin{array}{l}\text { Adiantum hispidulum sens. } \\
\text { lat. }\end{array}$ & Waiwera, Auckland \\
LRP4796 & $\begin{array}{l}\text { Adiantum raddianum } \\
\text { WB09 }\end{array}$ & Adiantum raddianum \\
LRP4552 & Adiantum viridescens & Hataitai, Wellington \\
WB04 & Adiantum viridescens & Eltham, Wanganui \\
\hline
\end{tabular}

\subsubsection{Alignments}

The sequence data for each of the four data sets were edited by eye using BioEdit version 5.0.9 (Hall 1999) and aligned in ClustalX version 1.83

(Thompson et al. 1997). For the non-coding regions in the trnL-trnF locus and rps4-trnS IGS, manual adjustments to the alignment were made to minimize insertions and deletions. Regions that could not be unambiguously aligned were excluded, and indels were treated as missing data. A partition homogeneity test was run on PAUP* version 4.b10 (Swofford 2002) to test for conflict between the four data sets. The alignments were then imported into MEGA version 4.0 (Tamura et al. 2007) and combined to form a concatenated data set. Adiantum capillus-veneris was originally selected as the outgroup. However, broader sampling of the Pteridaceae (Chapter 2 ) indicated $A$. formosum was the most distantly related of the native New Zealand Adiantum and therefore, it was chosen as the outgroup instead. The final alignment contained eight taxa, representing the species of Adiantum native in New Zealand and also the adventive $A$. raddianum

For the exemplars of the Adiantum hispidulum complex, sequences from the trnL-trnF locus were combined in a data set with sequence data from Adiantum raddianum, which was selected as an outgroup again based on results from the analysis above. These sequences were again edited by eye using BioEdit version 5.0.9 and aligned using ClustalX version 1.83. The 
alignments were imported into MEGA version 4.0 and manual adjustments were made to minimize insertions and deletions.

\subsubsection{Phylogenetic analysis}

Phylogenetic analyses under the maximum parsimony and maximum likelihood criteria were conducted using PAUP version 4.0b10 (Swofford 2002). Exhaustive parsimony searches were conducted on each of the individual data sets (trnL-trnF locus, rps4 gene and rps4-trnS IGS, rbcL, and $a t p B)$ to identify any incongruence between them. Heuristic searches under parsimony criteria were performed with 100 random addition sequence replicates and TBR branch swapping. Bootstrap values were assessed using 200 pseudoreplicates, each with 100 random sequence addition replicates.

Maximum likelihood analyses were implemented using the appropriate model of evolution as assessed by ModelTest version 3.6 (Posada and Buckley 2004) according to the Akaike Information criteria. Maximum likelihood settings ran for 100 replicates of random sequence addition. Bootstrapping was again performed to assess the confidence with settings consisting of 100 pseudoreplicates, one random sequence addition, and TBR branch swapping.

MrBayes 3.1.2 (Huelsenbeck and Ronquist 2001) was used to carry out Bayesian analyses (nst $=6$, rates=invgamma, and default priors) on all four of the data sets in this study. Analyses were run for 5,000,000 generations, with sampling from every $1000^{\text {th }}$ generation, and the initial $50 \%$ discarded as burnin. Standard deviations of split frequencies were checked at 2,500,000 generations to ensure a value of $\varangle 0.01$ (suggesting a convergence to stationary distribution had been achieved). 
Splitstrees 4.b4 (Huson 1998);

http://wwwab.informatik.unituebingen.de/software/jsplits/welcome_en.html, was used to construct a neighbornet network in order to visualize the haplotype variation in the A. hispidulum Swartz complex.

\subsection{Results}

\subsubsection{Morphology}

Three distinct hair types were found amongst the samples of Adiantum hispidulum. The most common hair type was referred to as hispidulum-like or type 1, with sparse, short stiff hairs and having pigmented, enlarged basal cells. Another hair type is what would be considered pubescens-like, or type 2, with dense long lax hairs and narrow basal cells. The third hair type, type 3, was more like $A$. hispidulum, but with the hairs being more abundant, much shorter and more like a spike (Figure 4.3).

\subsubsection{Alignment}

Alignment statistics for the individual data sets can be found in Table 4.2. The results of the partition homogeneity test $(p=0.52)$ allowed a concatenated data set. The concatenated alignment was 4013 base pairs in length. The alignment including the outgroup contained 543 variable sites, 158 of them being parsimony informative. Seven distinct haplotypes were recovered in the alignment corresponding to each of the species included in the alignment with the exception of the species $A$. viridescens and A. fulvum, which were identical at all sequenced loci. 


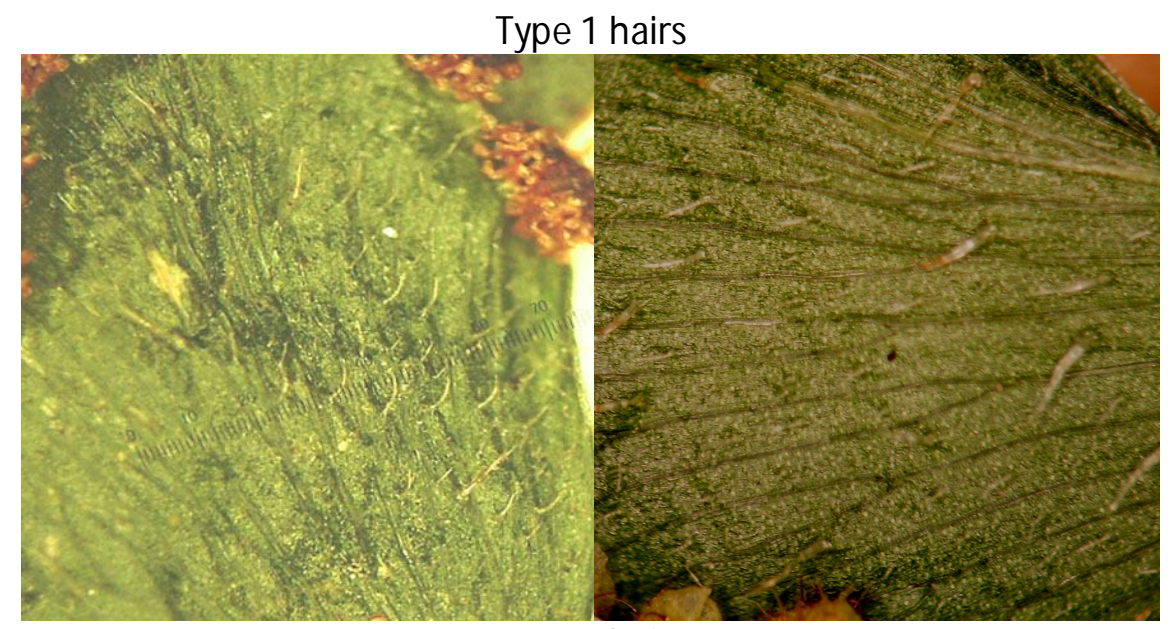

Type 2 hairs

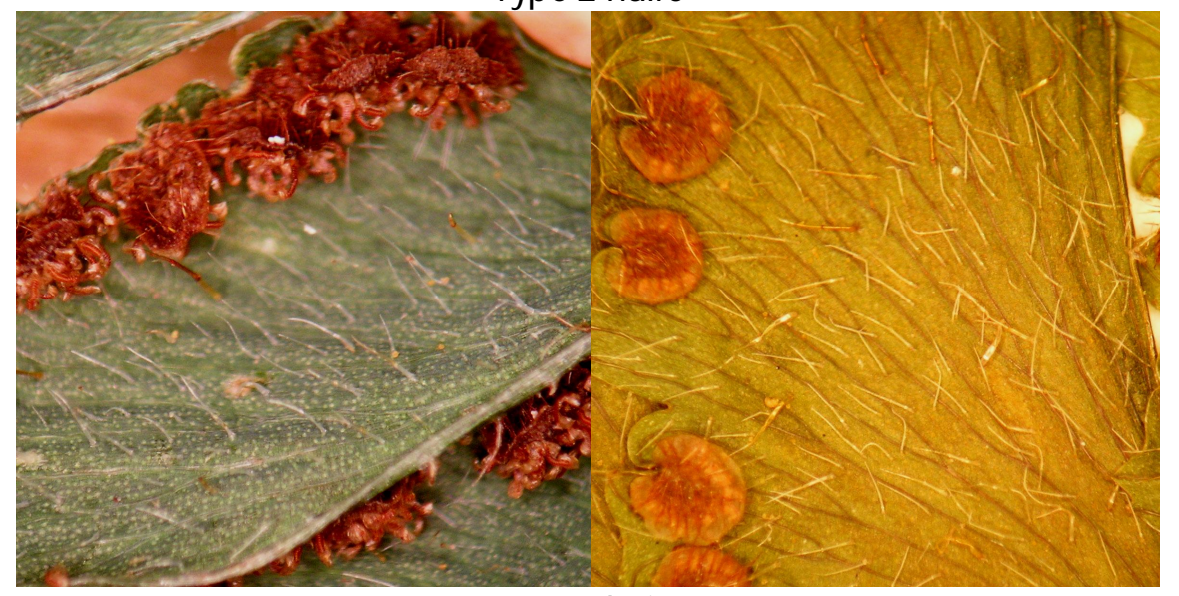

Type 3 hairs

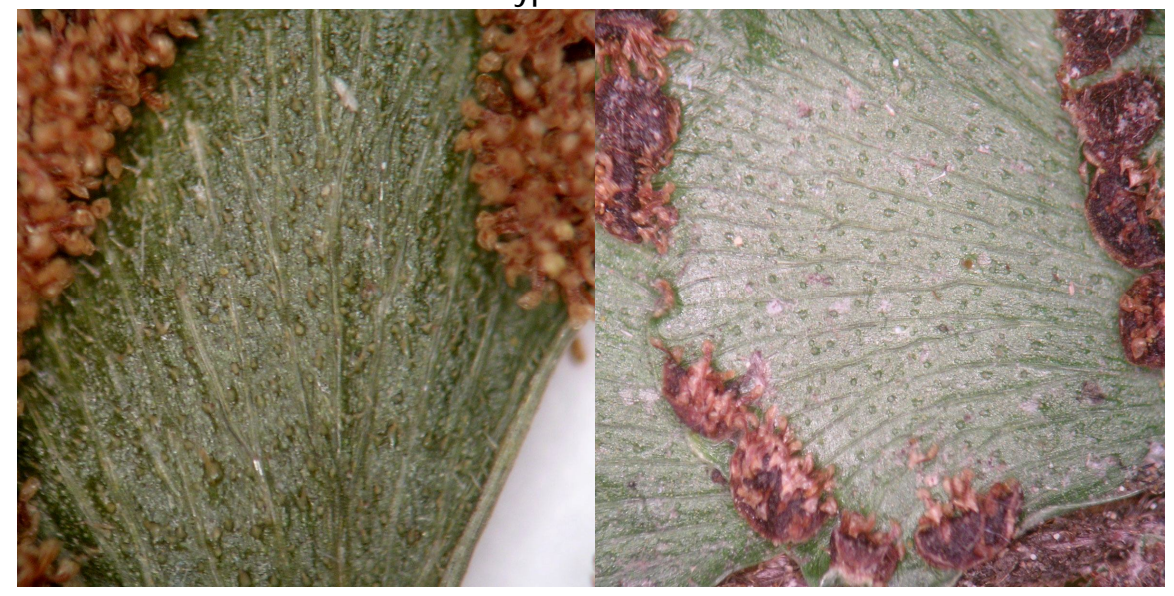

Figure 4.3. Photographs of the three hair types found on the abaxial side of pinnules among the Adiantum hispidulum complex. Each pair of photographs, magnification 70X, is of two different specimens exhibiting the respective hair type. 
Table 4.2. Summary statistics for the four data sets analyzed in this study by maximum parsimony analysis.

\begin{tabular}{cccccc}
\hline Data set & $\begin{array}{c}\text { Alignment } \\
\text { Length } \\
(\mathbf{b p})\end{array}$ & $\begin{array}{c}\text { Variable } \\
\text { sites }\end{array}$ & $\begin{array}{c}\text { Parsimony } \\
\text { Informative } \\
\text { sites }\end{array}$ & $\begin{array}{c}\text { No. of } \\
\text { MP } \\
\text { trees }\end{array}$ & $\begin{array}{c}\text { MP } \\
\text { Tree } \\
\text { length }\end{array}$ \\
\hline trnL-trnF locus & 916 & 162 & 35 & 1 & 77 \\
rbcL & 1143 & 88 & 23 & 23 & 101 \\
rps4 gene $\mathcal{E}$ rps4-trnS & 843 & 207 & 85 & 1 & 280 \\
IGS & & & & & \\
atpB & 1111 & 71 & 15 & 1 & 180 \\
concatenated & 4013 & 528 & 158 & 2 & 642 \\
\hline
\end{tabular}

MP- maximum parsimony

The trnL-trnF locus data set of representatives of the A. hispidulum complex had an alignment length of 922 basepairs. The ingroup taxa, excluding $A$. raddianum, had four variable sites of which all were parsimony informative at positions $230,534,650$, and 693 . These defined three distinct haplotypes within A. hispidulum.

\subsubsection{Phylogenetic analysis}

The parsimony exhaustive searches of each of the individual data sets (trnLtrnF locus, rps4 gene and rps4-trnS IGS, $r b c L$, and $\operatorname{atpB}$ ) recovered trees that were congruent with one another, other than for the relationships of $A$. hispidulum and A. raddianum to the rest of the New Zealand Adiantum (trees not shown). Each of the individual data sets recovered a single tree with the exception of $r b c L$ which recovered 23 trees.

The topologies recovered from the analyses of the concatenated data set were congruent across the different tree-building methods used, and were also congruent with topologies recovered from the individual analyses. Figure 4.4 represents one of the two most parsimonious trees recovered from the maximum parsimony analysis each with a length of 642 steps. Because the 


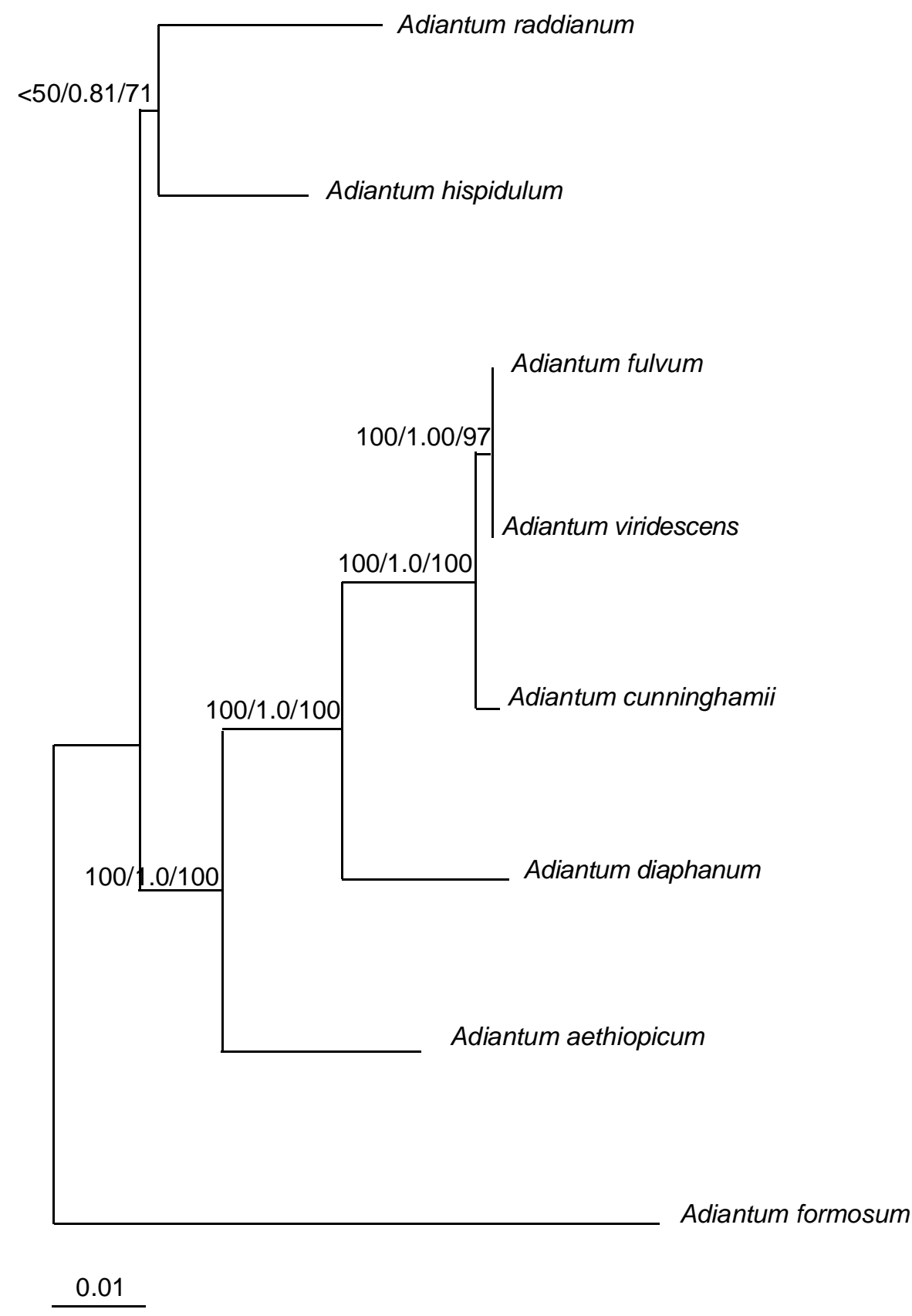

Figure 4.4. One of two most maximum parsimony trees for the concatenated data set. Bootstrap values, posterior probabilities, and maximum likelihood bootstrap values are above each branch, respectively.

topologies between the three methods were congruent, the trees recovered from the maximum likelihood and Bayesian analysis are not shown. The relationships in Figure 4.4 show that $A$. viridescens and $A$. fulvum, which are molecularly identical, are sister to A. cunninghamii. These are in turn sister to 
A. diaphanum, and A. aethiopicum is sister to this clade. The position of each of these species was supported with high bootstrap values (BS>95\%) and posterior probabilities of 1.0. The phylogenetic placement of A. raddianum and $A$. hispidulum was sister to the clade containing the other Adiantum species in each of the tree-building analyses. However, the relationship and grouping of $A$. raddianum with $A$. hispidulum was never well supported by either bootstrap values or posterior probabilities.

The neighbornet network for the representatives of the A. hispidulum complex showed no conflict and recovered the three haplotypes (Figure 4.5).

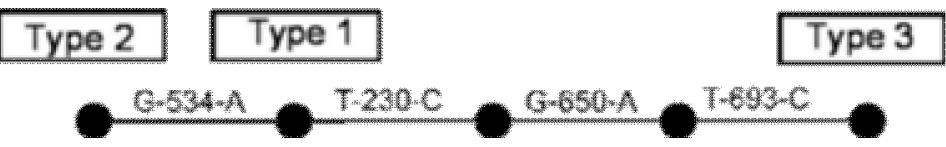

Figure 4.5. Neighbornet network representing the three hair types and the haplotype variation among the representatives of the Adiantum hispidulum complex. The base pair substitutions are labeled above the corresponding node.

\subsection{Discussion}

\subsubsection{Relationships of New Zealand Adiantum}

The relationships among the New Zealand Adiantum, from the results of phylogenetic analyses, show that most of the members of this genus in New Zealand are distantly related to one another with a large amount of genetic variation present between the different species. Comparing morphological characters, selected from the species key in Brownsey and Smith-Dodsworth (2000), to the phylogenetic relationships, it appears that homoplasy has occurred with respect to these characters among the species of New Zealand 
Adiantum. Morphologically, A. cunninghamii, A. fulvum, A. diaphanum, A. hispidulum, and $A$. viridescens are grouped together on the basis of having oblong lamina which is attached to the stalk at one corner (Brownsey and Smith-Dodsworth 2000), where as Adiantum aethiopicum and A. raddianum both have centrally attached stalks, but are distantly related to one another according to chloroplast sequence data suggesting convergent or parallel evolution of the central attachment of the lamina to the stalk. A large scale morphological investigation on character homoplasy in grammitid ferns suggests that some the most commonly used morphological characters used for taxonomic recognition are those which exhibit high levels of homoplasy (Ranker et al. 2004).

The grouping of Adiantum proposed by Tryon and Tryon (1982) placed both Adiantum raddianum and A. aethiopicum in the A. capillus-veneris group (Tryon and Tryon 1982). However, according to the topology recovered from a large scale investigation of Pteridaceae (Chapter 2) based on $r b c L$ DNA sequence data, $A$. raddianum and $A$. aethiopicum are quite distantly related to $A$. capillusveneris. In addition, the results from this study using several chloroplast loci, confirm this relationship as A. aethiopicum is in a clade with $A$. cunninghamii, A. diaphanum, A. fulvum, and $A$. viridescens as opposed to being placed with $A$. raddianum. Adiantum raddianum is native to South America yet has affinity to New Zealand species of Adiantum. Whether or not A. raddianum originated in New Zealand or in South America is unknown. Additional taxonomic sampling will be necessary to determine if additional species will have affinity to A. raddianum or the New Zealand Adiantum.

Adiantum cunninghamii, A. fulvum, and A. viridescens all have glabrous reflexed indusia, in addition to an oblong lamina attached to a stalk at one corner, where as, A. hispidulum has hairy reflexed indusia, while still having an 
oblong lamina attaching to the stalk at one corner (Brownsey and SmithDodsworth 2000). Adiantum hispidulum is consistently recovered as having affinity to $A$. raddianum though there is a lack of morphological characters to group them together. According to the topology based on $r b c L$ sequence data (Chapter 2), A. hispidulum is recovered as having affinity to the $A$. cunninghamii, A. fulvum, and A. viridescens, although not supported with bootstrap values or posterior probabilities. The topologies recovered from this study confirm the affinity of A. hispidulum to the New Zealand Adiantum, yet morphological and molecular data fail to establish its exact relationship to the other New Zealand Adiantum species.

Most interesting is Adiantum formosum which had the most different genetic distance compared to the other native New Zealand taxa and its distribution only extends to Australia. The study investigating the Pteridaceae with rbcL DNA sequences (Chapter 2) included 24 representatives of the genus Adiantum mostly from the South Pacific and South America. The relationship of A. formosum to the other Adiantum species was sister to the remainder of the South-West Pacific Adiantum with high support from both bootstrap values and posterior probabilities. According to the groups suggested by Tryon and Tryon (1982), A. formosum is placed in a group with A. fulvum and $A$. hispidulum, and would mostly likely be expanded to include $A$. viridescens and A. cunninghamii. Based on morphological characters, A. formosum shares several characters with the species mentioned above, including oblong lamina attached to the stalk at one corner and glabrous indusial. In addition, this grouping is consistent with chromosome numbers reporting A. fulvum, A. cunninghamii, and A. fulvum having $\mathrm{n}=58$ (Dawson et al. 2000). Tryon and Tryon (1982) also mention other Adiantum species that would be included in this group mostly from South America. Unfortunately DNA sequence data from these species was not available for the former analyses to determine if 
they would have affinities to A. formosum. Until further taxonomic sampling can be incorporated, the origins and relationships of $A$. formosum to other Adiantum species in the South-West Pacific remain unclear.

\subsubsection{Adiantum hispidulum complex}

The recognition in the Adiantum hispidulum complex of either a distinct species $A$. pubescens Schkuhr or a variety $A$. hispidulum var. pubescens (Schkuhr) Large et Braggins, has not been addressed since the publications of Parris (1980) and Large and Braggins (1993). Based on the morphological observations of the 64 A. hispidulum specimens collected around New Zealand and off shore islands, it is clear that three distinguishable hair types are present. Large and Braggins (1993) determined that differences in hair type were not a result of environmental factors but influenced by genetic factors. The trnL-trnF DNA sequence data shows that these three hair types are consistent with haplotype variation at the $t r n L-t r n F$ locus, with the exception of one specimen, suggesting that there are three separate taxa within the $A$. hispidulum complex as opposed to two. Two of the three distinct groups correspond to previous descriptions of $A$. hispidulum. Plants with type 1 hairs fit with the descriptions of $A$. hispidulum (Parris 1980, Large and Braggins 1993). Plants with type 2 hairs conform to those described as A. pubescens or A. hispidulum var. pubescens (Parris 1980, Large and Braggins 1993). The plants with type three hairs have no mention in the known literature of $A$. hispidulum. Parris (1980) describes several other hair types found amongst overseas representatives of $A$. hispidulum, but none match the description of hairs found on these plants. Furthermore, Large and Braggins (1993) discuss the variability of hair length amongst plants of $A$. hispidulum. Yet, they do not describe hairs that would be descriptive of type 3 hairs. 
The sample set obtained for $A$. hispidulum was small but still an almost perfect correspondence between hair type and haplotype was recovered. The plant that did not fit this pattern was an anomaly already as this plant was collected a great distance beyond the normal distribution of $A$. hispidulum in New Zealand (Aorangi Range, Wairarapa). Also, when it was found its appearance was unlike that of which would be seen with typical $A$. hispidulum plants (see appendix C). Although it cannot be ignored that this sample does not fit the pattern, further investigations of this disjunct population would be worthwhile.

The collection locations of these non-hispidulum-like specimens, i.e. type 2 and type 3 hairs, showed no obvious geographical pattern (Figure 4.2). This supports the finding of Large and Braggins (1993) that A. hispidulum and A. (hispidulum var.) pubescens are not geographically or ecologically separated. However, the distribution of pubescens-like plants and the plants with the third hair type in New Zealand are unclear and more thorough sampling is required.

Adiantum hispidulum also occurs in Australia where four distinct varieties are recognized (Bostock et al. 1998). The criteria for distinguishing the Australian varieties is contingent among more than just indumentum characters though two varieties seem to loosely conform to descriptions of New Zealand $A$. hispidulum (Australian A. hispidulum var. minus) and A. pubescens (Australian A. hispidulum var. hypoglaucum). Bostock et al. (1998) describe A. hispidulum var. hypoglaucum as having silky, pubescent, pale crowded lax hairs. Adiantum hispidulum var. minus was described as having pubescent pale hairs that were stiffly erect. The other two Australian varieties (A. hispidulum var whitei and A. hispidulum var. hispidulum) are both described as being sparsely pubescent. Based on the vague descriptions of the latter two, it is not possible 


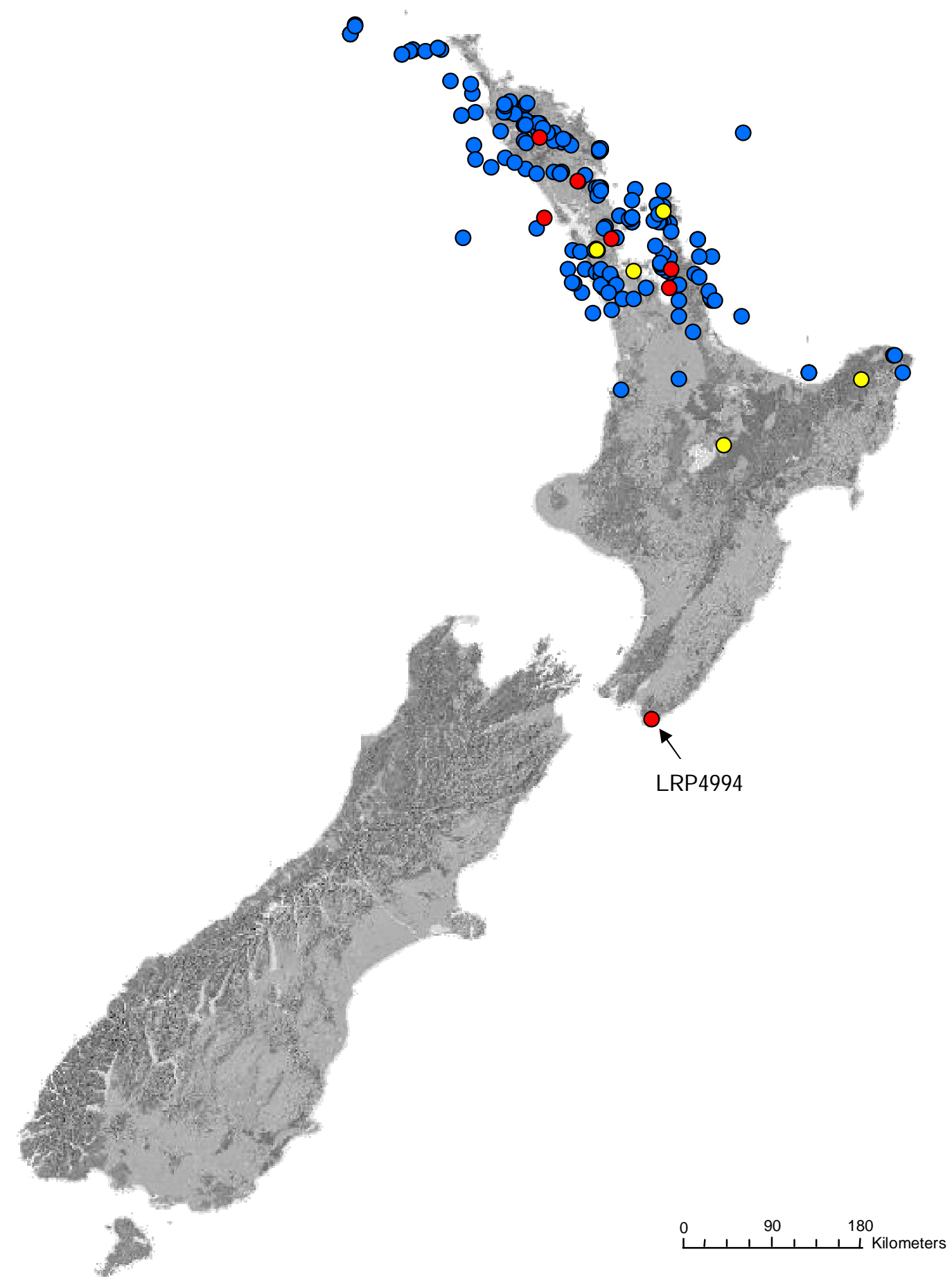

Figure 4.2. The distribution of the collection details for all specimens of the Adiantum hispidulum complex from the WELT herbarium. Each color represents the hair type observed: blue- type 1, red-type 2, and yellow- type 3. Note specimen LRP4994 which occurs beyond the range typical of that of $A$. hispidulum. 
to determine if they would conform to type 1 or type 3 hairs. No known molecular or even morphological investigations have been done with respect to the Australian representatives of A. hispidulum to determine their relationships to one another and also their relationships to those occurring in New Zealand.

The main problem with classifying these taxa is determining what criteria are required for recognizing a new species. Large and Braggins (1993) argue that differences in hairs, coupled with frond formation, which is quite variable anyway, is not enough to denote separate species. However, the addition of molecular data in support of three distinct haplotypes, corresponding to the three distinct hair types, provides a second character in support of distinct taxa. Similar problems were encountered in a study on Asplenium nidus, where morphological characters were insufficient for species recognition between sympatric species. However, evidence from $r b c L$ DNA sequence data and crossing experiments supported that three distinct, reproductively isolated species did exist though they were indistinguishable by morphological characters (Yatabe et al. 2001). Although it is unknown if the Adiantum hispidulum taxa are commonly found growing in sympatry through out New Zealand, crossing experiments could give insight as to whether these taxa are reproductively isolated and could constitute distinct species.

The genetic variation present in the $t r n L-t r n F$ locus was small; one base pair substitution distinguished those plants with type 2 hairs from type 1 hairs (the most common haplotype), and three base pair substitutions for those with type 3 hairs from type 1 hairs. However, when compared to the genetic variation found between the species $A$. cunninghamii, $A$. viridescens, and $A$. fulvum, A. cunninghamii is distinct by the same amount of base pair 
substitutions as is found between the haplotypes of $A$. hispidulum. The most prominent distinguishing morphological character for A. cunninghamii is a glabrous stipe and rachis, as compared to the hairy stipe and rachis of A. viridescens and A. fulvum. Although other characters have been recommended for distinguishing between the two species (e.g., lamina color and pinnule shape) these are often variable with respect to individual plants (Parris and Croxall 1974).

In addition, $A$. fulvum and $A$. viridescens are considered distinct species on the basis of one morphological characteristic, the presence of hair on the abaxial pinnae, and are molecularly identical according to multiple chloroplast loci. If these two species continue to be considered distinct species it might be consistent to consider recognizing two if not three distinct species among the A. hispidulum taxa corresponding to hair type and their respective haplotype. Nonetheless, the genetic variation coupled with differences in hair type present among the representatives of $A$. hispidulum warrants reinvestigation of these taxa and their status as either varieties or distinct species. Also, some level of consistency will need to be developed with the treatment of hairs with respect to the recognition of taxa within this genus in New Zealand. It would benefit future studies of these taxa if investigation were expanded beyond New Zealand and into other areas of the South West Pacific where the $A$. hispidulum complex is known to grow. 


\subsection{References}

Bostock, P. D., T. C. Chambers, and P. A. Farrant. 1998. Adaintaceae. Flora of Australia. CSIRO Publishing, Collingwood.

Brownsey, P. J., and J. C. Smith-Dodsworth. 2000. New Zealand Ferns and Allied Plants. 2nd edition. David Bateman Ltd., Auckland, New Zealand.

Dawson, M. I., P. J. Brownsey, and J. D. Lovis. 2000. Index of chromosome numbers of indigenous New Zealand pteridophytes. New Zealand Journal of Botany 38.

Hall, T. A. 1999. BioEdit: a user-friendly biological sequence alignment editor and analysis program for Windows $95 / 98$ NT. Nucleic Acids Symp. Ser. 41:95-98.

Huelsenbeck, J. P., and F. R. Ronquist. 2001. MrBayes: Bayesian inference of phylogeny. Biometrics 17:754-755.

Huson, D. H. 1998. SplitsTree: a program for analyzing and visualizing evolutionary data. . Bioinformatics 14:68-73.

Korpelainen, H., J. Britto, J. Doublet, and S. Pravin. 2005. Four tropical, closely related fern species belonging to the genus Adiantum L. are genetically distinct as revealed by ISSR fingerprinting. Genetica 125:283-291.

Large, M. F., and J. E. Braggins. 1993. A morphological assessment of Adiantum hispidulum Swartz and A. pubescens Schukuhr (Adiantaceae: Filicales) in New Zealand. New Zealand Journal of Botany 31:403-417.

Nadot, S., R. Bajon, and L. B. 1994. The chloroplast gene rps4 as a tool for the study of Poaceae phylogeny. Plant Systematics and Evolution 191:2738 .

Paris, C. A., and M. D. Windham. 1988. A Biosystematic Investigation of the Adiantum pedatum Complex in Eastern North America. Systematic Botany 13:240-255. 
Parris, B. S. 1980. Adiantum hispidulum Swartz and A. pubescens Schkuhr (Adiantaceae: Filicales) in New Zealand. New Zealand Journal of Botany 18:503-506.

Parris, B. S., and J. P. Croxall. 1974. Adiantum viridescens Colenso in New Zealand. New Zealand Journal of Botany 12.

Posada, D., and T. R. Buckley. 2004. Model selection and model averaging in phylogenetics: advantages of Akaike information criterion and Bayesian approaches over likelihood ratio tests. Systematic Biology 53:793-808.

Ranker, T. A., A. R. Smith, B. S. Parris, J. M. O. Geiger, C. H. Haufler, S. C. K. Straub, and H. Schneider. 2004. Phylogeny and evolution of grammatid ferns (Grammitidaceae): a case of rampant morphological homoplasy. TAXON 53:415-428.

Schuettpelz , E., and K. M. Pryer. 2007. Fern phylogeny inferred from 400 leptosporangiate species and three plastid genes. TAXON 56:1037-1050.

Souza-Chies, T. T., G. Bittar, S. Nadot, L. Carter, E. Besin, and B. Lejeune. 1997. Phylogenetic analysis of Iridaceae with parsimony and distance methods using the plastid gene rps4. Plant Systematics and Evolution 204:109-123.

Swofford, D. L. 2002. PAUP* Phylogenetic analysis using parsimony (* and other methods). Sinauer Associates, Sunderland.

Taberlet, P., L. Gielly, G. Pautou, and J. Bouvet. 1991. Universal primers for amplification of three non-coding regions of chloroplast DNA. Plant Molecular Biology 17:1105-1109.

Tamura, K., J. Dudley, M. Nei, and S. Kumar. 2007. MEGA4: Molecular Evolutionary Genetics Analysis (MEGA) software version 4.0. . Molecular Biology and Evolution 24:1596-1599.

Thompson, J. D., T. J. Gibson, F. Plewniak, F. Jeanmougin, and D. G. Higgins. 1997. The ClustalX windows interface: flexible strategies for multiple sequence alignment aided by quality analysis tools. Nucleic Acids Research 24:4876-4882. 
Trewick, S. A., M. Morgan-Richards, S. J. Russell, S. Henderson, F. J. Rumsey, I. Pinter, J. A. Barrett, M. Gibby, and J. C. Vogel. 2002. Polyploidy, phylogeography and Pleistocene refugia of the rockfern Asplenium ceterach: evedence from chloroplast DNA. Molecular Ecology 11:20032012.

Tryon, R. M., and A. F. Tryon. 1982. Ferns and Allied Plants With Special Reference to Tropical America. Springer-Verlag New York Inc., New York.

Yatabe, Y., S. Masuyama, D. Darnaedi, and N. Murakami. 2001. Molecular systematics of the Asplenium nidus complex from Mt. Halimun National Park, Indonesia: evidence for reproductive isolation among three sympatric $r b c L$ sequence types. American Journal of Botany 88:15171522. 


\section{Chapter 5}

\subsection{General Discussion}

\subsubsection{New Zealand Pteridaceae}

The investigation into the phylogenetic relationships of the New Zealand Pteridaceae to their overseas relatives produced topologies suggesting that New Zealand Pteridaceae species were generally part of predominately South West Pacific groups within their respective genera. For example, results from the 220-taxon rbcL data set showed that the New Zealand species from the genera Adiantum, Cheilanthes, and Pellaea were generally more closely related to one another than to overseas relatives. The exception to this pattern was Pteris tremula, which was more closely related to overseas species than to the other New Zealand Pteris. The New Zealand members of the genera Pellaea and Cheilanthes formed monophyletic groups nested within other members of the cheilanthoid ferns (Chapter 2). The New Zealand Pellaea was sister to members of Paragymnopteris as opposed to other members of the genus 
Pellaea. The New Zealand Cheilanthes did have affinity to other members of the genus Cheilanthes; however, this genus as a whole was highly polyphyletic. These results were not surprising because the genera comprising the cheilanthoid ferns are notorious for their confusing taxonomy, and are consistently resolved as paraphyletic and polyphyletic (Gastony and Rollo 1995, Kirkpatrick 2007, Zhang et al. 2007). Previous molecular studies of Pellaea and Cheilanthes, along with the results from Chapter 2, confirm that these genera are polyphyletic (Kirkpatrick 2007, Zhang et al. 2007). However, Pellaea sect. Platyloma, defined by Tryon and Tryon (1982), grouped together the members of the Australasian Pellaea in a monophyletic group indicating a possible new genus if taxonomic revisions are imposed. A revision of this nature has been suggested by Kirkpatrick (2007) where the species within Pellaea sect. Platyloma would constitute the new genus, Platyloma.

The New Zealand Cheilanthes were also more closely related to one another than to other non-New Zealand members of Cheilanthes. They formed a clade with the type species for Cheilanthes, C. micropteris. Although these two representatives of New Zealand Cheilanthes do group together, there are 13 other species of Cheilanthes that occur in the Australasian region (Bostock et al. 1998). These additional species would need to be incorporated into phylogenetic analyses to accurately determine their affinity to either the New Zealand Cheilanthes or to the overseas relatives, and hence, whether they support a South West Pacific group.

The New Zealand Adiantum species formed a group with the addition of the South American Adiantum raddianum and A. cuneatum. The affinity of $A$. raddianum and $A$. cuneatum to the New Zealand Adiantum as opposed to other South American Adiantum was surprising. Based on morphological characteristics, $A$. raddianum has traditionally been grouped with both $A$. 
aethiopicum and A. capillus-veneris (Tryon and Tryon 1982). However, results from Chapter 2 and Chapter 4 recover that $A$. raddianum is distantly related to A. capillus-veneris, and although situated in the same clade as A. aethiopicum, has closest affinity to $A$. hispidulum. With the present data, it is unclear if $A$. raddianum has origins in South America and has immigrated to New Zealand or if it originated in New Zealand and dispersed to South America. As more of the 150 species of Adiantum are sampled, the relationships between the constituents of the two main clades will become more obvious.

The members of the New Zealand Pteris were polyphyletic, with P. tremula found to be more closely related to Pteris species from South America than to the other New Zealand P. comans, P. saxatilis, and P. macilenta. Pteris tremula is found throughout the South Pacific (Bostock et al. 1998). The majority of the Pteris species found in New Zealand and Australia have a vast distribution through the tropics. Only one endemic species occurs in Australia and two endemic species in New Zealand (Bostock et al. 1998, Brownsey and SmithDodsworth 2000). The endemic species in New Zealand are believed to be part of an allopolyploid complex, where endemic P. macilenta is a hybrid between Pacific $P$. comans and endemic $P$. saxatilis. Furthermore, the relationships between Pteris on a global level were unresolved in the rbcL MP analysis presented in Chapter 2 causing uncertainty among the relationships at the species level, as well as, the relationships of the New Zealand Pteris to its overseas members.

\subsubsection{Pellaea}

The morphologically-intermediate Pellaea aff. falcata plants were recovered as being more closely related to $P$. rotundifolia than to $P$. falcata, suggesting that P. rotundifolia may be a polymorphic species throughout New Zealand 
(Chapter 3). Also, DNA sequence data recovered a sample of $P$. falcata collected from Tasmania to be molecularly identical to P. rotundifolia, raising concern that the $P$. aff. falcata plants are occurring outside of New Zealand. The biggest implication of this discovery is the difficulty in determining what is P. falcata in New Zealand and also other areas in the South Pacific.

The genetically different Pellaea falcata from the Kermadec Islands may be a new distinct species. However, until a more extensive sampling of these " $P$. falcata" plants is done, it will remain unclear whether this Pellaea species only occurs on the Kermadec Islands or whether it also exists on the mainland of New Zealand or other South Pacific Islands. Based on the finding of this thesis research, it is apparent that the problems with identifying Pellaea species in New Zealand is far greater than previously thought and also that this is an issue that extends beyond New Zealand to encompass Australia, and other South Pacific Islands.

\subsubsection{Adiantum}

The polymorphic Adiantum hispidulum is in need of reinvestigation based on the amount of haplotype variation detected amongst the 11 samples sequenced for this study. The three haplotypes corresponded to three distinct hair types that were visually distinguishable; these were: type 1- sparse, short stiff hairs, type 2- dense long lax hairs, and type 3- abundant, shorter than $A$. hispidulum, spike-like hairs. More extensive sampling of these plants will be necessary to not only to confirm the pattern found between haplotypes and hair type but also to better determine the distributions of these types throughout New Zealand. Based on previous species treatments within Adiantum in New Zealand, particularly A. fulvum and A. viridescens (Parris and Croxall 1974), single morphological characters were deemed appropriate 
to denote separate species. Given the morphological differences found among hairs coupled with haplotype variation, the plants recognized in the $A$. hispidulum complex warrant further investigation or at most a confirmation of their status as either varieties or separate species.

\subsubsection{Taxonomic sampling}

A main problem encountered with many phylogenetic investigations is obtaining an adequate amount of taxonomic sampling to represent a realistic amount of biodiversity. Many studies have emphasized the importance of the taxonomic sample set, where even the addition or deletion of a single taxon can change the inferred phylogenetic relationships (Poe 2003, Soltis et al. 2004, Martin et al. 2005). With many of the findings reported in this study, it has become clear that increased taxonomic sampling would improve both the clarity and the confidence of the results. The results from Chapter 2 confirm previous classifications of the Pteridaceae with respect to recovering five major monophyletic clades (i.e., cryptogrammoids, ceratopteridoids, cheilanthoids, pteridoids, and the adiantoids). But incongruent topologies recovered between the chloroplast genes $a t p B$ and $r b c L$ offered little insight into confident relationships at the generic level. The Pteridaceae is a very large and very diverse fern family that has a vast world wide distribution, which only compounds obtaining a sample set that is adequate for inferring robust relationships.

For example, previous studies reported recovering the genus Adiantum as paraphyletic with respect to the Vittarioid ferns (Prado et al. 2007, Schuettpelz and Pryer 2007, Schuettpelz et al. 2007). As reported by the results recovered from the 220-taxon $r b c L$ data set, with the addition of the New Zealand species of Adiantum, the genus appears to be monophyletic. Nonetheless, the 
vittaroids have affinity to Adiantum and should be included in the Pteridaceae family, but whether they are derived from within Adiantum, hence making this genus paraphyletic, is unclear. Also, the problems with the species of Pellaea in the South Pacific will begin to be clarified with increased sampling. Geuten et al. (2007) stress that rather than focusing on increasing the number of characters, more emphasis should be placed on choosing the appropriate taxa set to maximize the improvement and accuracy of inferred evolutionary relationships.

\subsubsection{New Zealand biodiversity}

The Pteridaceae in New Zealand is among the largest fern families in New Zealand (Breitwieser et al. in press). Accurately determining the species diversity within the family, as well as the relationships between these species is an important step towards cataloguing fern biodiversity in New Zealand. The advancement of molecular technologies has provided the tools to detect variation among species that lack distinguishable morphological characteristics used to traditionally classify fern species. Specifically, several morphologically-intermediate Pellaea plants have led to the mis-identification of P. falcata populations throughout New Zealand. It appears from both the collection efforts and the results from this study that $P$. falcata may be more threatened than previously thought. Having molecular markers available to accurately distinguish these plants will aid efforts of conservationists as they help to identify any possible remaining populations left in New Zealand. Furthermore, molecular haplotype variation with in the samples of $A$. hispidulum could lead to additional species diversity within Adiantum.

Gaining an understanding of the relationships of the New Zealand ferns to their overseas relatives, will help shed light on the origins of the flora in New 
Zealand. Inference from previous studies (Pryer et al. 2004, Perrie and Brownsey 2007) suggested that the members of the Pteridaceae in New Zealand are of recent origins, and are most likely a result of long distance dispersal. The relationships shown in the topologies recovered from the 220taxon $r b c L$ data set suggest that the direction of dispersal for the species of Pteridaceae is immigration into New Zealand. The results from this study will aid in further investigations of both the biogeographic history of Pteridaceae ferns in New Zealand, as well as, accurately describing species within the genera Pellaea and Adiantum. 


\subsection{References}

Bostock, P. D., T. C. Chambers, and P. A. Farrant. 1998. Adaintaceae. Flora of Australia. CSIRO Publishing, Collingwood.

Breitwieser, I., P. J. Garnock-Jones, A. D. Wilton, J. I. Raine, D. C. Mildenhall, M. S. Pole, P. J. Brownsey, and L. R. Perrie. in press. Phylum Tracheophyta, Lychophytes, Ferns, and seed plants.in D. Gordon, editor. The New Zealand Inventory of Biodiversity: A Species 2000 Symposium Review. The University of Canterbury Press, Christchurch, New Zealand.

Brownsey, P. J., and J. C. Smith-Dodsworth. 2000. New Zealand Ferns and Allied Plants. 2nd edition. David Bateman Ltd., Auckland, New Zealand.

Gastony, G. J., and D. R. Rollo. 1995. Phylogeny and Generic Circumscriptions of Cheilanthoid Ferns (Pteridaceae: Cheilanthoideae) Inferred from $r b c L$ Nucleotide Sequences. American Journal of Botany 85:341-360.

Kirkpatrick, R. E. B. 2007. Investigating the monophyly of Pellaea (Pteridaceae) in the context of a phylogenetic analysis of Cheilantoid Ferns. Systematic Botany 32:504-518.

Martin, W., O. Deusch, N. Stawski, N. Grunheit, and V. Goremykin. 2005. Chloroplast genome phylogenetics: Why we need independent approaches to plant molecular evolution. Trends in Plant Science 10:203-209.

Parris, B. S., and J. P. Croxall. 1974. Adiantum viridescens Colenso in New Zealand. New Zealand Journal of Botany 12.

Perrie, L. R., and P. J. Brownsey. 2007. Molecular evidence for long-distance dispersal in the New Zealand pteridophyte flora. Journal of Biogeography 34:2028-2038.

Poe, S. 2003. Evaluation of the strategy of long-branch subdivision to improve accuracy of phylogenetic methods. Systematic Biology 52:423-428.

Prado, J., C. Del Nero Rodrigues, A. Salatino, and M. L. F. Salatino. 2007. Phylogenetic relationships among Pteridaceae, including Brazilian species, inferred from $r b c \mathrm{~L}$ sequences. TAXON 56:355-368. 
Pryer, K. M., E. Schuettpelz, P. G. Wolf, H. Schneider, A. R. Smith, and R. Cranfill. 2004. Phylogeny and evolution of ferns (monilophytes) with a focus on the early leptosporangiate divergences. American Journal of Botany 91:1582-1598.

Schuettpelz , E., and K. M. Pryer. 2007. Fern phylogeny inferred from 400 leptosporangiate species and three plastid genes. TAXON 56:1037-1050.

Schuettpelz , E., H. Schneider, L. Huiet, M. D. Windham, and K. M. Pryer. 2007. A molecular phylogeny of the fern family Pteridaceae: Assessing overall relationships and the affinities of previously unsampled genera. Molecular Phylogenetics and Evolution 44:1172-1185.

Soltis, D. E., V. A. Albert, V. Savolainen, K. Hilu, Y. L. Qiu, M. W. Chase, J. S. Farris, S. Stefanovic, D. W. Rice, J. D. Palmer, and P. S. Soltis. 2004. Genome-scale data, angiosperm relationships, and "ending incongruence": A cautionary tale in phylogenetics. Trends in Plant Science 9:477-483.

Tryon, R. M., and A. F. Tryon. 1982. Ferns and Allied Plants With Special Reference to Tropical America. Springer-Verlag New York Inc., New York.

Zhang, G., X. Zhang, Z. Chen, H. Liu, and W. Yang. 2007. First insights in the phylogeny of Asian cheilanthoid ferns based on sequences of two chloroplast markers. TAXON 56:369-378. 


\section{Appendix A - Distribution maps of New Zealand Pteridaceae}

Map data based on collection information from the WELT, CHR, and AK herbaria and

includes cultivated specimens. Note that voucher information of Pellaea falcata was mapped as originally determined. 


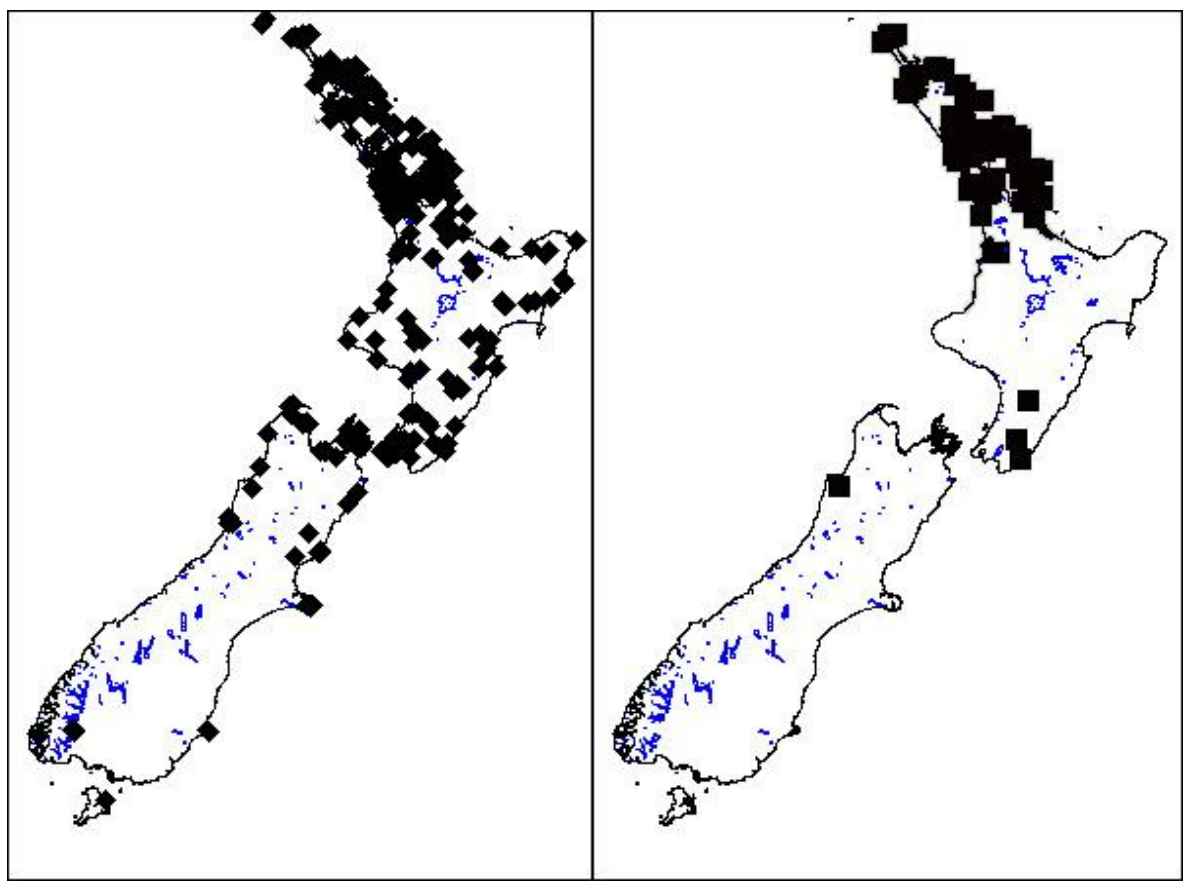

Figure Al. Adiantum cunninghamii

Figure A2. Adiantum aethiopicum

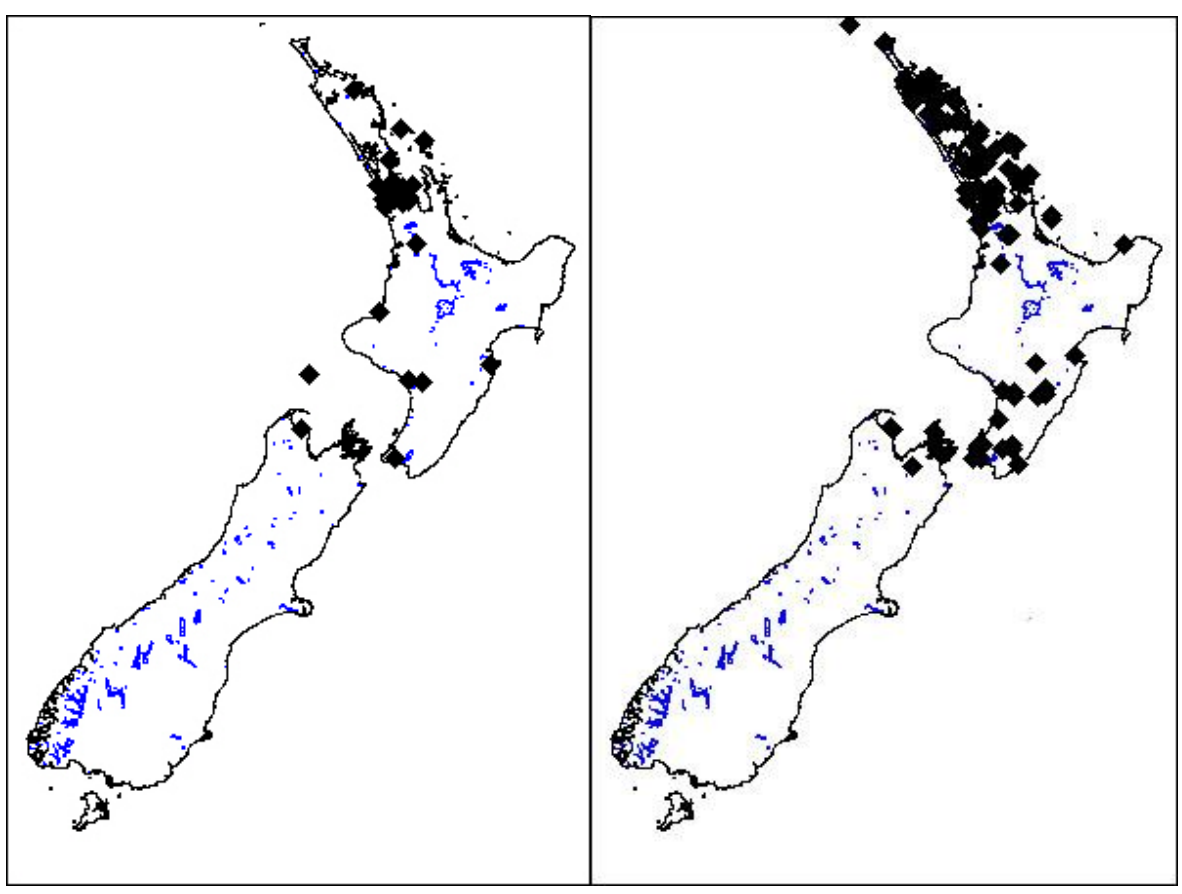

Figure A3. Adiantum raddianum

Figure A4. Adiantum diaphanum 


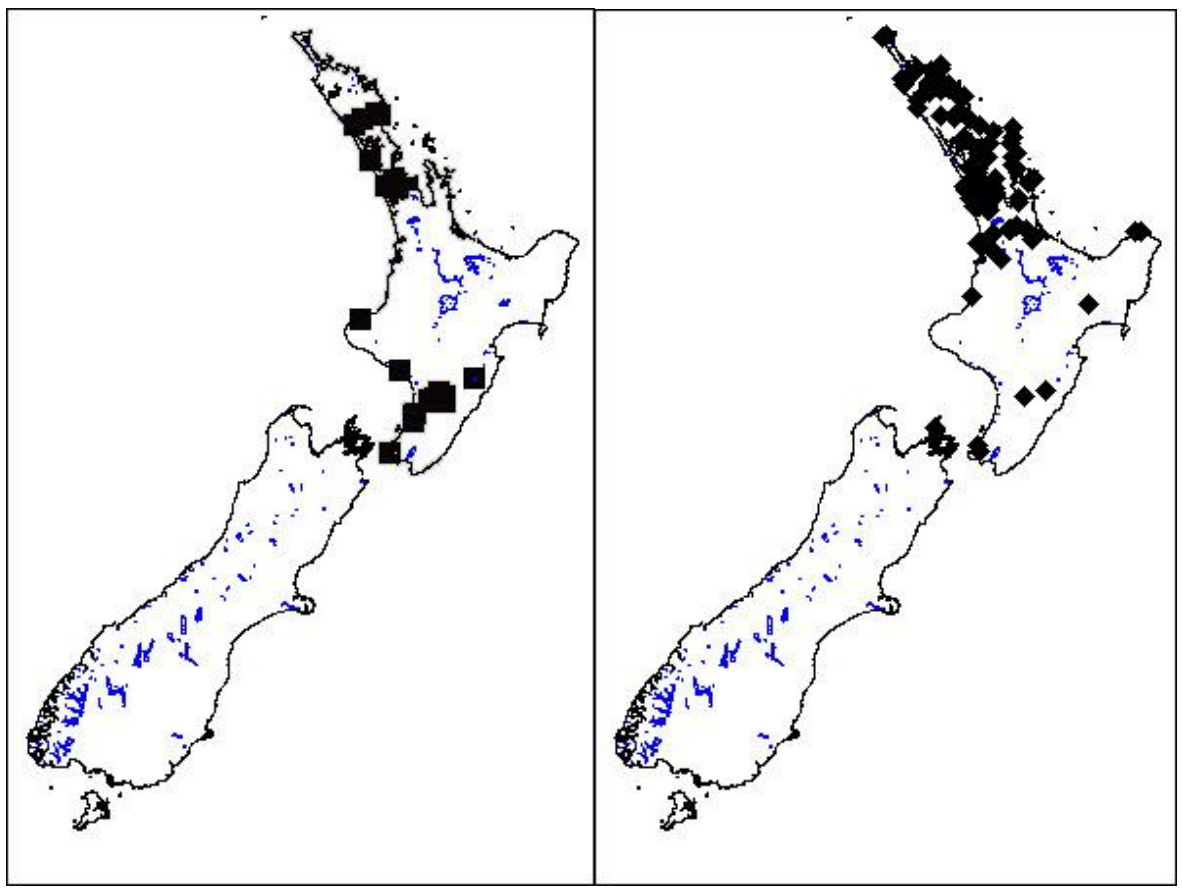

Figure A6. Adiantum formosum

Figure A7. Adiantum fulvum

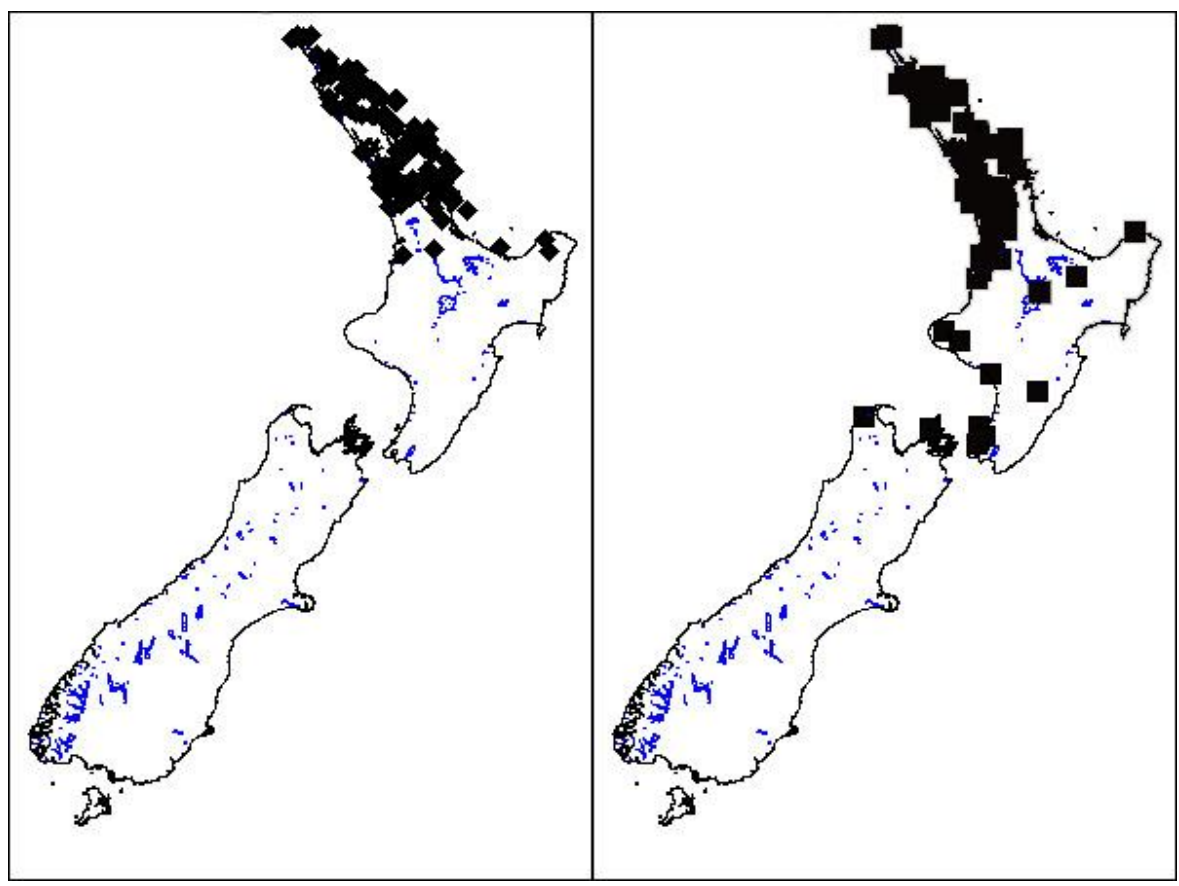

Figure A8. Adiantum hispidulum

Figure A9. Adiantum viridescens 


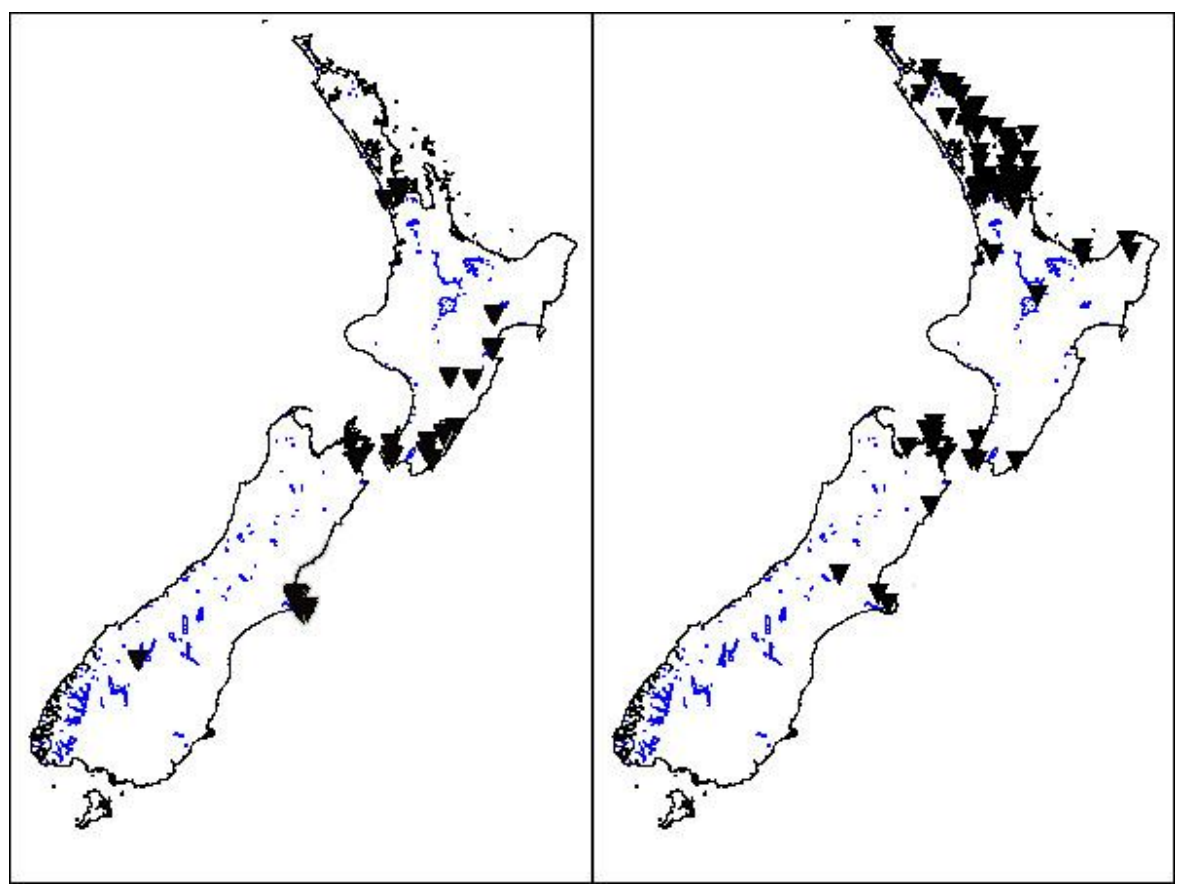

Figure A10. Annogramma leptophylla

Figure Al1. Cheilanthes distans

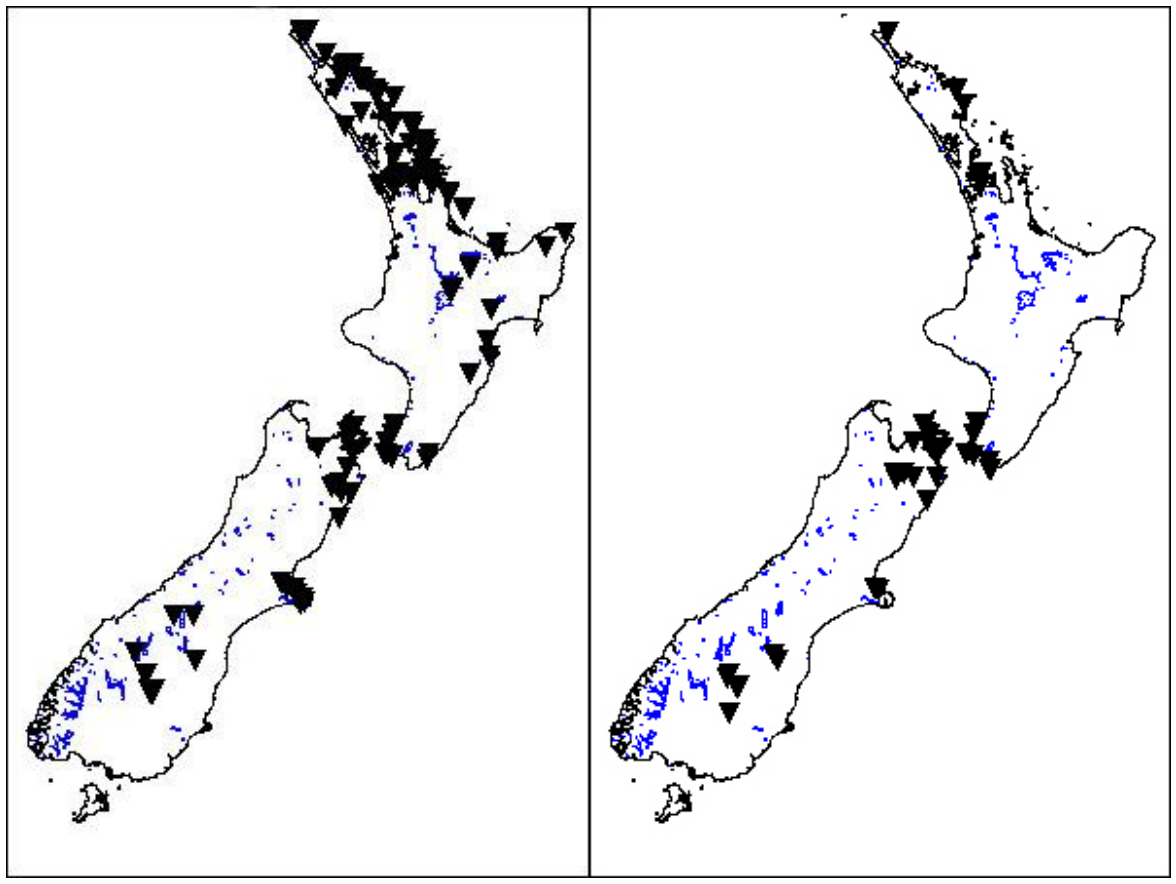

Figure A12. Cheilanthes siberi

Figure A13. Pellaea calidirupium 


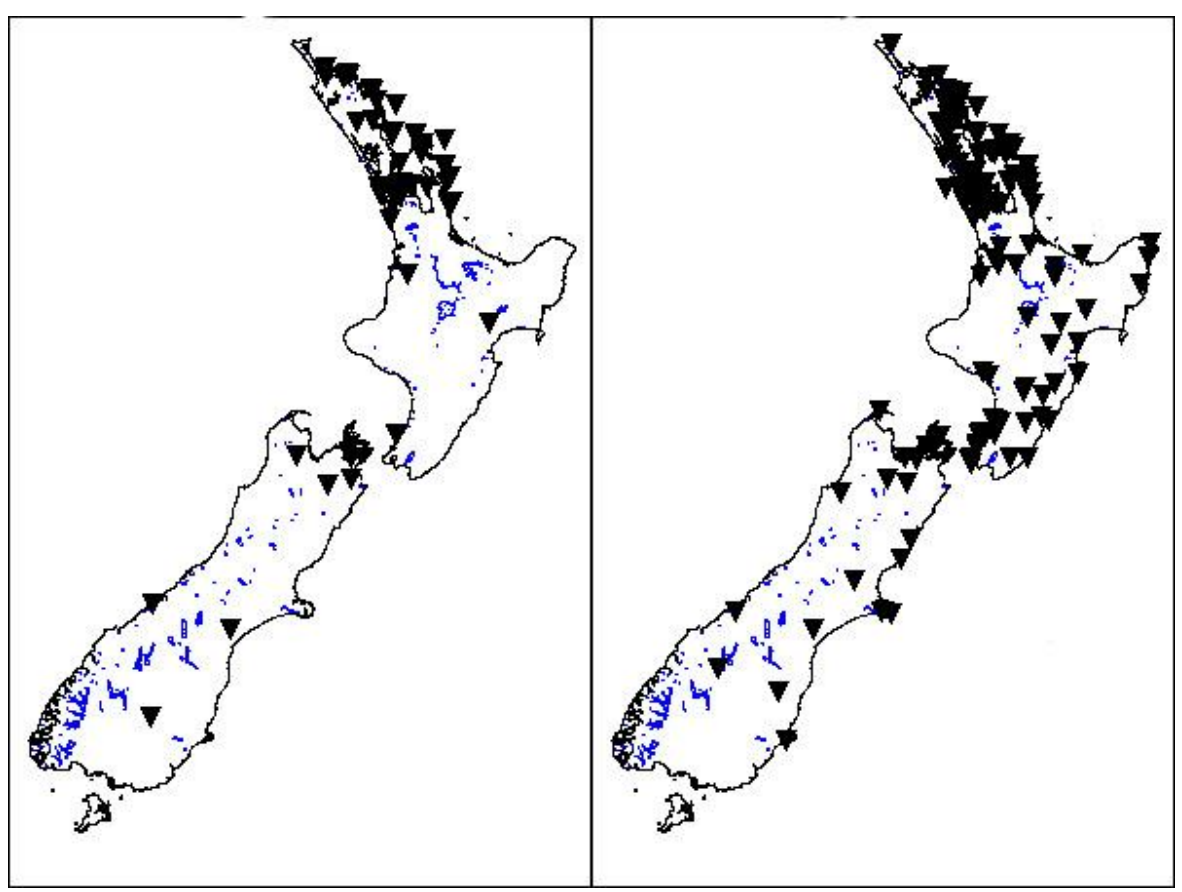

Figure A14. Pellaea falcata

Figure A15. Pellaea rotundifolia

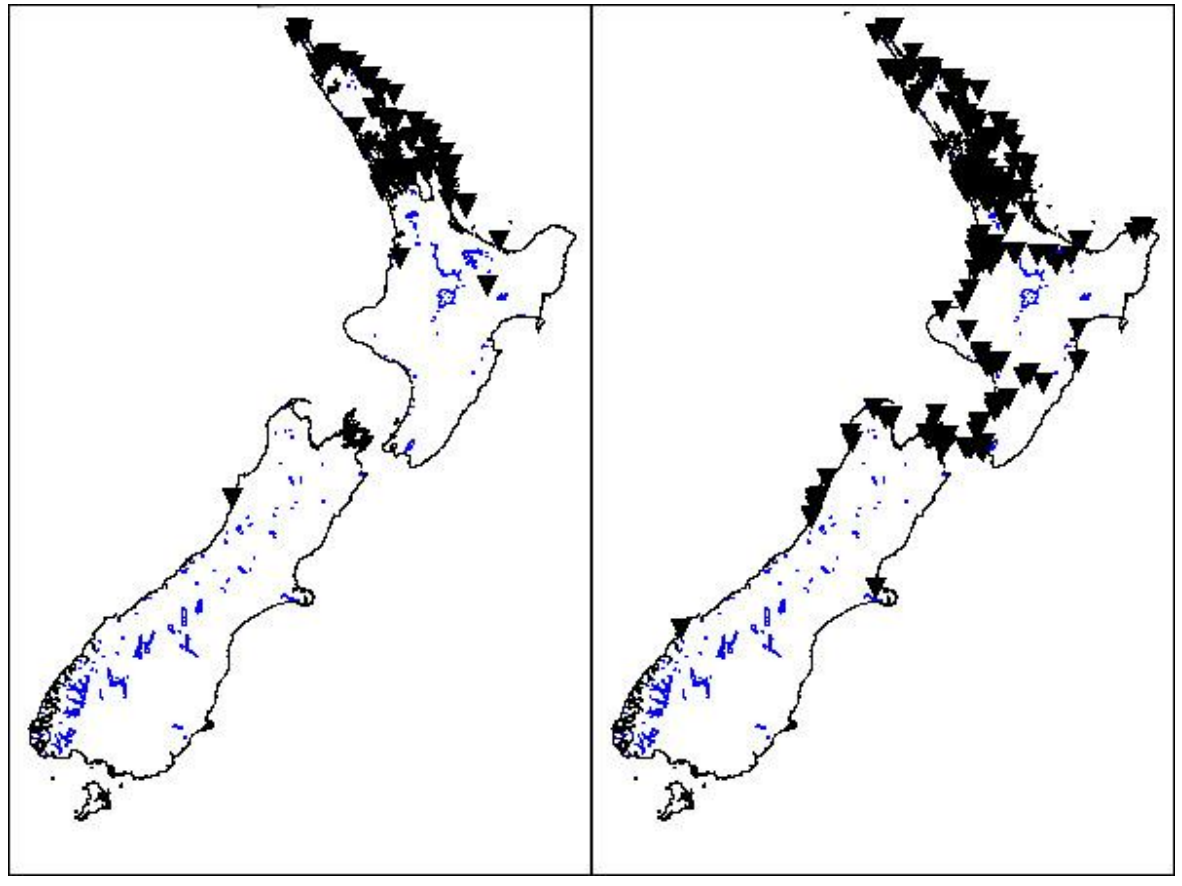

Figure A16. Pteris comans

Figure A17. Pteris macilenta 


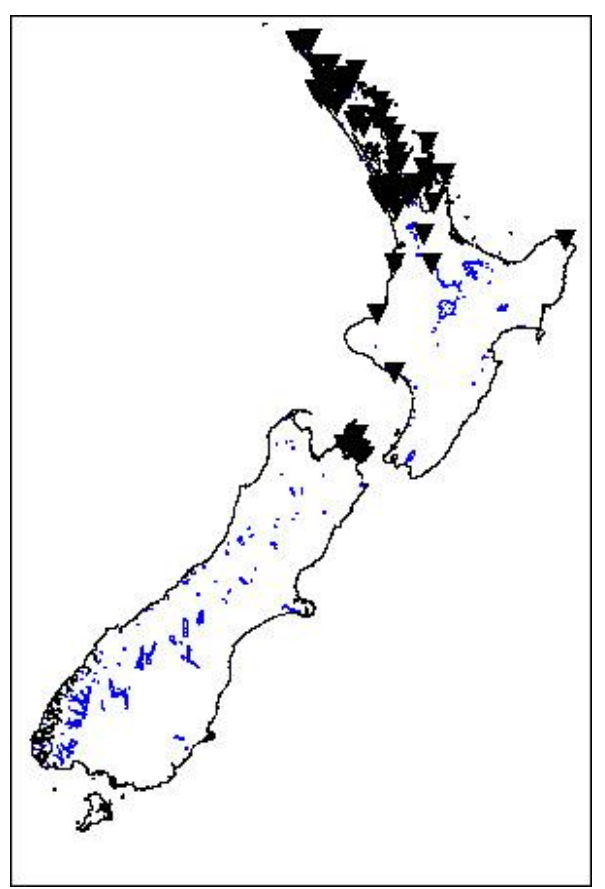

Figure A18. Pteris saxatilis 


\section{Appendix B - Transition vs. transversion graphs for $r b c L$ and $\operatorname{atp} B$ data sets}




\section{Transition/transversion vs. sequence divergence for the 88-taxon atpB data set}

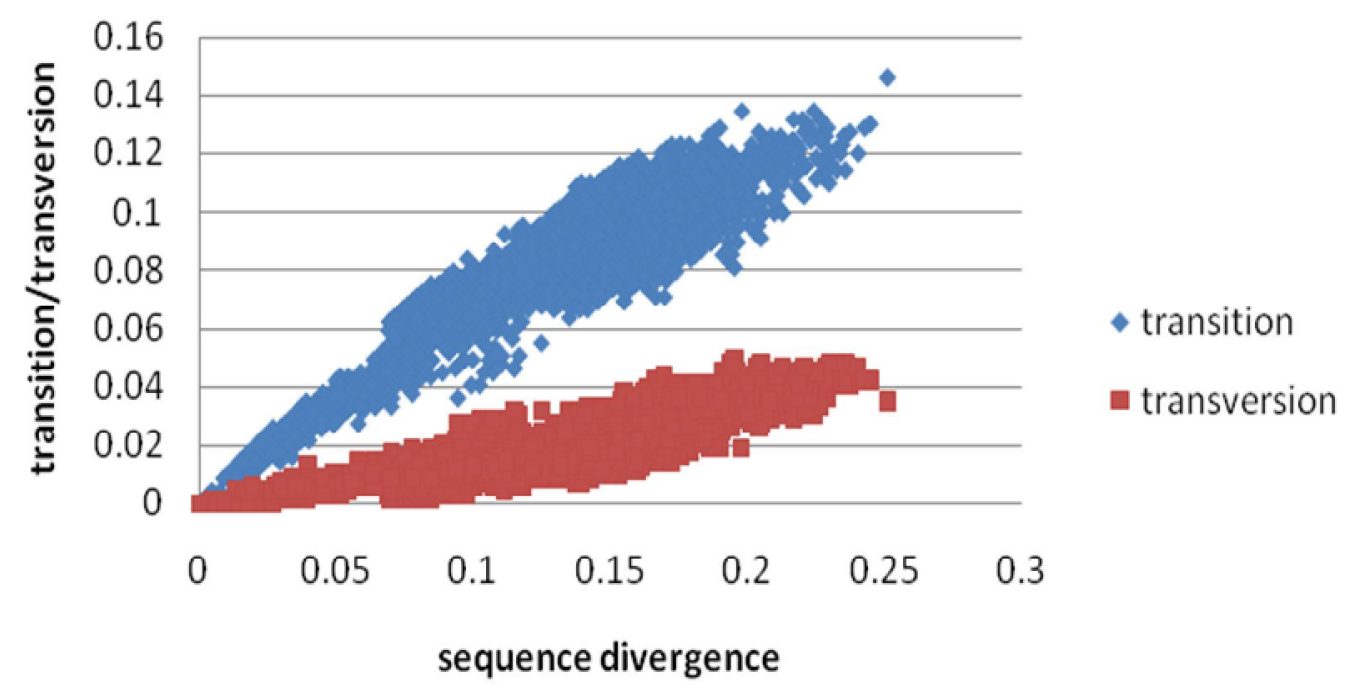

Figure B1. Graph of transition/tranversion vs. sequence divergence for the 88- taxon atpB data set.

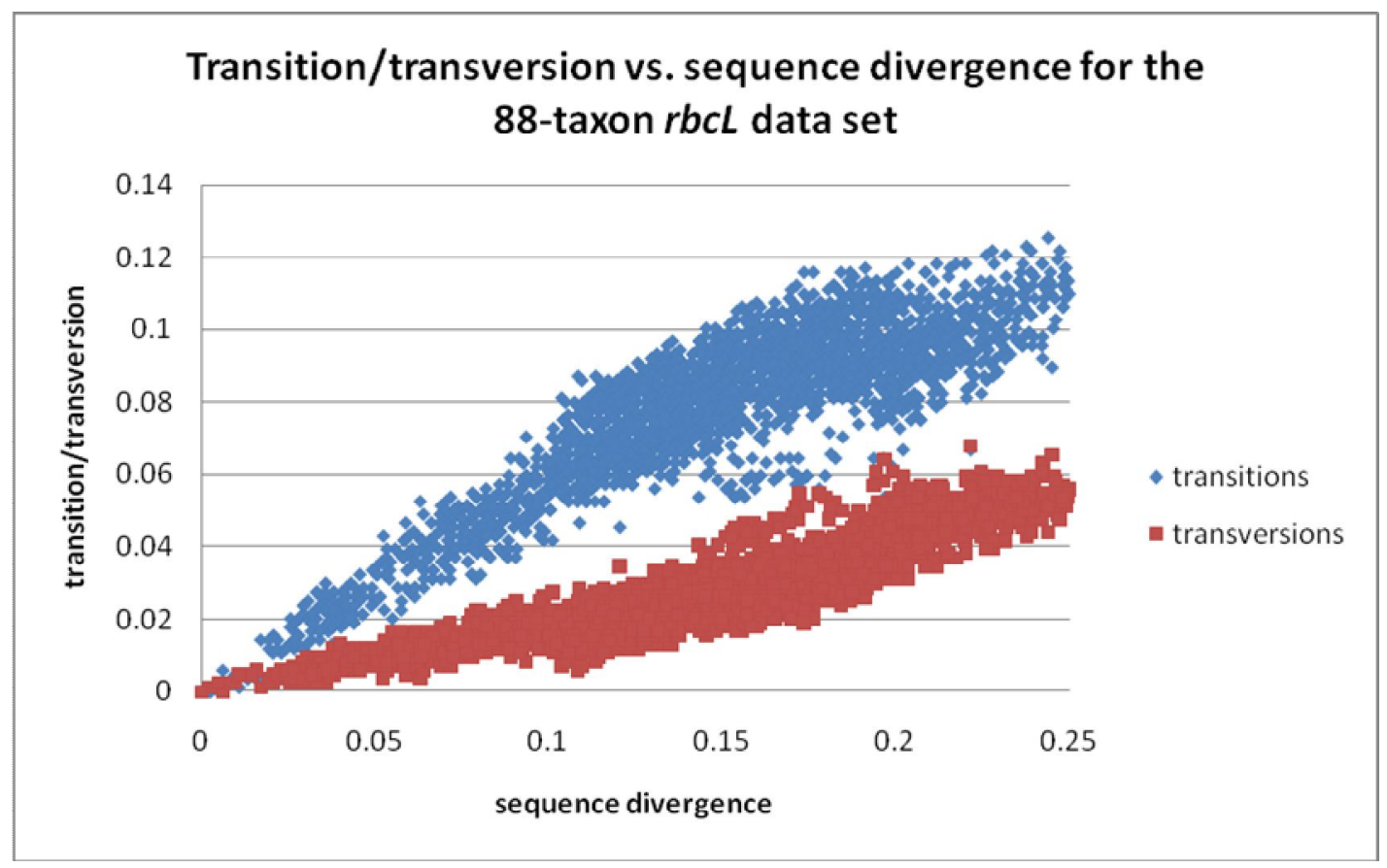

Figure B2. Graph of transition/tranversion vs. sequence divergence for the 88- taxon rbcL data set. 
Appendix C - Specimen LRP4994: Adiantum hispidulum (var. pubescens) 


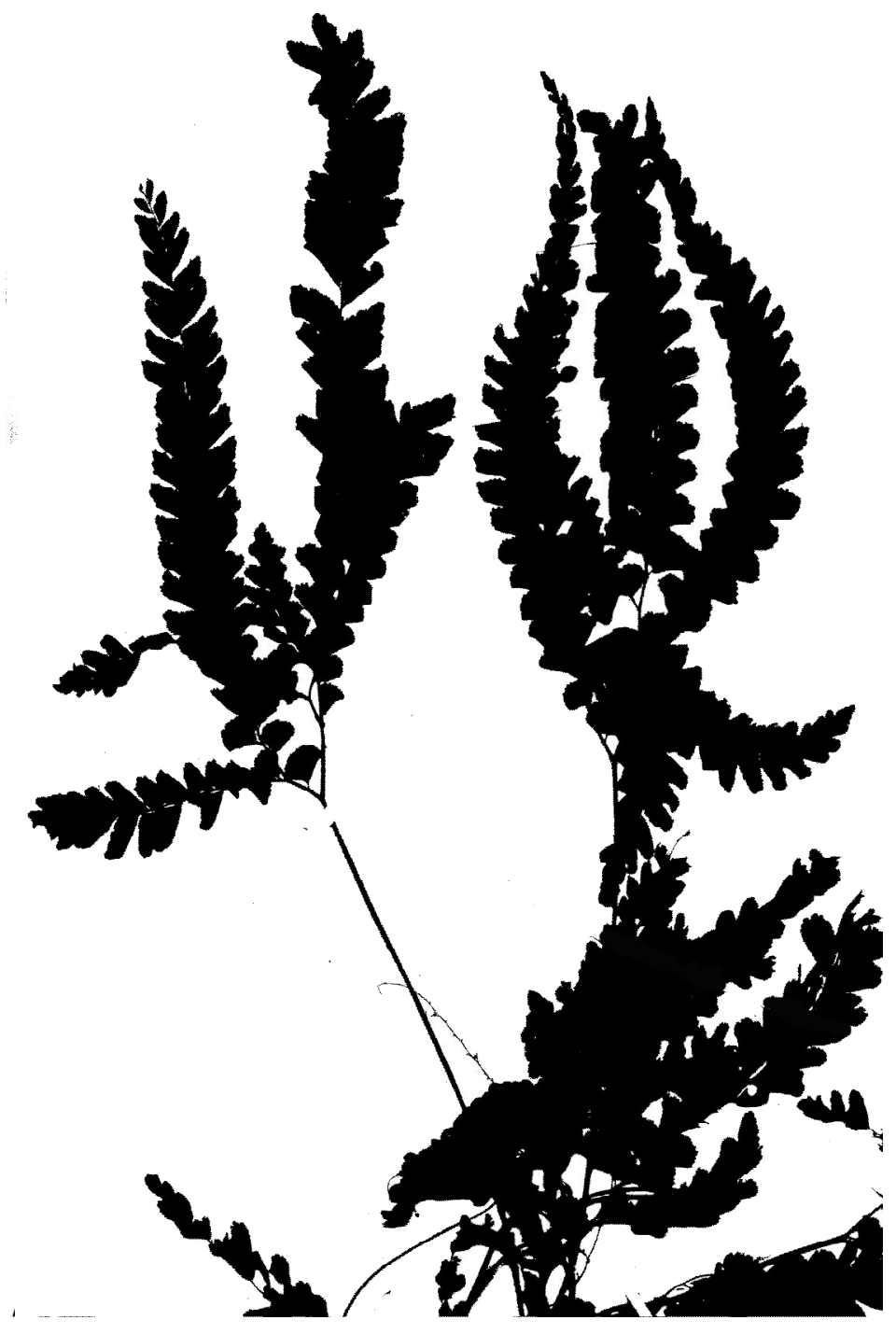

Figure $\mathbf{C l}$. Herbarium specimen from WELT herbarium of the Adiantum hispidulum sample, LRP4994. 
CD Appendix - Chloroplast sequence data and Nexus files 